Portland State University

PDXScholar

Spring 6-2-2015

\title{
Engineering Professional Development: Elementary Teachers' Self-efficacy and Sources of Self-efficacy
}

Donna Louise Webb

Portland State University

Follow this and additional works at: https://pdxscholar.library.pdx.edu/open_access_etds

Part of the Elementary Education and Teaching Commons, Engineering Commons, and the Science and Mathematics Education Commons

Let us know how access to this document benefits you.

\section{Recommended Citation}

Webb, Donna Louise, "Engineering Professional Development: Elementary Teachers' Self-efficacy and Sources of Self-efficacy" (2015). Dissertations and Theses. Paper 2337.

https://doi.org/10.15760/etd.2334

This Dissertation is brought to you for free and open access. It has been accepted for inclusion in Dissertations and Theses by an authorized administrator of PDXScholar. Please contact us if we can make this document more accessible: pdxscholar@pdx.edu. 
Engineering Professional Development: Elementary Teachers' Self-efficacy and Sources

\author{
of Self-efficacy \\ by \\ Donna Louise Webb \\ A dissertation submitted in partial fulfillment of the \\ requirements for the degree of \\ Doctor of Education \\ in \\ Educational Leadership: Curriculum and Instruction
}

Dissertation Committee:

Dannelle D. Stevens, Chair

Micki M. Caskey

Sybil S. Kelley

Pat Burk

Gwen Shusterman

Portland State University

2015 
(C) 2015 Donna Louise Webb 


\begin{abstract}
Currently, STEM (science, technology, engineering, and mathematics) is a popular buzz word in $\mathrm{P}-12$ education as it represents a means to advance American competitiveness in the global economy. Proponents of the engineering component of STEM advocate additional benefits in teaching engineering, such as its capacity to engage students in collaboration, and to apply critical thinking, systems thinking, negotiation, and communication skills to solve real-life contextual problems.

Establishing a strong foundation of engineering knowledge at a young age will provide students with internal motivation as it taps into their curiosity toward how things work, and it also prepares them for secondary science courses. Successful STEM education is often constrained by elementary teachers' low perception of self-efficacy to teach science and engineering. Elementary teachers with low self-efficacy in science are more likely to spend less instructional time teaching science, which suggests that teachers with little to no training in engineering might avoid teaching this topic. Therefore, the purpose of this study was twofold: (a) to examine the effects of engineering professional development on elementary (K-6) teachers' content and pedagogical content knowledge (PCK) and perceptions of self-efficacy to teach engineering, and (b) to identify and explain sources influencing self-efficacy. Professional development was conducted in a metropolitan area in the Pacific Northwest. Results revealed that after the engineering professional development, teachers experienced statistically significant gains in content, PCK, and self-efficacy to teach engineering. Increases in self-efficacy were mainly attributed to
\end{abstract}


mastery experiences and cultivation of a growth mindset by embracing the engineering design process. 


\section{Dedication}

I would like to dedicate this paper to my husband, Don Webb, whose support for me through the whole process of completing my doctorate has never wavered. 
Acknowledgements

When I first began my journey of working toward a Doctorate in Education at Portland State University, the advisors of my cohort asked each of us to draw a picture of a researcher. One detail I recall from that drawing was that my researcher was climbing a mountain. I remember thinking a mountain was appropriate because I was setting upon a journey of research that would be as difficult as climbing a mountain. Having the personal experience of climbing to the base camp of Mt. Everest and witnessing the commitment and risk mountaineers take to reach their goals, I knew climbing could be a monumental challenge. At the moment, I feel I have reached the summit. I am standing on top of the mountain and I am looking forward to the future that awaits me. Before I contemplate the future, I reflect upon the many people who have helped me along the way.

My primary support, my sherpas if you will, were my two cohort leaders, Dr. Dannelle D. Stevens and Dr. Micki M. Caskey. They were my cheerleaders along the way and did an amazing job of modeling and scaffolding the research and writing process. Dannelle, a.k.a. FreeWriting Guru, gave me so many tools to help me tap into the significance of my work, break it down, and put it into writing. I will always laugh thinking about the number of times I wrote and rewrote my purpose statement because of Dannelle's encouragement and wisdom. Micki, a.k.a. Queen of APA, was invaluable in helping me edit all my papers. I know I am a better writer today because of these strong, caring, and brilliant women! 
Every good mountaineer requires good climbing boots equipped with crampons to maneuver through difficult terrain. My crampons, if you will, was an assortment of people. Emily Saxton, Director of Research and Assessment for the Portland Metro STEM Partnership (PMSP), was critical in explaining the purpose, common measures, and basic logistics of the STEM Partnership. Emily spent extra time with me discussing the advantages and disadvantages of research methods and I am grateful for her time. Dr. Cary Sneider and Erika Hansen, co-instructors for the Advancing STEM Instruction through Engineering Design course, honored me by including me in the planning and teaching of the professional development course from which I collected my data. Likewise, Carol Biskupic-Knight, Director of PMSP's Teacher Academy, helped to enfold me within the professional development staff. Also, helping me through the difficult academic terrain was Dr. Swapna Mukhopadhyay, Dr. Susan J. Lenski, Dr. Samuel Henry, and Dr. Moti Hara.

Of course, climbing a really tall mountain would not be possible without addressing the problem of warmth, especially for me because I get cold very easily. My warmth consisted of the encouragement and support from family and friends. My husband, Don Webb, has supported me through this entire journey and reminded me of how proud he was of me during times when I complained about the amount of sacrifice expected of me. My son, Travis Shappell, helped me with editing and bouncing back ideas, particularly with regards to the benefits of learning engineering. As I previously mentioned, my journey included sacrifices. One sacrifice was in the time I spent with friends. My best friend, Debra Mathews, was my rock in this area. Both Debra's parents 
were educators and her father completed his doctorate while raising a family. With this perspective, Debra was so understanding of my busy schedule and always had positive words of encouragement for me. I consider her a true blessing in my life!

Looking ahead, I know there is more to do. Therefore, I would like to thank my dissertation committee members who participated in this journey of mine. Thanks to Dr. Dannelle Stevens for honoring me with your leadership as the chair of my committee. Thanks to Dr. Micki Caskey for all the tips and resources to support my reading and writing. Thanks to Gwen Shusterman, who agreed to be my Graduate Office Representative and inspires me with her own passion toward science teaching and learning. Thanks to Dr. Sybil Kelley, whose expertise in elementary science teaching and connection to the PMSP adds tremendous value to my work. Finally, thanks to Dr. Pat Burk for sharing your administrative perspective and vast fund of knowledge that contributes to the bigger picture of my work. 
Table of Contents

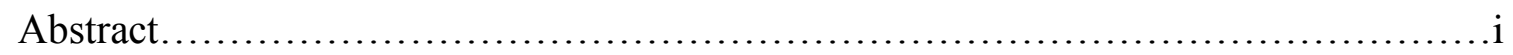

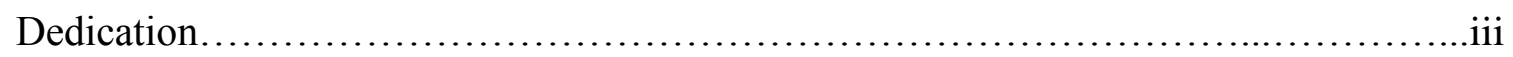

Acknowledgements.....................................................

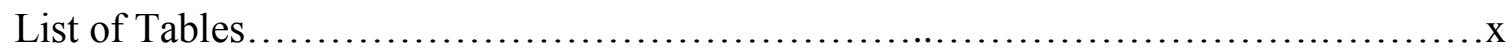

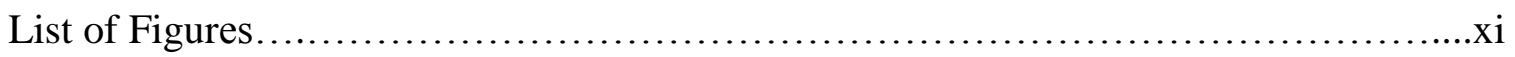

\section{CHAPTER 1}

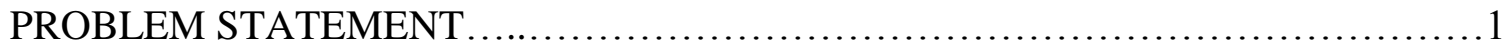

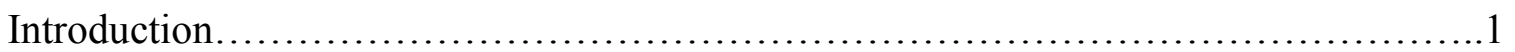

Background of the Problem.....................................................2

Elementary teacher preparation and perceptions in STEM and engineering.......2

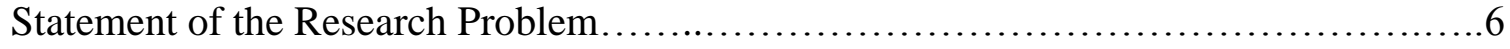

Significance of the Research Problem............................................. 7

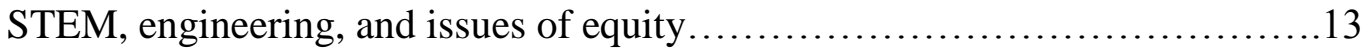

Presentation of Methods and Research Questions................................... 14

Methods and research questions....................................... 14

Definitions of key concepts............................................ 16

\section{CHAPTER 2}

LITERATURE REVIEW .................................................... 18

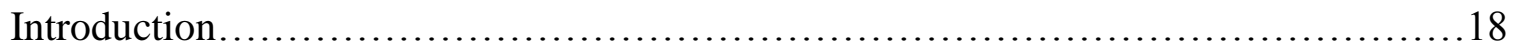

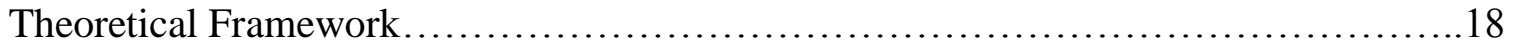

Social cognitive theory............................................... 19

Desimone's teacher professional development conceptual framework...........25

Review of the Research Literature ...........................................27

Effective science professional development.............................28

Association between teacher content knowledge, PCK, and self-efficacy.........33

Relationship between teacher self-efficacy and classroom practices.............34

Critique toward previous research involving teacher self-efficacy................38

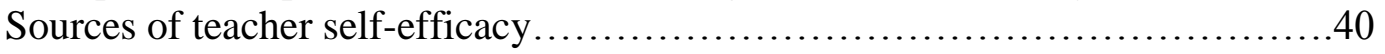

Critique toward previous research involving sources of self-efficacy............45

Review of the Methodological Literature.......................................47

Measuring teacher content and pedagogical content knowledge.................47

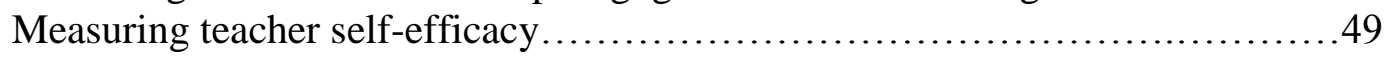

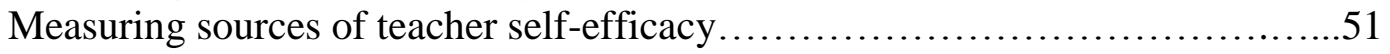




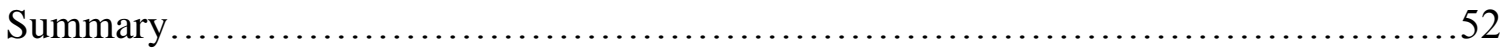

\section{CHAPTER 3}

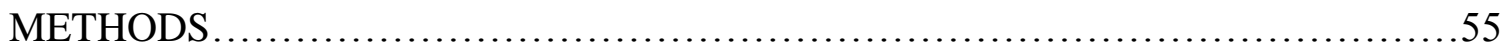

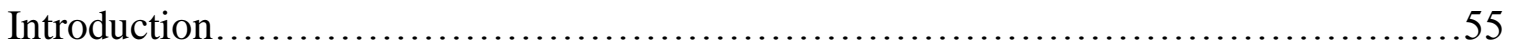

Research Methods..............................................................

Paradigm guiding the inquiry.........................................56

Type of research design and rationale ....................................57

Participants, context of the study, sampling, and rationale ...................60

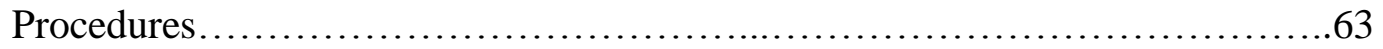

Overview of the engineering professional development......................66

Phase one...........................................................67

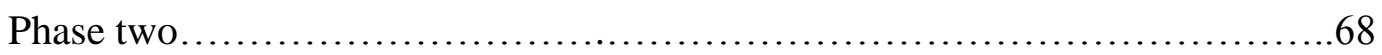

Maintaining data................................................... 70

Instruments and measures............................................. 70

Teacher Demographic Survey......................................... 71

ED Course Assessment...................................................71

Teacher Self-efficacy Survey .......................................... 72

Observational notes................................................... 74

ED Course post-post survey........................................... 74

Interview Questions............................................... 75

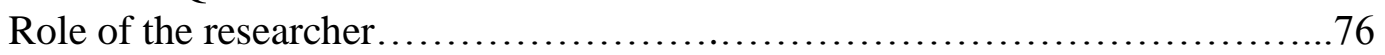

Data collection and analysis............................................ 79

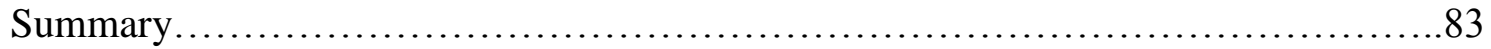

\section{CHAPTER 4}

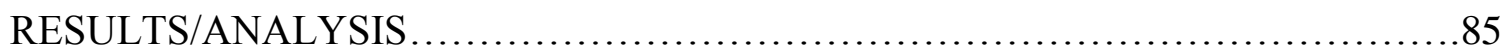

Introduction............................................................... 85

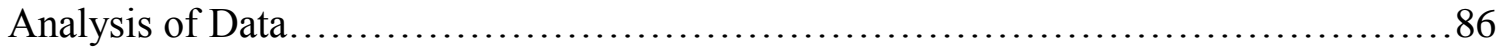

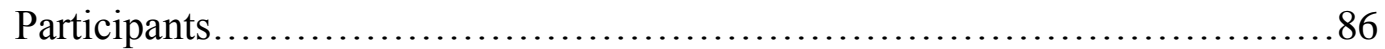

Phase one.............................................................. 87

Teacher content and pedagogical content knowledge.......................88

Teacher self-efficacy ............................................... 90

Correlational analysis of TSES ........................................ 93

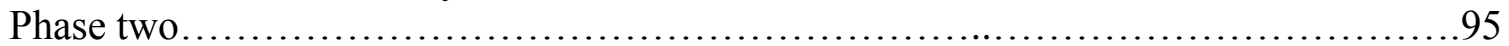

Teacher self-efficacy ................................................. 96

Sources of teacher self-efficacy ..................................... 97

Verbal persuasion as a source of self-efficacy fundamental to PD...............99

Vicarious experiences as a source of self-efficacy fundamental to PD...........102

Emotional arousal as a source of self-efficacy fundamental to PD................104

Mastery experiences as a source of self-efficacy fundamental to PD.............106

Open-endedness as a source of self-efficacy inherent to engineering PD.........111

Growth mindset as a source of self-efficacy inherent to engineering PD........112

Limitations of study..................................................... 117 
Summary.

\section{CHAPTER 5}

CONCLUSION ................................................................ 121

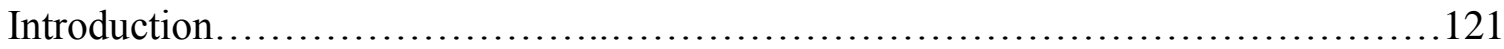

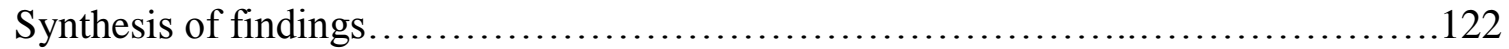

Research question one.............................................. 122

Research question two................................................ 124

Self-efficacy subscales and issues of equity...............................125

Research question three..............................................126

Sources of self-efficacy within effective professional development............128

Sources of self-efficacy novel to engineering professional development.........132

Implications............................................................. 137

Summary .................................................................... 140

References................................................................ 141

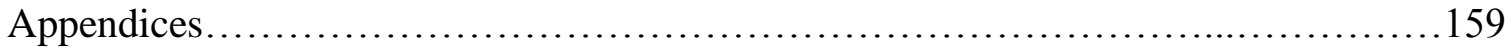

A. Advancing STEM Instruction through Engineering Design Agenda..........159

B. Follow-up Agenda............................................... 174

C. Teacher Consent Form.............................................. 176

D. Teacher Demographic Survey..................................... 178

E. ED Course Assessment.............................................179

F. Teacher Self-efficacy Survey .................................... 185

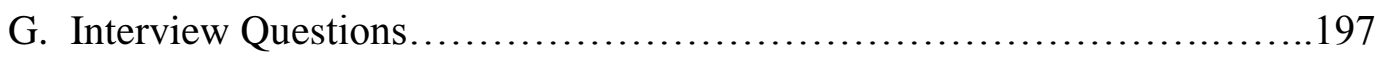

H. Observational notes................................................. 198

I. ED Course post-post survey..................................... 199

J. ED Course Assessment Rubrics...................................200 
List of Tables

Table

Page

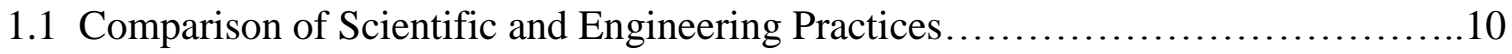

1.2 Nuanced Differences in Scientific and Engineering Practices According to Cunningham and Carlsen (2014) ........................................ 12

3.1 Instruments Selected and Constructs Measured...............................71

4.1 Teacher and School Characteristics of Participants.............................. 87

4.2 Changes in Pre-post Measured Constructs after Engineering Professional Development........................................................... 89

4.3 Four Subscales of TSES and Alignment with Questions..........................91

4.4 Descriptive Statistics of Changes in Self-efficacy Sorted by Teacher and School Characteristics.........................................................94

4.5 Mean Changes in Self-efficacy for Instructional Strategies and Student Engagement......................................................97

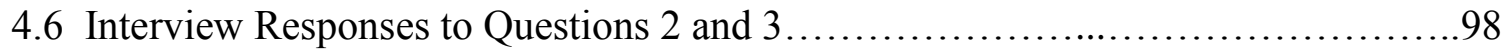

4.7 Evidence Supporting Verbal Persuasion as a Source of Self-efficacy.............101

4.8 Evidence Supporting Vicarious Experiences as a Source of Self-efficacy..........103

4.9 Evidence supporting Emotional Arousal as a Source of Self-efficacy..............105

4.10 Evidence of Student Successes Supporting Mastery Experiences as a Source of

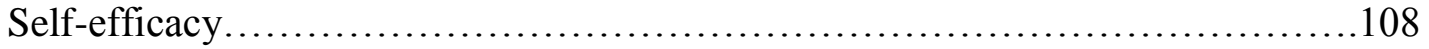

4.11 Evidence of Perception of Value Supporting Mastery Experiences as a Source Of Self-efficacy...................................................... 110

4.12 Evidence of Open-endedness as a Source of Self-efficacy ....................113

4.13 Evidence of Growth Mindset as a Source of Self-efficacy.....................115 


\section{List of Figures}

Figure

Page

2.1 Relationship Between Bandura's Three Elements of Social Cognitive Theory......20

2.2 Desimone's Path Model Combined with Bandura's Social Cognitive Theory........26

2.3 Research Questions and Methods Selected to Answer Them.....................48

3.1 Summary of an Exploratory Sequential Design Approach.........................59

3.2 Research Questions with Instruments and Data Analysis Used to Answer

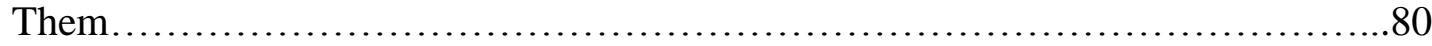

3.3 Steps Involved in the Thematic Network Analysis............................ 82

3.4 Example of a Thematic Network Structure.................................82

4.1 Final Thematic Network............................................... 100

5.1 Webb's Revision of Desimone's (2009) Path Model..............................132

5.2 Webb's Revision of Bandura's Three Elements of Social Cognitive Theory........136 


\section{Chapter 1: Problem Statement}

In Friedman's (2005) analysis of globalization, he claimed the United States (US) is in a "quiet crisis" because our economic strength has been based on our ability to “innovate new products, services, and companies" (p. 253) and this strength is declining as fewer Americans are training to become scientists and engineers. The U.S. Department of Commerce (2011) reported that the number of Science, Technology, Engineering, and Mathematics (STEM) jobs in the US is expected to increase by $17 \%$ from 2008 to 2018. Clearly, Friedman's claims are credible as the President's Council of Advisors on Science and Technology (PCAST) report (2012), Engage to Excel, revealed that filling STEM jobs will be a challenge if current rates of students receiving STEM degrees remain the same.

Efforts to fill STEM jobs and to improve America's economic and educational competitiveness have accelerated the demand for P-12 STEM education. According to Sanders (2009), the National Science Foundation perceives STEM education as teaching the four separate disciplines of science, technology, engineering, and mathematics. While the National Research Council (NRC, 2011) has strongly recommended the teaching of STEM at the elementary level, I argue successful STEM education is constrained by two significant problems: first, elementary teachers' lack content knowledge and pedagogical skills coupled with weak perceptions of their own preparation to teach engineering (Banilower et al., 2013; Brophy, Klein, Portsmore, \& Rogers, 2008; Cunningham \& Carlsen, 2014; Culver, 2012; Daugherty, 2012; Johnson \& Cotterman, 2013; Katehi, Pearson, \& Feder, 2009; Mativo \& Park, 2012; Rockland et al., 
2010; Yasar, Baker, Robinson-Kurpius, Krause, \& Roberts, 2006); and, second, they seem to suffer from weak self-efficacy to adequately teach the engineering component of STEM (Baker, Krause, Yasar, Roberts, \& Robinson-Kurpius, 2007; Bybee, 2009; Nadelson et al., 2013; Nadelson \& Farmer, 2012; Yoon, Diefes-Dux, \& Strobel, 2013). Engineering, as explained by Brophy, Klein, Portsmore, and Rogers (2008), "requires applying content knowledge and cognitive processes to design, analyze, and troubleshoot complex systems in order to meet society's needs" (p. 371). Thus, there exists the need to increase the capabilities of elementary teachers to teach and integrate the "E" in STEM.

\section{Background of the Problem}

In the following section of Chapter 1, I examine the current condition of elementary teacher preparation and perceptions of preparation to teach STEM and engineering as well as how these factors affect teacher self-efficacy. I also describe a research study that addresses the problem of elementary teachers' inadequate preparation to teach engineering.

\section{Elementary teacher preparation and perceptions in STEM and engineering.}

With recent focus on STEM education, a growing body of research has examined the perceptions and preparation to teach STEM (Brown, Brown, Reardon, \& Merrill, 2011; Mativo \& Park; 2012; Moman-Powell \& Brown-Schild, 2011; Nadelson, Seifert, Moll, \& Coats, 2012; Nadelson et al., 2013). Exploring P-12 teacher and administrator perceptions of STEM, Brown et al. (2011) found less than 50\% of participants could accurately define STEM. Findings such as Brown et al. (2011) has driven other 
researchers to measure elementary teachers' perceptions and preparation within the context of STEM professional development interventions. Professional development is a supportive learning opportunity for teachers to enhance their content knowledge and pedagogical skills with the purpose of changing teacher practices to improve student outcomes (Supovitz \& Turner, 2000). For example, Moman-Powell and Brown-Schild (2011) studied the effects of scientist-teacher partnerships on teacher self-efficacy towards inquiry and STEM teaching. Their investigation showed increases in selfefficacy for teachers who had no prior careers in STEM. Nadelson, Seifert, Moll, and Coats (2012) determined a four-day STEM institute significantly improved elementary teachers' self-efficacy towards inquiry and STEM. Their program not only produced gains in teacher content knowledge and perceptions, but also generated decreases in pedagogical discontentment. In a similar study, STEM professional development enhanced elementary teacher self-efficacy and confidence for teaching STEM and had a positive influence on attitudes toward engineering (Nadelson et al., 2013).

Notable is that the research confirms that professional development interventions for teachers are the key to solving the problem of lack of content knowledge and pedagogical skills combined with weak perceptions of preparation and self-efficacy to teach STEM. I suggest a similar strategy should be pursued with engineering education. Unfortunately, one criticism of STEM professional development is that the majority of programs place little attention on engineering content knowledge as priority is given to science and mathematics (Bybee, 2009; Johnson \& Cotterman, 2013). As Bybee (2009) stated, "The S, T, E, and M are separate and not equal" (p. 61). Many proponents of 
engineering education have raised similar claims that STEM professional development and curriculum does not place enough emphasis on the "E" in STEM (Johnson \& Cotterman, 2013; Lord, 2011; Rockland et al., 2010; Yoon et al., 2013).

Research has revealed several barriers elementary teachers face in being able to teach engineering including: (a) insufficient content knowledge and pedagogical skills, (b) lack of support from administrators, (c) absence of training in teacher preparation courses and inservice professional development, (d) limited instructional materials, (e) little emphasis of engineering in state and national standards, and (f ) perceiving there to not be enough time to learn and integrate engineering (Brophy et al., 2008; Bybee, 2009; Culver, 2012; Daugherty, 2012; Katehi et al., 2009; Yasar et al., 2006). Typically, elementary teachers have experienced minimal to no coursework to prepare them to teach science, let alone engineering (Banilower et al., 2013; Bybee, 2009; Culver, 2012; Fulp, 2002; Nadelson \& Farmer, 2012; Nadelson et al., 2013; Mativo \& Park, 2012). Fulp (2002) reported teacher certification programs do not require preservice elementary teachers to complete enough science and math courses. Nadelson and Farmer (2012) further pointed out that engineering "rarely appears in the elementary teacher preparation curriculum" and so "it is unlikely that K-12 teachers are adequately prepared to teach engineering" (p. 3). Equally problematic is that most elementary teachers did not learn engineering when they were students in P-12 (Cunningham \& Carlsen, 2014). Therefore, it is no surprise that in a national survey, Banilower et al. (2013) found that only $1 \%$ of elementary teachers had any engineering undergraduate coursework and $73 \%$ reported not feeling adequately prepared to teach engineering. 
In fairness, elementary teachers have had little need to possess content knowledge in engineering because engineering occupied modest to no inclusion in national and state standards. In fact, the old national science standards focused mainly on three generally agreed upon divisions: physical science, life science, and earth and space sciences (NRC, 1996). Engineering and technology held very little weight and attention, which influenced state standards. For example, Carr, Bennett, and Strobel (2012) examined all 50 states' standards and found 41 states had engineering standards, but when inspecting the elementary grade band, only 22 states had engineering and technology standards and six states had explicit engineering.

Only recently have researchers begun to investigate elementary teachers' preparation and perceptions to teach engineering (Baker et al., 2007; Culver, 2012; Mativo \& Park, 2012; Mendoza-Diaz \& Cox, 2012; Yasar et al., 2006; Yoon et al., 2013). Studies with preservice elementary teachers found participants were not adequately prepared to teach engineering due to misconceptions about engineering and lack of content knowledge (Mativo \& Park, 2012) as well as pedagogical content knowledge (Culver, 2012). According to Shulman (1987), pedagogical content knowledge (PCK) involves the ways of teaching a subject to make it understandable to others; " it represents the blending of content and pedagogy into an understanding of how particular topics, problems, or issues are organized, represented, adapted to the diverse interests and abilities of learners, and presented for instruction" (p. 8). Furthermore, Yasar, Baker, Robinson-Kurpius, Krause, and Roberts (2006) developed a survey instrument to measure P-12 teachers' perceptions of engineers and prior knowledge of design, 
engineering, and technology (DET) concepts. Their study discovered that elementary teachers expressed low confidence, familiarity, and interest in teaching DET.

Early research persuaded advocates of engineering education that professional development was a crucial component to improve elementary teachers' ability to teach the "E" in STEM and there was a demand to explore best approaches for engineering professional development (Capobianco \& Joyal, 2008; Liu, Carr, \& Strobel, 2009; Sun, Boots, \& Strobel, 2012; Rockland et al., 2010; Wojnowski \& Pea, 2014). Although few researchers have examined the effects of engineering professional development on elementary teachers' perceptions and preparation, current studies are filling this gap. For example, Duncan, Diefes-Dux, and Gentry (2011) found elementary teachers' exhibited statistically significant positive changes in understanding of engineering after a weeklong summer academy. Yoon et al. (2013) released results of the first year of a five-year study of the INSPIRE summer institute that prepares elementary teachers to integrate the "E" in STEM. Their findings demonstrated the professional development program not only significantly elevated teacher content knowledge of the engineering design process and familiarity with DET, but also reduced teacher perceived difficulties in integrating the "E" in STEM.

\section{Statement of the Research Problem}

Professional development is the essential intervention for helping teachers implement the new science standards, particularly because of the greater emphasis on engineering (Wilson, 2013). While studies have revealed features of engineering professional development that can improve elementary teachers' deficiencies in self- 
efficacy, content, and pedagogical content knowledge, there remains an inchoate understanding of the most influential sources of self-efficacy (Klassen, Tze, Betts, \& Gordon, 2011). Such an understanding is important as Ramsey-Gassert, Shroyer, and Staver (1996) found a positive correlation between elementary teachers' science content knowledge and self-efficacy to teach science. Their study suggests that teachers who lack content knowledge in engineering will possess low self-efficacy toward engineering and thus will be less likely to teach it. Therefore, the purpose of this study is twofold: (a) to examine the effects of engineering design professional development on elementary (K-6) teachers' content knowledge and pedagogical content knowledge and perceptions of self-efficacy to teach engineering, and (b) to describe and explain teachers' perceptions of the aspects of their professional development experience or any other factors that may have influenced their self-efficacy.

\section{Significance of the Research Problem}

In the next section of Chapter 1, I delineate the reasons why elementary teachers need to be better prepared to teach engineering, which includes changes to the national science standards and the benefits teaching engineering has on students, teachers, and the larger society.

\section{Significance of teaching the "E" in STEM. Supporters for STEM and} engineering education emphasize the economic benefits to promoting engineering in P-12 classrooms (Katehi et al., 2009; Laskey \& Yoon, 2011; Nadelson et al., 2012; NGSS, 2013; Melguizo \& Wolniak, 2012; Wojnowski \& Pea, 2014). I contend other equally important justifications bear acknowledgement of how engineering influences students, 
teachers, and the larger society that supports the reason teachers need to be better prepared to teach the "E" in STEM. While sharing some similarities with scientific practices, engineering practices surpass scientific practices in its ability to foster student creativity, critical thinking, negotiation, higher-order cognitive skills, self-regulation, and learning from mistakes (Brophy et al., 2008; Cunningham \& Carlsen, 2014; Laskey \& Yoon, 2011; Stouffer, Russell, \& Olivia, 2004). Engineering design is an iterative process that is more open-ended because there can be multiple solutions to the same problem (Lammi \& Becker, 2013; Moore, Tank, Glancy, Kersten, \& Ntow, 2013). When an engineering problem is initially approached, students communicate and brainstorm solutions. Through the process, students often realize the best solution may come from synthesizing various people's ideas and therefore see value in negotiation (Brophy et al., 2008). But analysis is also part of the process because students cultivate systems thinking; the ability to break down complex systems to understand how interrelated parts are structured and function and at the same time see the whole picture to solve a problem (Bybee, 2009; Carr et al., 2012; Lammi \& Becker, 2013). Plus, students learn that failure is a valuable part of learning and the engineering design process (Cunningham \& Carlsen, 2014; Kapur \& Bielaczyc, 2012). When a designed prototype fails, an engineer identifies failure points, learns from mistakes, and improves the prototype. In the same way, when students are challenged to improve their prototypes, they are encouraged to be reflective and apply creativity and critical thinking skills. Improving creativity for grades P-6 is imperative as Kim (2011) found a decline in creative thinking scores within this age range when analyzing the Torrance Test of Creative Thinking from 1990 to 2008. 
Learning engineering can help all students develop skills required for life in the $21^{\text {st }}$ century. As Darling-Hammond and Adamson (2013) stated:

The changing nature of work in today's world places a premium not simply on students acquiring information but on their ability to analyze, evaluate, design, and create new solutions and products. By the year 2000, the top three skills demanded by Fortune 500 companies had shifted from reading, writing, and arithmetic to teamwork, problem-solving, and interpersonal skills. (p. 1)

Furthermore, all students need to understand engineering principles as future voting citizens to make informed decisions about global problems (Vasquez, Sneider, \& Comer, 2013).

Engineering is significant for teachers because of recent changes to national science standards. Although scientific inquiry remains to be the prominent instructional approach to teaching science, engineering is gaining equal status with its greater emphasis in the new science standards, the Next Generation Science Standards (NGSS, 2013). Rationale for more engineering includes its capacity to provide a different context for students to apply and deepen learning of science and mathematics concepts (NGSS, 2013). Adopting engineering within the science standards was recommended by the National Academy of Engineering (Katehi et al., 2009). The NGSS promotes engineering by incorporating it alongside scientific inquiry. However, according to Pratt (2012), the term inquiry used in the previous standards is being replaced with practices within the NGSS as research supports that students should engage in two types of practices: scientific and engineering. Scientific practices teaches students how to think and act like a real scientist; to ask and answer questions about the natural world (NRC, 2012). When engaging in scientific practices, students basically ask a question, plan an 
investigation to answer the question, collect and analyze data, and construct an explanation from their evidence (as shown in Table 1.1). In other words, students employ steps of the scientific method. Engineering practices are separate learning activities as students define "problems of human needs and aspirations and propose solutions in the form of new products and processes" (Bybee, 2011, p. 39). When students engage in engineering practices, a simple way of looking at it is that they are implementing the engineering design process.

While the NRC (2012) communicated the distinctions between scientific and engineering practices, Cunningham and Carlsen (2014) argued misrepresentations of engineering practices need to be understood by teachers. For example, Cunningham and Carlsen (2014) stated one of the main differences between scientific and engineering Table 1.1 Comparison of Scientific and Engineering Practices (National Research Council, 2012)

Scientific Practices

1. Asks a question

2. Develops explanation using models

3. Plans and carries out an investigation to test a hypothesis

4. Analyzes and interprets data

5. Uses math and computational thinking

6. Constructs explanation to explain results

7. Engages in argument to defend best explanation from evidence

8. Communicates results

\section{Engineering Practices}

1. Defines the problem

2. Makes models/prototypes

3. Plans and carries out an investigation to test the prototypes

4. Analyzes data to compare prototypes

5. Uses math and computational thinking

6. Selects best solution based on criteria

7. Engages in argument to defend solution and redesigns

8. Communicates best solution 
practices is in their goals. The goal of scientific practices is to find answers and the goal of engineering practices is to find solutions. Yet, many educators see answers and solutions to mean the same thing. They pointed out that answers are part of a conceptual progress while solutions involve applying concepts to create useful technology. Cunningham and Carlsen (2014) identified other nuances that distinguish scientific from engineering practices. I include a visual representation of these differences with permission from the authors (see Table 1.2) because I think it provides a better illustration of engineering practices and exactly how it differs from scientific practices. In addition, the new science standards included engineering as part of one of its four disciplinary core ideas: (a) physical science, (b) life science, (c) earth and space sciences, and (d) engineering, technology, and applications of science (NGSS, 2013). For states that adopt the NGSS, this likely means that state assessments will devote $25 \%$ of its test items to engineering, technology, and applications of science, just as Massachusetts is currently doing (Carr et al., 2012). Because Brophy et al. (2008) claimed standards effect what is taught in the classroom, elementary teachers need to learn how to teach engineering as outlined by the NGSS. In sum, the engineering design process allows students to collaborate, and apply critical thinking, systems thinking, negotiation, and communication skills to solve real-life, contextual problems (Tornkvist, 1998). Exposure to STEM is imperative at the elementary level as Ferrini-Mundy (2013) stated, without substantial learning of STEM in the early years "it is improbable that students will be prepared, either in adequate numbers or with appropriate knowledge, to make choices leading to STEM careers" (p. 278). Establishing a strong foundation of 
Table 1.2

Nuanced Differences in Scientific and Engineering Practices According to Cunningham and Carlsen (2014)

\begin{tabular}{|c|c|c|}
\hline $\begin{array}{l}\text { Practices (from } \\
\text { NRC, 2012) }\end{array}$ & $\begin{array}{l}\text { Relative emphasis in } \\
\text { science }\end{array}$ & $\begin{array}{l}\text { Relative emphasis in } \\
\text { engineering }\end{array}$ \\
\hline $\begin{array}{l}\text { 1. Asking questions and } \\
\text { defining problems }\end{array}$ & $\begin{array}{c}\text { Goal is theoretical/conceptual } \\
\text { progress }\end{array}$ & $\begin{array}{l}\text { Goal is a useful, novel } \\
\text { technology }\end{array}$ \\
\hline $\begin{array}{l}\text { 2. Developing and using } \\
\text { models }\end{array}$ & Explanation and prediction & Analysis and evaluation \\
\hline $\begin{array}{l}\text { 3. Planning and } \\
\text { carrying out } \\
\text { investigations }\end{array}$ & $\begin{array}{l}\text { Hypothesis-testing, may be } \\
\text { sequential }\end{array}$ & Evaluation, usually iterative \\
\hline $\begin{array}{l}\text { 4. Analyzing and } \\
\text { interpreting data }\end{array}$ & $\begin{array}{l}\text { Attention to measurable } \\
\text { aspects of the found, natural } \\
\text { world }\end{array}$ & $\begin{array}{l}\text { Attention to diverse criteria: } \\
\text { scientific (e.g. material } \\
\text { properties) and other (e.g. } \\
\text { cost, risk of failure) }\end{array}$ \\
\hline $\begin{array}{l}\text { 5. Using mathematics } \\
\text { and computational } \\
\text { thinking }\end{array}$ & $\begin{array}{l}\text { Testing conceptual models } \\
\text { with real data }\end{array}$ & $\begin{array}{l}\text { Designing concrete things, } \\
\text { using both real and simulated } \\
\text { data }\end{array}$ \\
\hline $\begin{array}{l}\text { 6. Constructing } \\
\text { explanations and } \\
\text { designing solutions }\end{array}$ & $\begin{array}{l}\text { Objective is a single "best } \\
\text { explanation" }\end{array}$ & $\begin{array}{l}\text { Objective is a preferred } \\
\text { design, selected from among } \\
\text { alternatives, with explicit } \\
\text { consideration of tradeoffs }\end{array}$ \\
\hline $\begin{array}{l}\text { 7. Engaging in } \\
\text { argument from evidence }\end{array}$ & $\begin{array}{c}\text { Goal is to persuade scientific } \\
\text { peers }\end{array}$ & Goal is to satisfy a client \\
\hline $\begin{array}{l}\text { 8. Obtaining, } \\
\text { evaluating, and } \\
\text { communicating } \\
\text { information }\end{array}$ & $\begin{array}{l}\text { Free exchange of information } \\
\text { is an important norm }\end{array}$ & $\begin{array}{l}\text { Products are often legally } \\
\text { proprietary, and information } \\
\text { guarded }\end{array}$ \\
\hline
\end{tabular}

Note. Reproduced from "Teaching Engineering Practices," by C. M. Cunningham and W. S. Carlsen, 2014, Journal of Science Teacher Education, 25, p. 200. 
engineering knowledge at a young age will not only provide students with internal motivation as it taps into a children's curiosity toward how things work, but also prepares them for middle and high school science courses (Brophy et al., 2008). The blending of interest and preparation in students can influence them to choose engineering as a career and contribute to solving problems that benefit local and global contexts (NGSS, 2013).

STEM, engineering, and issues of equity. Sanders (2014), an engineer, suggested that because today's computers do the work of calculation, the most important attribute for future engineers is to be creative. According to Petty (1983), creativity is when one is "able to originate or bring into existence by force of the imagination" (p. 31). I argue creativity is best fostered when people with diverse backgrounds and perspectives collaborate to innovate solutions to problems. Antonio et al. (2004) conducted a study with undergraduate students and found different opinions from minority students were perceived to contribute powerfully to novel thinking within a group setting. Yet, STEM and engineering professionals are far from diverse. In 2006, out of all the bachelor degrees awarded in science and engineering, only 9.3\% were earned by Asian-American and Pacific Islanders, $8.3 \%$ by Black students, $7.7 \%$ by Hispanic students, and $0.7 \%$ by Native Americans (Museus, Palmer, Davis, \& Maramba, 2011). In comparison to their White classmates, underrepresented minority (URM) groups report unique barriers that influence their persistence in a STEM major (Chang, Eagan, Lin, \& Hurtado, 2011). Yet, a STEM career is particularly rewarding for URM's as Melguizo and Wolniak (2012) found minority groups attaining STEM degrees and employment experience significant economic benefits. So, what can educators do about this problem? 
In their comprehensive examination of URM students in STEM, Museus et al. (2011) identified six key factors that promote their success in STEM: (a) access to bilingual education, (b) parent support, (c) culturally responsive teaching, (d) early exposure to STEM, (e) interest in STEM subjects, and (f) developing self-efficacy in STEM subjects. Clearly, teachers hold significant influence in many of these factors. Here again, I believe professional development can be part of the answer. First, teachers need to feel confident and possess strong self-efficacy to teach engineering and STEM. I believe STEM lessons can be so engaging for students, they have the ability to prove to teachers that all students can be successful in STEM. Second, engineering professional development can integrate culturally responsive teaching strategies to help support a diverse student population.

\section{Presentation of Methods and Research Question}

In the last section of Chapter 1, I present my research questions and briefly introduce the methods through which I will answer the research questions. Also, I provide definitions of key concepts within the study and explain their relevance to the problem.

Methods and research questions. While it is true that research in engineering education is emerging, there remains neglected areas of inquiry, especially within the area of assessment methodology (Mendoza-Diaz \& Cox, 2012). Mendoza-Diaz and Cox (2012) explored P-12 engineering education literature published between 2001 and 2011. Their work revealed the majority of studies focused on teacher content knowledge and attitudes and the most common intervention was in the form of professional development. 
However, Mendoza-Diaz and Cox (2012) acknowledged that "the variety of knowledge concepts and attitudinal constructs among studies is very limited" (p. 15). For this reason, this study will measure the construct of self-efficacy and explore teacher perceptions of the sources of self-efficacy. I intend to use a mixed methods approach to measure elementary teacher self-efficacy before and after participating in engineering professional development. Self-efficacy will be measured using a survey incorporating known variables. While the survey reveals outcomes, it does not explain how the process took place or the sources of self-efficacy. Maxwell (2013) pointed out quantitative studies typically use variance questions that "focus on difference and correlation" and qualitative studies use process questions that "focus on how things happen" (p. 82). As such, I plan to collect qualitative data through interviews, surveys, and participant observations to expose sources influencing self-efficacy that help explain how changes took place and to corroborate quantitative outcomes. Because content and PCK are considered pre-requisites to self-efficacy, as I explain further in chapter two, I also measure engineering content and PCK using surveys. In sum, I contend a mixed-method approach would extend understanding of how and why self-efficacy was influenced by engineering professional development.

Results from this study may be able to help the co-teachers of the engineering professional development to modify and improve the program. In addition, conclusions from this study can possibly identify ways to address elementary teachers' preparation, beliefs, and practices towards engineering instruction that can be communicated to 
district leaders, curriculum specialists, principals, and teachers to strengthen the teaching

and learning of STEM. The following research questions will guide this study:

1. How did the professional development program affect elementary teachers' content and pedagogical content knowledge to teach engineering?

2. How did the professional development program affect elementary teachers' perceptions of self-efficacy to teach engineering?

3. After the engineering professional development program, what aspects of the program or other factors did elementary teachers' identify as influencing their self-efficacy to teach engineering?

\section{Definitions of Key Concepts}

The following list of definitions is relevant to my problem of practice and

research study:

- STEM education - According to Sanders (2009), the National Science Foundation perceives STEM education as the teaching of the four separate disciplines of science, technology, engineering, and mathematics. STEM education represents the larger topic of my study.

- Engineering, as explained by Brophy et al.(2008), "requires applying content knowledge and cognitive processes to design, analyze, and troubleshoot complex systems in order to meet society's needs" (p. 371). Engineering is the specific content area that elementary teachers need to be better prepared to teach to successfully teach STEM.

- Professional development is a supportive learning opportunity for teachers to enhance their content knowledge and pedagogical skills with the purpose of changing teacher practices to improve student outcomes (Supovitz \& Turner, 2000). Professional development is one type of solution to my research problem that I propose to increase elementary capabilities to teach engineering.

- Pedagogical content knowledge - According to Shulman (1987), pedagogical content knowledge involves the ways of teaching a subject to make it understandable to others; " it represents the blending of content and pedagogy into an understanding of how particular topics, problems, or issues are organized, represented, adapted to the diverse interests and abilities of learners, and presented for instruction" (p. 8). A teacher needs to develop both content knowledge and pedagogical content knowledge to be effective in teaching a diverse classroom of students.

- Systems thinking; the ability to break down complex systems to understand how interrelated parts are structured and function and at the same time see the whole picture to solve a problem (Carr, et al., 2012; Lammi \& Becker, 2013). Similar to 
inquiry, systems thinking is an important cognitive process to foster in children through the learning of engineering.

- Scientific practices teaches students how to think and act like a real scientist; to ask and answer questions about the natural world (NRC, 2012). When students engage in scientific practices, they ask a question, plan an investigation to answer the question, collect and analyze data, and construct an explanation from their evidence. Essentially, students employ the scientific method.

- Engineering practices are separate learning activities as students define "problems of human needs and aspirations and propose solutions in the form of new products and processes" (Bybee, 2011, p. 39). When students engage in engineering practices, they implement the engineering design process. 


\section{Chapter 2: Literature Review}

In the previous chapter, I presented the problem with elementary teachers' lacking adequate preparation in content knowledge and pedagogical skills, as well as positive perceptions of self-efficacy to competently teach engineering. To address this problem of practice, I proposed a study to examine the effects of engineering design professional development on elementary teachers' content and pedagogical content knowledge and perceptions of self-efficacy to teach engineering. Also, I recommended the exploration of sources of self-efficacy that influence self-efficacy as a consequence of participating in the engineering professional development. I emphasized the justifications for teachers needing to improve their capabilities to teach engineering based on the overall importance of P-12 engineering education. Moreover, I claimed the need for professional development to provide engineering content knowledge and PCK to improve elementary teachers' perceptions of self-efficacy. In this chapter, I analyze my research problem through a theoretical lens and professional development conceptual framework to facilitate a deeper understanding of the problem. Then, I review literature relevant to my problem to argue the importance for my research because it accounts for a gap in the literature.

\section{Theoretical Framework}

Ingrained within the literature is the notion that the purpose of professional development is to change teacher practices (Supovitz \& Turner, 2000). The intention behind this study is to stimulate changes in teacher behavior such that they feel confident to teach engineering. To accomplish this objective, this study will be guided by the 
combining of two theoretical perspectives: (a) Bandura's $(1977,1982,1986)$ social cognitive theory as it purports a relationship between a person's beliefs and behavior, and (b) Desimone's (2009) teacher professional development conceptual framework, which integrates teacher beliefs and other research-based factors associated with changing teacher knowledge and practices into a theory of professional development.

Analyzing interventions in P-12 engineering education, Mendoza-Diaz and Cox (2012) claimed the greatest weakness within the current literature was the lack of theoretical frameworks guiding investigations. For this study, I selected Bandura's (1977, 1982, 1986) social cognitive theory and Desimone's (2009) professional development framework because they represent already agreed upon theoretical foundations underlying the Portland Metro STEM Partnership's professional development program. According to Saxton et al. (2013), the Portland Metro STEM Partnership is a "collective impact partnership formed to improve STEM education" and is comprised of various Portland area stakeholders (p. 3). Effective professional development is one focus area of the partnership, which has already established three core professional development outcomes and measures: (a) pedagogical content knowledge, (b) instructional practices, and (c) teacher self-efficacy (Saxton et al., 2013).

Social cognitive theory. The basic idea behind Bandura's (1986) social cognitive theory is that people function as a result of three interacting elements: (a) environmental factors, (b) behavior, and (c) cognitive and other personal factors, including beliefs (see Figure 2.1). Pertinent to my study is the reciprocal relationship between these three elements. Bandura (1986) explained the reciprocal relationship between these three 
elements within the context of television viewing. In short, people have many choices of television programs to watch from various channels (television environment). Personal preferences of an individual affects which programs they watch (personal factor). Preferences influence which programs are actually selected to watch (behavior). Over time, viewer ratings affect which programs survive as well as network decisions to add new programs. Viewer behavior re-shapes the television environment.
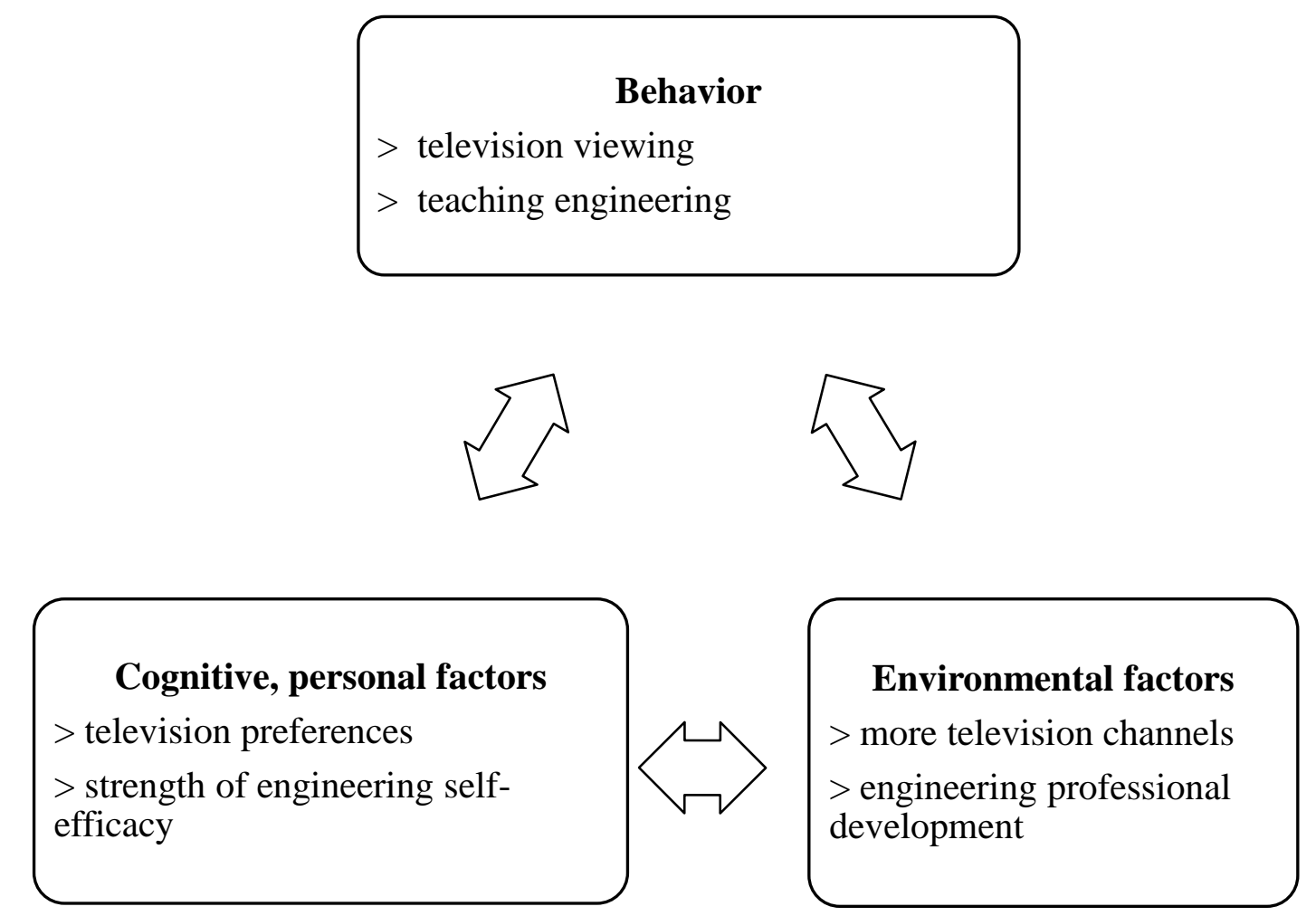

Figure 2.1 Relationship between Bandura's three elements of Social Cognitive Theory with examples

Applying Bandura's (1986) theory to engineering education suggests that an environmental factor, such as engineering professional development (see Figure 2.1), can affect the beliefs of a teacher, which in turn influences a teachers' behavior in teaching engineering. The central mechanism in formulating changes in a persons' behavior is 
elucidated within Bandura's (1977) construct of self-efficacy. Even if a person knows the correct way to behave, they might not act that way because of self-efficacy. Bandura (1986) asserted that a self-efficacy belief "mediates the relationship between knowledge and action" (p. 390). Self-efficacy is a motivational construct because it influences effort and persistence, which in turn influences one's performance. To elaborate how the mechanism of self-efficacy works, it is necessary to further explore Bandura's work and explain how it applies to engineering education.

Bandura (1977) identified two sub-groups of self-efficacy that affect behavior: personal self-efficacy and outcome expectancy. Bandura (1982) defined personal selfefficacy as "judgments of how well one can execute courses of action required to deal with prospective situations" (p. 122). Outcome expectancy is a "person's estimate that a given behavior will lead to certain outcomes" (Bandura, 1977, p. 193). For example, a person believing they can competently teach engineering is an efficacy judgment.

Outcome expectancy is when a teacher anticipates and is confident that their teaching of engineering will result in student success in learning engineering.

Furthermore, Bandura (1986) believed that personal self-efficacy precedes outcome expectancy and outcome expectancy is dependent upon personal self-efficacy. People with high personal self-efficacy expect positive outcomes and people with low personal self-efficacy expect negative outcomes. In his study with 'phobic' participants, Bandura (1982) demonstrated that people with a high level of personal self-efficacy combined with a high level of outcome expectancy will positively affect people and in turn affect their choice of activities, how much effort they will exert, and how long they 
will continue their effort in the face of constraints. When people with high levels of personal self-efficacy and low levels of outcome expectancy encounter constraints, they will not be able to sustain effort for long, attribute more power to the constraints, and ultimately give up. People with low levels of both personal self-efficacy and outcome expectancy will not be able to reduce emotional fears and they will give up more quickly. Applying Bandura's theory to engineering education suggests a teacher's behavior would be negatively influenced if they possessed both a low sense of personal self-efficacy and outcome expectancy toward engineering. Teachers with low self-efficacy toward engineering may avoid teaching the subject. Even if a teacher has high personal selfefficacy to teach engineering and yet a low level of outcome expectancy, when faced with constraints, they will not be able to persevere.

Bandura (1977) also tested four factors that could affect a person's level of selfefficacy: (a) mastery experiences, (b) vicarious experience, (c) verbal persuasion, and (d) emotional arousal. Mastery experience is when a person actively experiences a task, gradually increasing their involvement with the task until repeated successes cause them to feel they have attained mastery of the experience. Repeated failures cause a person to have lower self-efficacy. Vicarious experiences involve people observing others who appear to be similar to themselves who are modeling a task. Successful modeling increases the observer's self-efficacy, while unsuccessful modeling decreases selfefficacy. Verbal persuasion is when credible people talk a person into believing they possess capabilities to perform a task. Positive reinforcement talk increases a person's self-efficacy and negative talk decreases self-efficacy. Emotional arousal or 
physiological states involves the influence of stress or fear a person experiences when performing a task that can facilitate or debilitate a person's performance of a task.

Working with subjects who had a fear of snakes, Bandura applied two of the four factors as treatments to investigate how each factor would affect a person's level of selfefficacy. Some participants experienced mastery, which involved subjects handling a real snake, gradually increasing the threat of the interaction, and cultivating mastery of their performance. Others took part in a vicarious experience, which comprised of subjects watching others holding a snake. Performance tasks were measured as a posttest. While both treatments strengthened self-efficacy, Bandura found mastery experiences to be more influential in strengthening self-efficacy and positively changing how the participants interacted with a snake. The essence of Bandura's (1977) findings imply that an elementary teacher's self-efficacy toward teaching engineering can be strengthened by fostering mastery and vicarious experiences. Such experiences can be generated through professional development by having teachers observe other teachers teaching engineering and by actively engaging in engineering activities.

While Bandura's work convinces me that engineering professional development can improve elementary teachers' self-efficacy toward teaching engineering, researchers must address specific assumptions of social cognitive theory that influence outcomes. The ability to improve self-efficacy assumes enough time has been applied for an influence to take hold. Bandura (1986) insisted the three determinants of human functioning are not fixed, but rather are dynamic elements that can shift over time; he argued that "it takes time for a causal factor to exert its influence" (p. 25). Part of this 
has to do with Bandura's (1997) belief that self-efficacy develops through reflection upon the four sources of self-efficacy. In other words, social cognition theory assumes enough time has been given for a person to experience various sources and environmental influences that influence a person's self-efficacy. Researchers should be cautious of this aspect of time influencing changes in teacher self-efficacy through professional development. Ignoring the influence of time could hinder understanding the problem of teacher self-efficacy toward teaching engineering and thus the solution to the problem.

Another aspect of self-efficacy researchers must consider was best expressed by Tschannen-Moran and Hoy (2001) when they stated that self-efficacy is an "elusive construct" because it is complex and difficult to capture using a measurement tool (p. 783). Bandura (1986) acknowledged that self-efficacy and thus behavior was more complex because it could be influenced by external factors. For instance, drawing from the previous example of television viewing, a person's choice of programs could be affected by ones lack of or availability of money to purchase premium channels. Similarly, a teacher could be influenced by their lack of access or access to adequate resources, which in turn can affect their choice to teach engineering. According to Lee and Houseal (2003), there are external and internal factors that account for classroom science practices. Self-efficacy is considered an internal factor. External factors include time, supplies, classroom management, dealing with diverse learners, and pressures to meet state standards and benchmarks. Of significant concern to both science and engineering advocates is the consequence of the No Child Left Behind (NCLB) legislation that pressures elementary teachers to spend more time teaching language arts 
and mathematics and spend less time teaching science (McMurrer, 2008). In fact, Milner, Sondergeld, Demir, Johnson, and Czerniak (2012) found that elementary teachers' beliefs toward science changed after NCLB which, in turn, negatively affected their practices in the classroom. In sum, while self-efficacy is an essential construct to measure to predict human behavior, researchers must be prudent in how it is measured as well as being aware of other factors influencing self-efficacy. Because the aspects of time and the elusiveness of self-efficacy are important to contemplate, they will be further discussed in chapter three when discussing the research methods.

In the following section, I describe Desimone's (2009) teacher professional development conceptual framework. As previously mentioned, I include Desimone's framework because it was selected by the Portland Metro STEM Partnership as a foundation supporting professional development (Saxton et al., 2013). The Portland Metro STEM Partnership contributes various STEM professional development for Portland metropolitan area teachers and the organization through which I plan to teach engineering professional development. Desimone's (2009) model was a good fit for the Portland Metro STEM Partnership because it works with teachers during professional development and extends to how teachers implement new learning in their classrooms (Saxton et al., 2013). I also support its inclusion because it combines well with Bandura's social cognitive theory and uses research-based, effective components of professional development.

Desimone's teacher professional development conceptual framework. Desimone (2009) established a common conceptual framework to guide studies that seek 
to identify causal relationships and evaluate the effectiveness of teacher professional development programs. Her framework consists of interacting elements within a "path model" that combines two main components (see Figure 2.2). First, the professional development program includes five "critical features" that reflect research-based characteristics associated with producing improvements in teacher knowledge, practices, and student achievement. The five critical features are: (a) content focus, (b) active learning, (c) coherence, (d) duration, and (e) collective participation. Second, the framework requires professional development to be built upon a theory or theories that explain how the program influences teacher learning and change and to a smaller degree potentially affect student outcomes. Bandura's social cognitive theory of self-efficacy is inserted as Desimone's second component to provide a theoretical explanation of how and why teacher practices change.

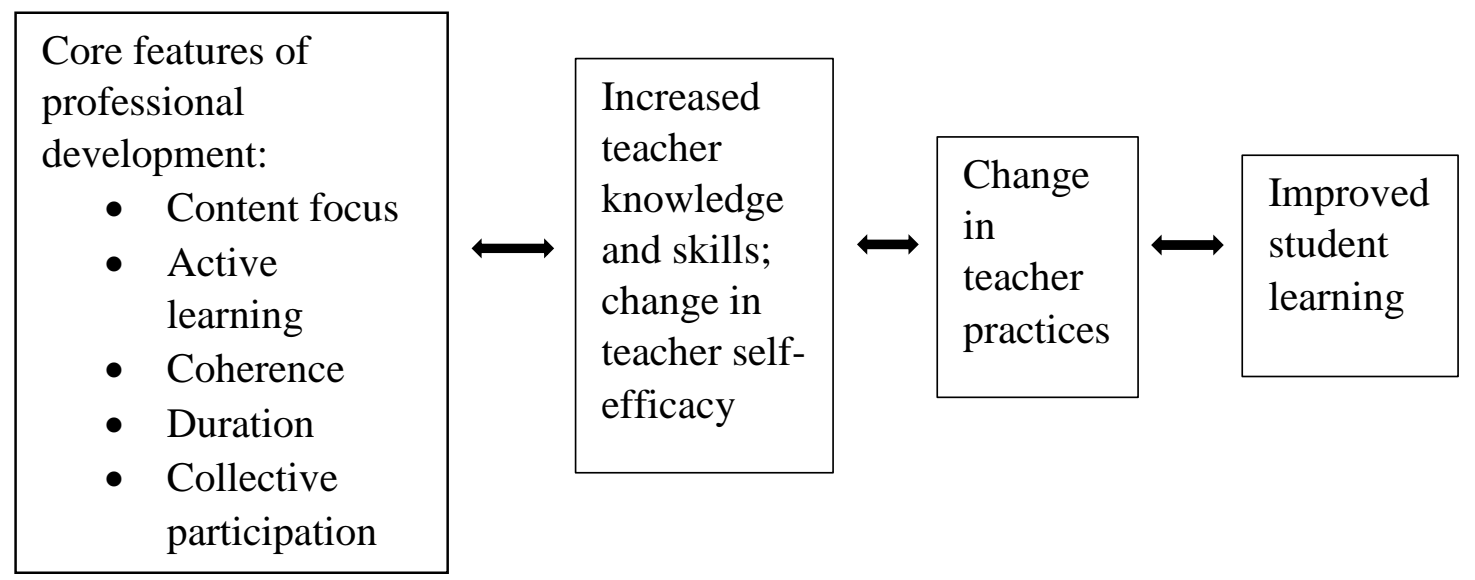

Figure 2.2 Desimone's (2009) path model combined with Bandura's (1977, 1982, 1986) Social Cognitive Theory

To implement Desimone's (2009) model, four steps are required: (a) teachers take part in professional development, (b) the professional development focuses on elevating 
content knowledge and skills to change beliefs and practices, (c) teachers use new knowledge and beliefs to change instructional practices, and (d) changes to teacher instruction enhances student learning. The focus of my study will be on the first three steps of Desimone's model. Elementary teachers will participate in engineering professional development that incorporates Desimone's (2009) five core features. First, engineering content and PCK will be woven into instruction. Second, active learning will be fostered as teachers participant in multiple engineering lessons. Third, coherence will be supported as lessons will be demonstrated to align with school goals (especially for teachers in schools participating in the Portland Metro STEM Partnership), state standards and national expectations that teachers teach NGSS. Fourth, duration will be supported as the summer professional development will consist of 40 hours of contact time and include a follow-up session during the school year. Fifth, collective participation in the professional development is encouraged by inviting teachers from schools who have partnered with the Portland Metro STEM Partnership. Wilson (2013) called for comparable features to be a part of science professional development to prepare teachers to teach the NGSS.

\section{Review of the Research Literature}

Given these theoretical frameworks above, in this section of Chapter 2, I survey the literature relevant to my problem and build an argument as to how to solve the problem of elementary teachers' lacking preparation to teach engineering. Specifically, I review the research literature on effective features of science professional development, particularly those associated with enhancing teacher content knowledge, PCK, and self- 
efficacy. I also examine the link between teacher self-efficacy and practices in the classroom. I include studies having to do with preservice teacher self-efficacy because participants are similar to elementary inservice teachers as they have limited preparation and exposure to engineering content knowledge. I lean toward recent studies and limit my studies to those using professional development as an intervention and within the context of science, engineering, or STEM education. I exclude studies that only incorporate secondary or higher level teacher participants because the participants tend to specialize in a content area, which impacts their confidence and beliefs (Appleton, 2008). In addition, I critique the construct of self-efficacy in light of how it is measured and viewed within the literature.

Next, I review the research literature on sources of teacher self-efficacy. Considering the lack of research investigating sources of teacher self-efficacy as noted by Henson (2002) and Klassen, Tze, Betts, and Gordon (2011), I include studies in other content areas and within P-12 education, but limit studies to contemporary investigations that assess sources of teacher and not student self-efficacy. As with the literature on teacher self-efficacy, I critique the studies on sources of teacher self-efficacy that expose opposing viewpoints. Last, I review and critique the methodological literature relevant to my study to justify my own selection of specific research methods.

Effective science professional development. To be effective, science professional development must focus on content and PCK (Desimone, 2009; Guskey, 2003; Mundry, 2005; NRC, 2007b; Wilson, 2013). Mundry (2005) described the shifts in perspectives of what is most effective in science and math professional development. 
Because research confirmed the importance of quality teaching contributing to student achievement, professional development must focus on content and PCK because it allows teachers' to deepen their understanding of student learning and thinking. Such targets are particularly important for science professional development because science is a field in which new science discoveries and advancements occur at a fast pace. Even the National Research Council (2007) stated that for students to learn engineering it was not enough to improve teacher content knowledge; teachers also needed to enhance PCK.

In fact, science professional development centered on content and PCK has been shown to improve elementary teachers' content and PCK (Appleton, 2008; Heck, Rosenbery, \& Crawford, 2006; Heller, Shinohara, Miratrix, Hesketh, \& Daehler, 2010). Heck, Rosenbery, and Crawford (2006) conducted a longitudinal study between 1997 and 2006 on how reform-based math and science instructional professional development influenced K-12 teachers' attitudes, content and pedagogical preparedness, and classroom practices. Their overall goal was to follow systematic changes over time. Although teachers received varying hours of professional development, these researchers found a significant relationship between professional development and increases in content and pedagogical preparedness. Moreover, they concluded that as hours of professional development increased, so too did teacher content and pedagogical preparedness. Appleton (2008) combined professional development with mentoring to examine the effects on elementary teachers' science PCK. Using a case study methodology, he discovered as a result of the program that two elementary teachers' science PCK improved. One teacher claimed the program increased her confidence, which helped her 
take risks and change her practice. In a national study incorporating 268 fourth grade teachers, Heller, Shinohara, Miratrix, Hesketh, and Daehler (2010) analyzed four different professional development models. Three of the treatments included a focus on science content and PCK, with two having a greater number of activities to enhance PCK. The fourth model represented a control group. Their mixed-method research revealed that all three treatments focusing on science content and PCK caused gains in teacher content and PCK.

Likewise, STEM and engineering professional development centered on content and PCK has been shown to improve elementary teachers' content and PCK (Brown, Alford, Rollins, Stillisano, \& Waxman, 2013; Duncan, Diefes-Dux, \& Gentry, 2011; Hsu, Cardella, \& Purzer, 2010; Yoon et al., 2013). In a mixed-methods study with a sample of 649 participants, Brown, Alford, Rollins, Stillisano, and Waxman (2013) evaluated the influence of STEM K-12 teacher preparation programs on science and math content and PCK. Participants were preservice and inservice teachers within a Master's degree program. The program strove to promote content knowledge and PCK while providing strategies to integrate STEM and problem-based learning. However, the researchers did not measure content and PCK. Instead, they conducted interviews and a survey to find out if perceptions of participant content knowledge and PCK had changed. Researchers found participants significantly improved in their perceptions of their science and math content and PCK.

With the intention of improving elementary teachers' impact on student understanding of engineering, some researchers examined the effects of engineering 
professional development programs aimed at improving teacher content, PCK, or both (Duncan et al., 2011; Hsu et al., 2010; Yoon et al., 2013). Hsu, Cardella, and Purzer (2010) developed their own rubric instrument to measure elementary teachers' knowledge of the engineering design process before and after a week-long workshop teaching the Engineering is Elementary engineering design process model. Their mixedmethods study was piloted with 62 teachers who were asked to complete and comment upon an actual engineering design task. They concluded the engineering professional development program advanced teacher engineering design content knowledge. Duncan et al. (2011) assessed the effects of a week-long INSPIRE engineering workshop. These researchers took a unique approach by having teachers take photos and write journal reflections before and during the workshop. Data was coded based upon Revised Bloom's Taxonomy. As a result, teachers showed a significant growth in their ability to understand engineering. Also working with participants in an INSPIRE workshop, Yoon et al. (2013) collected quantitative data in the form of various pre and post surveys to ascertain changes in teacher attitudes and content knowledge, as well as trying to determine if changes were correlated to teacher and school characteristics. Results exhibited that the program significantly increased teacher engineering content knowledge, but no significant difference was linked to teacher and school characteristics. Importantly, these investigations furnish evidence of a link between Desimone's (2009) first two steps of her 'path model': a) teachers take part in professional development, and b) the professional development focuses on elevating content knowledge and skills to change beliefs and practices. 
Some studies advanced one step farther by demonstrating science professional development focused on content and PCK to be linked to improvements in classroom practices. Within a large-scale survey of mostly elementary teachers and some principals, Supovitz and Turner (2000) examined the effects of high quality professional development focused on science knowledge content and alignment with school standards and goals (coherence) on teachers' attitudes, beliefs, and teaching practices. Their quantitative investigation found that increased hours of science professional development was statistically significant in association with teacher use of inquiry practices in the classroom. As a side undertaking, they looked at the influence of school factors of principal support and availability of resources. Teachers who felt supported by their principals in teaching science and had resources available were reported to significantly using more inquiry practices in their instruction. Pecore, Kirchgessner, and Carruth (2013) conducted a mixed-methods study that examined the impact of an informal professional development of mostly K-8 teachers on teachers' content knowledge, attitudes, and classroom lessons. The program was described as informal because it occurred at a zoo and outside of a classroom. Even so, the program used authentic handson experiences, combined with content knowledge from university faculty, real scientists, and zoo employees. The researchers expressed significant increases in teachers' content knowledge, significant improvement in attitudes, and a high use of lessons created as a result of the program. In fact, during a follow-up session, $89 \%$ of the teachers reported using the lesson they developed from the professional development. Pecore et al. (2013) stated teachers believed both their content and PCK had improved. 
In a qualitative collective case study, Harlow (2014) explored how a physics professional development program influenced the teaching practices of five elementary teachers. Her research provided evidence that three of the five teachers transferred practices from the program into their classroom practices. The two teachers who did not significantly transfer practices were the two teachers that expressed the most comfort and confidence to teach science prior to the program. Significantly, these studies exhibit implementation of Desimone's (2009) core features of professional development and support the relationship between the second and third steps of her 'path model': a) the professional development focuses on elevating content knowledge and skills to change beliefs and practices, and $\mathrm{b}$ ) teachers use new knowledge and beliefs to change instructional practices.

Association between teacher content knowledge, PCK, and self-efficacy. The above mentioned investigations provide evidence that professional development enhancing elementary teachers' content and PCK can improve teacher content, PCK, and instructional practices. These studies bring forth a compelling question: What is the underlying mechanism related to teacher change? I argue the main mechanism behind teacher change lies within the construct of teacher self-efficacy. Recent studies have suggested a link between teacher self-efficacy, content knowledge, and PCK (Park \& Oliver, 2008; Southerland, Sowell, \& Enderle, 2011). The construct of PCK was generated by Shulman (1987) who recognized that expert teachers possessed the knowledge to "transform the content knowledge he or she posseses into forms that are pedagogically powerful and yet adaptive to the variations in ability and background 
presented by students" (p. 15). Park and Oliver (2008) insisted there are two dimensions of PCK: understanding and enactment, and that self-efficacy connects them. In their study with science teachers, Park and Oliver (2008) found that when teacher self-efficacy is increased, the teacher is inspired to enact their understandings. When the teacher acts and is successful, their understandings are reinforced and self-efficacy is further increased. Southerland, Sowell, and Enderle (2011) looked at the connection between teacher content knowledge, PCK, and self-efficacy in a different light. Their inquiry found that when teachers perceive themselves to be deficient in content and PCK, they express pedagogical discontentment. Pedagogical discontentment not only negatively influenced teacher self-efficacy, but also made teachers less likely to consider new teaching practices.

Therefore, in the following section, I convey the research exploring the relationship between self-efficacy and classroom instructional practices. I critique the construct of teacher self-efficacy, yet argue for its inclusion as a means of evaluating engineering professional development and measuring teacher growth. Next, I review and critique the literature using self-efficacy to evaluate STEM and engineering professional development.

Relationship between teacher self-efficacy and classroom practices. The positive relationship between teacher self-efficacy and teacher practices has been wellestablished within the science education literature (Haney, Lumpe, Czerniak, \& Egan, 2002; Lakshmanan, Heath, Perlmutter, \& Elder, 2011; Posnanski, 2002; Ramsey-Gassert, Shroyer, \& Staver, 1996; Riggs \& Enochs, 1990; Sandholtz \& Ringstaff, 2011, 2013; 
Sinclair, Naizer, \& Leadbetter, 2011). Riggs and Enochs (1990) argued that "investigation of teacher beliefs is vital to a more complete understanding of teacher behavior" (p. 625). Based upon Bandura's theory, Riggs and Enochs (1990) constructed an instrument to measure inservice elementary teacher's self-efficacy beliefs towards science teaching, naming it the Science Teaching Efficacy Beliefs Instrument (STEBI-A). Before long, Enochs and Riggs (1990) created a similar instrument, STEBI-B, to measure self-efficacy beliefs of preservice teachers. Both STEBI models integrate Bandura's two subgroups of self-efficacy by measuring personal science teaching efficacy (PSTE) and a teacher's science teaching outcome expectancy (STOE). Using the STEBI-A tool, Posnanski (2002) collected quantitative data to measure the effects of a science professional development program on elementary teachers' self-efficacy beliefs. His study found the program, called Decisions in Teaching Elementary School Science, significantly influenced PSTE. While STOE increased, the increase was not statistically significant. Posnanski (2002) used another survey and a qualitative component to determine the effect of the program on teaching practices. Results indicated teachers planned to change teaching practices with new strategies acquired through the program. Follow-up discussions confirmed many teachers did implement new teaching practices, especially cooperative learning and inquiry activities. Comments reflecting more confidence to teach science confirmed changes measured quantitatively.

Even more recent studies have supported the positive relationship between teacher self-efficacy and science teaching practices (Sandholtz \& Ringstaff, 2011; Sinclair et al., 2011). Sinclair, Naizer, and Ledbetter (2011) evaluated a three-week summer 
professional development program for elementary and middle school teachers that included follow-up meetings, mentoring, and peer collaboration. Their mixed-methods research measured the impact of the program on teacher content knowledge, selfefficacy, and classroom teaching practices. The main focus was to find out if teachers followed through with implementation of program inquiry strategies and pedagogical skills. Content knowledge was assessed through a pre and post-test. The STEBI-A tool measured teacher self-efficacy and Classroom Observation Protocol (COP) instrument measured observations of classroom practices. Data analysis determined there was a significant increase in teacher content knowledge and self-efficacy even though the posttests occurred 11 months after the program. Demonstrated use of inquiry and PCK strategies also improved. A post feedback survey was administered with open-ended questions that supported changes in content knowledge, PCK, and use of inquiry strategies. The researchers identified the most common emerging theme was that teachers reported the program had positive effects on their confidence and motivation to teach science.

Sandholtz and Ringstaff (2011) used the STEBI-A instrument to measure teachers' self-efficacy of rural teachers participating in professional development that integrated science, mathematics, and language arts instruction. These researchers applied Desimone's (2009) professional development conceptual framework to their study and showed the program not only increased teachers' content knowledge and self-efficacy, but also produced a reciprocal effect in teachers increasing science instructional time and 
use of new strategies. Changes in teacher practices were not only self-reported through interviews, but were also measured through classroom observations.

To further the conversation within science research literature, some researchers took on the challenge of answering the question: can teacher changes in science selfefficacy and instructional practices sustain over time? Sandholtz and Ringstaff (2013) continued their program with the same participants for another year and revealed selfefficacy gains maintained from year to year. In like manner, teachers' reported positive changes in teaching more science and the adoption of new strategies. In a longitudinal study, Lakshmanan, Heath, Perlmutter, and Elder (2011) examined the influence of standards-based science and mathematics professional development for elementary and middle school teachers that spanned three years to incorporate summer content courses and professional learning communities. Content knowledge (instructor made) and selfefficacy (STEBI-A) pre and post-tests were performed. Similar to previous research findings, teacher PSTE increases were significant, but STOE increases were not. As data was collected at five points in time, it was interesting that participants with initially lower PSTE showed the greatest improvement over time. Classroom practices were measured using the Reformed Teaching Observation Protocol (RTOP) instrument. Not only did the researchers discover significant increases in teachers' use of standards-based instructional practices, but also found a positive correlation between changes in teacher PSTE and changes in instructional practices. All these previously described studies showing evidence of a positive relationship between teacher self-efficacy and teaching practices 
suggests the importance of exploring self-efficacy within engineering professional development.

\section{Critique toward previous research involving teacher self-efficacy. Few}

researchers have evaluated affective aspects of teachers within the context of STEM and engineering professional development. As discussed in chapter one, Yasar et al. (2006) developed a survey measuring P-12 teachers' perceptions of engineers and familiarity of design, engineering, and technology (DET). Two of the 41 survey items dealt with DET self-efficacy. Administering their survey with 98 P-12 teachers, they found teacher confidence to teach and integrate DET concepts to be weak. Mendoza-Diaz, Cox, and Adams (2013) used this survey within engineering professional development to investigate elementary teachers' perceptions and familiarity with DET with the goal of evaluating differences based on ethnicity and exposed that minority teachers were more motivated to learn and teach DET than majority teachers. Analogously, Yoon et al. (2013) used the DET survey within their study and discovered the INSPIRE engineering professional development elevated teacher familiarity and perceptions of DET. Because the DET survey employed in the above studies only measured a small piece of selfefficacy, I contend they are limited in their analysis of self-efficacy.

In fact, I assert there exists a gap in the research literature on investigations that examine the construct of self-efficacy within the setting of STEM, and particularly engineering professional development. Moman-Powell and Brown-Schild (2011) evaluated self-efficacy within STEM professional development, but they measured selfefficacy to teach inquiry. In a quantitative study, Nadelson et al. (2012) modified the 
STEBI-A instrument by replacing the word science with STEM. They gave pre and post surveys to elementary teachers participating in a four-day i-STEM workshop and concluded that the program significantly improved teacher self-efficacy to teach STEM. In a comparable study, Nadelson et al. (2013) examined the impact of a three-day STEM workshop on elementary teachers' efficacy to teach STEM. Even though the workshop was conducted over a shorter period of time, teachers still generated gains in self-efficacy to teach STEM.

Seminal to my study is the fact that the above mentioned studies explored elementary teacher self-efficacy within the context of STEM professional development programs and not engineering. Mendoza-Diaz and Cox (2012) reviewed P-12 engineering research literature published between 2001 and 2011 and analyzed different research methods applied. Although three studies were found that used self-efficacy as a measured construct, none of these studies involved elementary teachers. Searching the literature from 2011 onward did not reveal any published research having to do with elementary teachers' self-efficacy within the context of engineering professional development. I argue such findings advocate the need for a study to quantitatively measure elementary teacher self-efficacy before and after engineering professional development. However, my study will also qualitatively measure self-efficacy as a way of confirming quantitative results. Such an approach is necessary as Tschannen-Moran, Hoy, and Hoy (1998) complained that qualitative research on teacher self-efficacy was “overwhelmingly neglected" (p. 242). 
In the previous section within my review of the research literature, I reviewed and critiqued the literature around the construct of teacher self-efficacy. In the following section, I analyze and critique the literature involving teacher sources of self-efficacy. Moreover, I provide rationale for the importance of further exploration of this concept within the context of engineering professional development for elementary teachers.

Sources of teacher self-efficacy. While it is true that an abundant amount of research on teacher self-efficacy exists, less research has explored how sources of selfefficacy operate (Henson, Kogan, \& Vacha-Haase, 2001; Klassen et al., 2011). To review, Bandura (1986) identified four sources of self-efficacy: (a) mastery experiences, (b) vicarious experience, (c) verbal persuasion, and (d) emotional arousal. Bandura (1997) believed people formulate self-efficacy through their assimilation of the four sources of self-efficacy. However, Bandura (1977) claimed mastery experiences to be the most powerful influence on self-efficacy because it is based upon authentic performance experiences. But, is this true for teaching self-efficacy? Ramsey-Gassert et al. (1996) collected quantitative data in the form of a questionnaire and surveys from 23 elementary teachers participating in a project to advance STEM education. Triangulated data was used to develop interview questions to explore external and internal factors that influence teacher self-efficacy. They believed negative factors could pose as barriers to enhancing self-efficacy while positive factors could support the strengthening of selfefficacy. Their research revealed that quality science teacher preparation and inservice workshops as well as positive science teaching experiences were the most influential factors in strengthening self-efficacy. Another prominent factor was support from peers 
and administrators (verbal persuasion). These results express the affirmative influence of mastery experiences as a source of teacher self-efficacy and suggests the role of other sources of self-efficacy may be favorable factors at play. In fact, Tschannen-Moran and Woolfolk-Hoy (2007) surveyed self-efficacy of 255 K-12 teachers using TSES and compared scores of novice and veteran teachers. Novice teachers were defined as inservice teachers with three years or less experience. Their research revealed some differentiation because verbal persuasion was most influential as a self-efficacy source for novice teachers, while mastery experiences were most influential for veteran teachers. Teacher self-efficacy and its sources have been examined in other content areas besides science (Ross \& Bruce, 2007; Tschannen-Moran \& McMaster, 2009; TschannenMoran \& Hoy, 2007). Ross and Bruce (2007) constructed a math professional development program with the intention of incorporating Bandura's four sources of selfefficacy to improve self-efficacy. Their quantitative study was unique because they were able to randomly assign 106 sixth grade math teachers from the same school district into either a treatment or control group. The treatment group attended a math professional development program that used strategies to provide all four sources of self-efficacy. The researchers collected teacher characteristics and determined there was no significant difference between the two groups. Pre and post teacher self-efficacy was measured using the TSES survey modified for math. Teachers in the treatment group had higher gains in self-efficacy than the control group, but not significantly. However, the subscale of classroom management self-efficacy showed significant improvements. 
Tschannen-Moran and McMaster (2009) investigated four different formats of professional development to teach an innovative reading strategy to elementary teachers. Each of the four formats increased the input of self-efficacy sources, such that treatment one included verbal persuasion only (from workshop instructors). Treatment two consisted of verbal persuasion and vicarious experiences (viewing other teachers modeling). Treatment three involved verbal persuasion, vicarious experiences, and practice in teaching (within teacher groups). Treatment four was the same as treatment three with the addition of follow-up coaching in the teacher's classroom. Emotional arousal was not incorporated as a treatment. Self-efficacy was measured using the TSES instrument. The researchers found that treatment four was associated with the greatest gains in teacher self-efficacy. Unexpectedly, gains in self-efficacy did not align with increasing levels of treatments. Treatment one had the next highest influence on teacher self-efficacy.

Likewise, self-efficacy and its sources have been examined with preservice elementary teachers. Woolfolk-Hoy and Spero (2005) conducted a longitudinal study and measured elementary teacher self-efficacy at three different points in time: (a) during the first year of a teacher preparation program, (b) at the end of student teaching experience in a teacher preparation program, and (c) at the end of the first year of teaching. Teacher self-efficacy was measured using four different instruments. All four instruments showed significant increases in self-efficacy in 53 teachers from the beginning of teacher preparation to the end of student teaching experiences. Two instruments showed significant decreases in self-efficacy, with another revealing 
approaching significance decreases, in 29 teachers from the end of student teaching to the end of their first year of teaching. Sources of efficacy were also explored using a researcher made survey implemented only at the end of the participants first year of teaching. Decreases in teacher self-efficacy at the end of the first year of teaching were correlated to negative influences of verbal persuasion. Verbal persuasion could come in the form of feedback from peers, administrators, and/or parents. Increases in teacher selfefficacy at the end of the first year of teaching were correlated to positive influences of verbal persuasion. These results provide evidence that verbal persuasion is a powerful influence in the critical years between teacher preparation and first year teaching situations and suggests it is important to include positive forms of verbal persuasion for teachers learning a new topic.

Palmer (2006) was interested in sources of self-efficacy for preservice teachers, but hypothesized there were alternative or nuanced sources formulating self-efficacy. With participants enrolled in a science methods course, he used the STEBI-B to measure pre and post self-efficacy. Throughout the course, students were exposed to science content and PCK, hands-on activities and provided experiences reflecting all four of Bandura's sources of self-efficacy. For example, mastery experiences were in the form of an assignment whereby students were required to teach a lesson to an elementary level child. The course did not include in school teaching experiences. Qualitative data was also collected in the form of informal reflections and analyzed to identify sources of selfefficacy. STEBI-B results displayed a significant improvement in self-efficacy after taking the course. After analyzing the reflections, categories surfaced that aligned with 
Bandura's (1986) four sources of self-efficacy. However, a deeper understanding of these categories emerged. Palmer (2006) declared the most influential source of selfefficacy, based upon it being stated the most often, was cognitive pedagogical mastery. He defined cognitive pedagogical mastery as "success in mastering an understanding of some motivating and effective techniques for teaching science" (p. 339). Although Bandura (1986) also called mastery experiences enactive mastery, cognitive represents a successful understanding and not successful doing of a task. The researcher also mentioned cognitive content mastery (successful understanding of content) and simulated modelling (teaching through role play) as sources of enhancing self-efficacy. Palmer (2006) argued that content knowledge and PCK are pre-requisites for self-efficacy as a result of mastery experiences.

In response to Palmer's (2006) study, Bautista (2011) designed a science methods course for preservice teachers that provided opportunities for students to engage in various mastery and vicarious experiences. Bautista (2011) applied a mixed method approach and measured self-efficacy using the STEBI-B and identified sources of selfefficacy using a questionnaire of seven open-ended questions. STEBI-B results found significant increases in PSTE and STOE subscales of the self-efficacy instrument. Answers to questions were analyzed using categories from both Bandura (1997) and Palmer (2006). The questionnaire corroborated STEBI-B results as $93 \%$ of the teachers reported their confidence improved as a result of the methods course. Written responses also revealed mastery experiences, cognitive pedagogical mastery, cognitive self- 
modelling (imagining future success in performance), and symbolic modelling (observing teachers perform on video) to be the most influential sources of self-efficacy.

Critique toward previous research involving sources of self-efficacy. The conclusions from the previously stated investigations evoke significant questions about sources of teacher self-efficacy. Bandura (1986) acknowledged that self-efficacy is content-specific. Is self-efficacy affected by a person's level of general teaching experience? Does the formulation of self-efficacy for inservice elementary teachers' lacking content knowledge and PCK manifest in a similar way as it does for preservice teachers?

Most compelling is that Palmer (2011) explored sources of self-efficacy for inservice teachers. In a mixed-methods study, he examined the effectiveness of a science workshop that purposely included the following sources of self-efficacy:

(a) cognitive mastery, (b) mastery experiences, (c) modelling (different forms of vicarious experiences), and (d) verbal persuasion. Quantitative data consisted of measuring self-efficacy using the STEBI-A as a pre, post, and post/posttest. Qualitative data was collected in the form of questionnaires and interviews to furnish evidence of sources of self-efficacy. As he expected, self-efficacy scores increased as a consequence of the workshop, and significantly between the pre and posttests. Results revealed that strengthened self-efficacy was perceived by teachers to be caused through cognitive mastery (success in understanding how to teach science). The next most influential source of self-efficacy was a form of verbal persuasion, specifically when feedback was immediately given to teachers within debriefing sessions or after they were observed 
teaching. The author called this type of verbal persuasion 'in situ feedback.' Palmer's (2011) findings demonstrate the need for a more nuanced understanding of existence of sources of self-efficacy. I assert that Palmer (2006, 2011) also suggested unanswered questions about sources of teacher self-efficacy.

Changes in self-efficacy as a result of the engineering professional development can be used to evaluate the effectiveness of the program. Nonetheless, revealing changes in self-efficacy alone does not reveal what aspects of the program influenced selfefficacy. Sources of self-efficacy need to be identified to provide designers of engineering professional development with evidence of what factors positively influence elementary teacher self-efficacy. Klassen et al. (2011) insisted, "Investigating the sources of teacher efficacy is a priority for future teacher efficacy research" (p. 39). Henson, Kogan, and Vacha-Haase (2001) contended that little research has explored how sources of self-efficacy formulate and suggested qualitative research in self-efficacy would help 'mature' the research. Despite these statements, it is significant that no research has been published that explores the sources of self-efficacy within the context of engineering professional development. Accordingly, I argue my study is needed to uncover authentic sources of elementary teachers' self-efficacy within the context of engineering professional development and fill this void in the research literature.

In the last section of Chapter 2, I review the research of methodological literature pertinent to my study. I assess and critique the methodological literature to select methods for my study and present reasons for my selection. 


\section{Review of the Methodological Literature}

According to Vogt, Gardner, and Haeffele (2012) regarding a researcher's selection of research methodology, "one's choice of design should be driven by the research question, the context in which one is trying to answer it, and the objectives of the research" (p. 49). In the methods and research questions section of chapter one, I explained my intention to use a mixed-methods research methodology because it is best suited to answering my research questions. In Figure 2.3, I restate my three research questions and identify the methods I have selected to answer them. Research question two, for instance, focuses on what happens to teacher self-efficacy. I think a quantitative measure (survey) can best capture this information. On the other hand, research question three is different type of question because I seek to understand how and why self-efficacy may have changed. Because qualitative methods are more exploratory in nature, such an approach opens the door to any and all variables influencing self-efficacy, and thus is more useful in answering research question three.

Measuring teacher content and pedagogical content knowledge. To review, the Portland Metro STEM Partnership has already established three core professional development outcomes and measures: (a) pedagogical content knowledge, (b) instructional practices, and (c) teacher self-efficacy (Saxton et al., 2013). The partnership provides professional development for local teachers, which includes an engineering course that began in the summer of 2013. Although Saxton et al. (2013) planned to develop a STEM PCK rubric to measure outcomes for teachers, their instrument has yet to be developed. Therefore, the co-instructors of the engineering course developed their 
own survey to measure engineering content and pedagogical content knowledge. One of the co-instructors was the lead writer for the new engineering standards within the NGSS which lends credibility to this instrument that focuses on basic principles of engineering

1. How did the professional development program affect elementary teachers' content and pedagogical content knowledge to teach engineering?

survey

2. How did the professional development program affect elementary teachers' perceptions of selfefficacy to teach engineering?

survey interviews

3. After the engineering professional development program, what aspects of the program or other factors did elementary teachers' identify as influencing their self-efficacy to teach engineering?

$$
\text { survey interviews observations }
$$

Figure 2.3 Research questions and methods selected to answer them

and how teachers can assess student understandings about engineering and apply strategies for teaching engineering. The survey instrument consists of open-ended questions and is administered before (pre) and after (post) the engineering professional development program. Because Palmer (2006) viewed content and PCK as 'prerequisites' for teachers developing self-efficacy, I include the measurement of these concepts within research question one. I use a survey instrument created by the coinstructors of the engineering professional development course because it has already been piloted and improved from the previous year. 
Measuring teacher self-efficacy. In the previously discussed literature that measured teacher self-efficacy within the context of STEM and engineering, all the researchers used surveys to measure self-efficacy (Mendoza-Diaz et al., 2013; Nadelson et al., 2012, 2013; Powell-Moman \& Brown-Schild, 2011; Yasar et al., 2006; Yoon et al., 2013). Vogt et al. (2012) stated surveys are commonly used methods, especially when researchers are determining whether or not participants are changing beliefs over time as a result of taking part in a program. My intention surrounding research question two is to obtain quick answers to structured questions regarding teacher beliefs about teaching engineering before and after participation in engineering professional development. As such, a survey represents an excellent method by which to answer research question two. However, a survey alone has limitations because my own personal experience with post professional development surveys is that I become so energized and positive after the program that my responses reflect an all-time high. Because Bandura (1986) warned that self-efficacy shifts over time, I plan to use interviews at a later time to corroborate selfefficacy results obtained through the survey.

Literature discussed within the review of the research literature section revealed an assortment of survey instruments administered. Which survey instrument is best for my study? Gibson and Dembo (1984) were the first researchers to develop an instrument called the Teacher Efficacy Scale (TES) to measure teacher self-efficacy. The TES tool measured Bandura's two subscales, but called them personal teacher efficacy (PTE) and general teaching efficacy (GTE). Over time, more content-specific forms of the TES were developed, including the previously mentioned STEBI model. As more research in 
the field of education examined self-efficacy, doubts and criticism began to emerge regarding the instruments used to measure self-efficacy. Tschannen-Moran et al. (1998) criticized the TES because they believed the GTE portion did not measure Bandura's subscale of teacher outcome expectancy, but instead measured external locus of control. Henson et al. (2001) investigated the effectiveness of four teacher efficacy instruments, including the STEBI-A model. While these researchers found the subgroup of PSTE to be reliable, the other subgroup of STOE was not found to be reliable. Blame was focused upon the instrument using items having more to do with external barriers influencing student outcomes and less to do with teachers' beliefs. As Lakshmanan et al. (2011) used the STEBI-A five times within science professional development and found significant increases in PSTE, but no changes in STOE, more concerns over the STEBI instrument were raised.

Viewing the STEBI-A as a flawed instrument, Tschannen-Moran and Hoy (2001) re-evaluated the construct of teacher self-efficacy and proposed a new instrument by which to measure it. They claimed that previous self-efficacy tools failed to align well with Bandura's theory and tended to focus on teachers' perception of past performance. Most objectionable to these researchers was the inability of previous instruments to balance domain specificity with the capacity to generalize. Therefore, Tschannen-Moran and Hoy (2001) developed a teacher self-efficacy instrument that reflected Bandura's theory and possessed a "unified and stable factor structure and assesses a broad range of capabilities that teachers consider important to good teaching, without being so specific as to render it useless for comparisons of teachers across contexts, levels, and subjects" 
(p. 801-802). Because STEM teaching includes four different content areas and for the reasons stated above, the Portland Metro STEM Partnership chose Tschannen-Moran and Hoy’s (2001) Teacher Sense of Self-Efficacy Survey (TSES) as a common measure for teacher self-efficacy (Saxton et al., 2013). Thus, I exclude the use of the STEBI-A instrument within my study and in its place adopt the TSES instrument.

Measuring sources of teacher self-efficacy. Klassen et al. (2011) reviewed teacher self-efficacy research conducted between 1998 and 2009. These researchers found $76.7 \%$ of the studies used quantitative methods, $8.7 \%$ used qualitative methods, and $14.7 \%$ used a mixed-methods approach. While Klassen et al. (2011) acknowledged the TSES survey was an effective measure of teacher self-efficacy, they complained that a reliable measure of sources of teacher self-efficacy was missing. Agreeing that an instrument was needed to measure teacher sources of self-efficacy, Kieffer and Henson (2000) developed a new measure called Sources of Self-efficacy Instrument (SOSI). Unfortunately, the authors deemed the SOSI to have psychometric challenges. Therefore, I agree with Klassen and his colleagues (2011) when they asserted that qualitative studies were vital to pave the way for creating such a quantitative measure.

To answer research question three, I selected qualitative methods by using a survey, interviews, and participant observations. I included open-ended questions within the post-post survey. I planned to conduct interviews midway through the school year; after teachers have had the opportunity to teach an engineering lesson. Also, I intended to write field notes while observing the engineering professional development follow-up session that takes place in the spring and after teachers have had experiences teaching 
engineering. It is important to note I hold specific reasons why I selected these methods. First, the post-post survey questions can assist in establishing sources of teacher selfefficacy and represents an informal and reflective activity. Second, interviews can corroborate the quantitative survey outcomes. According to Vogt et al. (2012) an interview is an "organized conversation in which one person asks the questions, and another answers them" and they are often used to "interpret the answers in survey research" (p. 32). Also, the interviews aim to provide a more in-depth understanding of what factors or events surrounding the professional development influenced teacher selfefficacy. Third, observation notes were written while observing teachers participate in the follow-up session. Such a setting provides an opportunity to witness the depth of sources of self-efficacy within a sharing session (Vogt et al., 2012). To answer research question three, I used three methods of data collection because a limitation of qualitative research is that it can have issues with validity (Creswell \& Plano-Clark, 2011). To alleviate this issue with regards to my data methods, I employed triangulation; "the use of several means to examine the same phenomenon" (Vogt et al., 2012, p. 110). Such a strategy builds strength to my study because I draw on various methods to reveal evidence of supporting themes related to sources of teacher self-efficacy.

\section{Summary}

In Chapter 2, I communicated the theoretical framework of social cognitive theory as the lens through which to analyze the problem of elementary teachers' lacking adequate preparation to teach the "E" in STEM. Applying Bandura's (1986) social cognitive theory and construct of self-efficacy to engineering education suggests that 
effective professional development can enhance teacher self-efficacy beliefs to teach engineering, which in turn positively influences a teachers' classroom practices. Because previously discussed research showed evidence of a relationship between teacher science self-efficacy and classroom practices, I argued the importance for more content-specific studies to examine and advance teacher self-efficacy to teach engineering. In addition, I offered a professional development conceptual framework to use as a model for engineering professional development and as a way of facilitating a deeper understanding of the problem. Desimone's (2009) path model combines research-based components of quality professional development with Bandura's construct of self-efficacy to show how teachers can grow and change classroom practices.

Within the review of the research literature, I presented evidence linking effective professional development with improvements in teacher content and PCK. Likewise, I showed evidence showing a correlation between teacher content knowledge, PCK, and changes in teacher self-efficacy, which in turn lead to changes in classroom practices. Such evidence strongly suggests the importance for engineering professional development as a means of strengthening teacher self-efficacy so teachers will feel more confident to teach engineering. Despite the importance of engineering professional development, it is significant that no research has been published that measures the construct of elementary teacher self-efficacy to teach engineering.

Equally, I claimed the formation of self-efficacy is important to explore because it offers an understanding of how to strengthen teacher self-efficacy within professional development. Reviewing the research literature revealed few investigations exploring 
sources of teacher self-efficacy and none within the context of engineering professional development. For professional development to be of high quality it is necessary to ascertain what aspects of the program had the most positive impact on teacher selfefficacy. Such an understanding is important so effective strategies and models for engineering professional development can be replicated.

Lastly, I examined the methodological literature relevant to my study. First, I analyzed my research questions and the intentions of my study within the context of engineering professional development. Then, I explored research methods within the literature to match them with my questions and objectives. In doing so, I selected surveys, interviews, and participant observations as tools to collect data within a mixedmethod approach. A mixed-method approach will blend the strengths of quantitative and qualitative data. Also, by triangulating data sources that include a survey, interviews, and observations, I establish validity within my study. 


\section{Chapter 3: Methods}

Individual states are systematically adopting the Next Generation Science

Standards and implementing these standards poses both opportunities and challenges.

When compared to the old standards, one challenge is that there is a greater emphasis in the expectation for P-12 teachers to teach engineering. In Chapter 1, I presented evidence indicating that elementary teachers' lack of content knowledge and pedagogical skills seems to relate to weak perceptions of self-efficacy to successfully teach engineering. As a result of this problem, I emphasized the purpose of my study was twofold: (a) to examine the effects of engineering design professional development on elementary (K-6) teachers' perceptions of self-efficacy, content, and pedagogical content knowledge to teach engineering, and (b) to describe and explain teachers' perceptions of the aspects of the program as well as any other factors that may have influenced their self-efficacy. The following research questions directed this study:

1. How did the professional development program affect elementary teachers' content and pedagogical content knowledge to teach engineering?

2. How did the professional development program affect elementary teachers' perceptions of self-efficacy to teach engineering?

3. After the engineering professional development program, what aspects of the program or other factors did elementary teachers' identify as influencing their self-efficacy to teach engineering?

In light of the purpose of my study and the research questions I aspire to answer, I

reviewed the methodological literature in Chapter 2 to analyze and select appropriate

methods. In Chapter 3, I describe a more elaborate explanation of chosen methods and reasons for their selection. I provide details regarding the engineering professional development course, participants and context of the study, and procedures employed, 
which includes the use of data collection instruments. As a co-instructor of the engineering course and the researcher, I express my position as having dual roles. Lastly, I describe and justify steps taken to collect and analyze the data so I can answer the research questions within my study.

\section{Research Methods}

Paradigm guiding the inquiry. According to Creswell and Plano-Clark (2011), paradigms vary in their stances toward "the nature of reality (ontology), how we gain knowledge of what we know (epistemology), the roles values play in research (axiology), the process of research (methodology), and the language of research (rhetoric)" (p. 41). Guba and Lincoln (2005) analyzed how various paradigms come together, contrast and can contradict each other. While Guba and Lincoln (2005) allowed some overlap across paradigms, Morgan (2007) criticized their incommensurate view toward ontological assumptions. In other words, if a researcher accepted the ontological assumptions of one paradigm, they had to reject ontological assumptions of all other paradigms. Morgan (2007) claimed this kind of "top-down approach" was too narrow. Essentially, ontological assumptions inform and guide epistemological and methodological approaches; therefore embracing one ontological stance limits the methods to be used. Consequently, this study will be guided by the pragmatic paradigm that rejects a topdown view of epistemological, ontological, axiological, and methodological stances (Morgan, 2007). According to Creswell (2009), the pragmatic paradigm "opens the door to multiple methods, different worldviews, and different assumptions, as well as different forms of data collection and analysis" (p. 11). Pragmatism accepts singular or multiple 
realities and multiple stances on the role of values (Creswell \& Plano-Clark, 2011). Pragmatic researchers focus on solutions to a problem and draw understandings from both qualitative and quantitative assumptions and methodologies (Creswell, 2009).

The pragmatic paradigm is well suited to my research because of its notion of transferability. Morgan (2007) defined transferability as "whether the knowledge we gain can be transferred to other settings" (p. 72). I anticipate my study will have the limitation of having a small sample size. Does this limitation make it impossible for my study to generalize? Morgan's (2007) perception of transferability is that he does not believe "it is possible for research results to be either so unique that they have no implications whatsoever for other actors in other settings or so generalized that they apply in every historical and cultural setting" (p. 72). Morgan's view validates my use of mixed methods by implying that the results could apply to other settings and at the very least be informative to others searching for solutions.

Type of research design and rationale. Creswell and Plano-Clark (2011)

insisted a mixed-methods approach should fit a researcher's questions in a study and be justified in its use. I argue my study warrants a mixed-methods approach because I believe the quantitative data alone will not provide a complete understanding. Essentially, I agree with Maxwell (2013) that a mixed-method approach "reduces the risk that your conclusions will reflect only the biases of a specific method, and allows you to gain a more secure understanding of the issue you are investigating" (p. 102). I incorporate qualitative data because of its ability to elicit an assortment of responses. For instance, I feel strongly about not wanting to identify variables influencing teacher self- 
efficacy up front. Because I bring my own assumptions, perhaps I will miss something. In other words, I contend it is more accurate for sources of teacher self-efficacy to be generated in an emergent or inductive manner, which is a strength of qualitative methods (Morgan, 2013). Mintzes, Marcum, Messerschmidt-Yates, and Mark (2013) employed a similar strategy when studying the effects of professional learning communities on elementary teachers' self-efficacy. In their study, a quantitative approach was used to measure self-efficacy and a qualitative approach was used to measure sources of selfefficacy.

To accommodate an approach that collects quantitative and qualitative data in the manner previously mentioned, I use a mixed-method explanatory sequential design approach to examine the construct of self-efficacy in two phases (Creswell \& PlanoClark, 2011). Such an approach is a "design in which the researcher begins by conducting a quantitative phase and follows up on specific results with a second phase. The second, qualitative phase is implemented for the purposes of explaining the initial results in more depth" (Creswell \& Plano-Clark, 2011, p. 82). In the quantitative, Phase One part of the study (see Figure 3.1), teachers' content and PCK to teach engineering will be measured using an instructor made instrument. In addition, teachers' perceptions of self-efficacy to teach engineering will be measured using the Teacher Sense of Self Efficacy (TSES) Survey as a retrospective pre and post-test. A retrospective pre-test differs from a pre-test because self-reported data is collected at the same time as the posttest. The participants achieving the top $25 \%$ of gains in the self-efficacy measure will be asked to participate in the second phase of the study in which qualitative data will be 
collected through a survey, interviews, and observations. Morgan (2013) termed this mixed methods approach as "sequential contributions" whereby one method is used to augment the use of another method (p. 10). In his sequential contributions model,

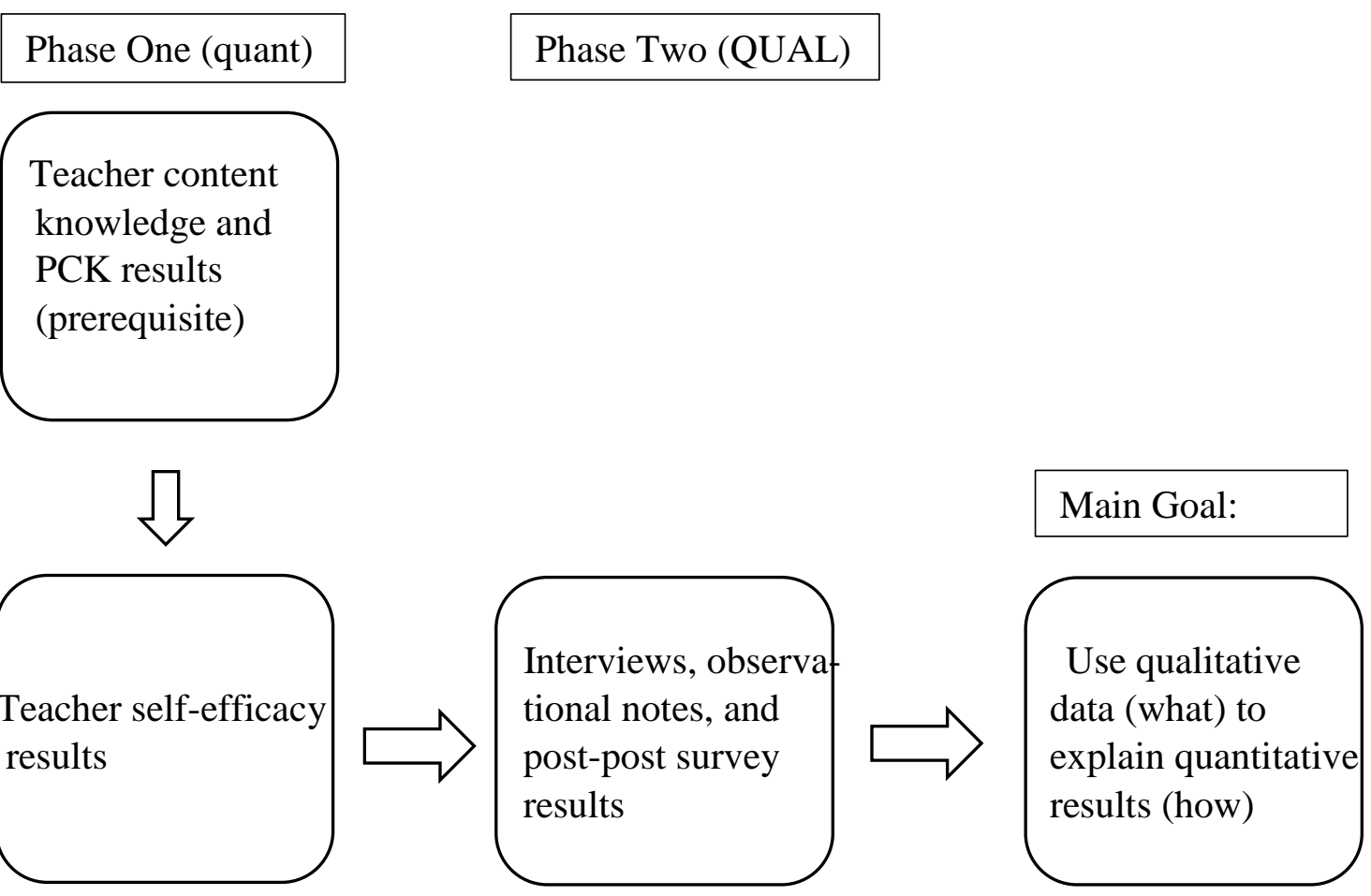

Figure 3.1 Summary of an explanatory sequential design approach

Morgan (2013) described four basic types of design: (a) qual $\rightarrow$ QUANT, (b) quant $\rightarrow$ QUAL, (c) QUANT $\rightarrow$ qual, and (d) QUAL $\rightarrow$ quant. I employ the quant $\rightarrow$ QUAL design as I use quantitative data results (TSES survey) as an input in selecting participants for the qualitative part of the study. The capitol letters (QUAL) signifies that the qualitative portion of the study is the core goal. What is more important in my study is not what happens to teacher self-efficacy, but rather exploring why teacher selfefficacy changed. 
One limitation to this approach is that the specific participants in Phase Two are not known until Phase One results are analyzed. While the IRB board may have an issue with this, it is important to communicate to participants during Phase One the possibility of being contacted at a later date. Nonetheless, results from Phase Two are essential for two reasons: (a) they assist in corroborating Phase One outcomes, and (b) they provide evidence of the aspects of the program and any other possible factors that may have influenced teacher self-efficacy to teach engineering.

In sum, Phase One of the study answers how teacher content knowledge, PCK, and self-efficacy were affected by the engineering professional development experience. Phase Two explains why teacher self-efficacy was affected (factors influencing selfefficacy). I selected an explanatory sequential design approach because of certain strengths it brings to my study. Due to its chronological structure, it is easier to implement and write about. Also, by including qualitative data within the second phase of my study to identify factors influencing the formation of teacher self-efficacy, I ensure a more emergent process to take place.

Participants, context of the study, sampling, and rationale. In 2011, the Oregon STEM Initiative was released to begin the process of creating a vision and plan for statewide STEM education. Through the initiative, the Oregon STEM Education Partnership was formed which consists of various business, community, and educational leaders. Local partnerships or regional hubs were established across the state by the Oregon STEM Education Partnership. The Portland Metro STEM Partnership (PMSP) represents one of six statewide regional STEM hubs that partner with local public 
schools, businesses, and community organizations to promote STEM education. The key partners within PMSP include Portland State University (PSU), local businesses (Intel, Oregon Health and Science University, Vernier Software and Technology, JP Morgan Chase, and McKinstry Co.), informal education providers (Outdoor School, Oregon Museum of Science and Industry, Oregon Zoo, and Oregon FIRST Robotics), and four metro-area school districts (Beaverton, Forest Grove, Hillsboro, and Portland). An important component of PMSP is the Teacher's Academy that collaborates with PSU to provide research-based professional development for local teachers, especially for teachers within partnering school districts. For the summer of 2014, the Teacher's Academy is offering 24 different STEM-related professional development courses. Recently, PMSP received an Oregon Hub grant to help fund the organization and professional development courses at the regional level.

This study concentrated on a relatively small sample of 10 adult elementary teachers participating in a professional development course offered by the Teacher's Academy titled, Advancing STEM Instruction through Engineering Design. While the sample size of this study is small, the study holds merit because it represents a bottom-up type of systematic educational improvement. In their work with the Carnegie Foundation, Dolle, Gomez, Russell, and Bryk (2013) criticized the previous years approach in research and development to bring about advancements in education. One specific problem is how there are knee-jerk reactions to educational challenges that seek to implement broad changes. Instead, enacting sustained efforts of implementation are necessary to foster change. An innovative approach to change educational systems 
backed by the Carnegie Foundation is known as networked improvement communities. Dolle et al. (2013) defined a network improvement community as a "social mechanism through which collaborative designs and practice theories produced by design-based implementation research can become live resources for the improvement of systems" (p. 444). Part of this network strategy is to begin small and improve a system from the bottom up with the ultimate goal of "achieving efficacy with reliability at scale" (Dolle et al., 2013, p. 445). As such, I argue the PMSP is an example of networked improvement community. The course Advancing STEM Instruction through Engineering Design sponsored within this community serves as a small step toward changing teacher practices in a sustainable manner.

Teachers participating in the Advancing STEM Instruction through Engineering Design course were currently teaching in elementary schools located within and around a metropolitan city in the Northwestern United States. Although 13 elementary teachers participated in the course, three teachers declined consent to participate. Purposive sampling was selected as the sampling method for this study. According to Plano-Clark and Creswell (2010), purposive sampling is when researchers "intentionally select sites and individuals to learn about or understand the central phenomenon" (p. 253). As stated by the course creator, Dr. Cary Sneider (personal communication, May 8, 2014), the teachers participating in the Advancing STEM Instruction through Engineering Design course are taking the course for one or more of the following reasons: (a) they are interested in STEM and engineering, (b) they want to learn more about engineering because they have little to no background knowledge to teach it, (c) they need to learn 
more about engineering since Oregon adopted the NGSS, and (d) they are currently teaching in a designated STEM school. Because of these characteristics, the participants likely possess attributes desired by this researcher, such as being an elementary teacher who does not feel prepared to teach engineering and is taking an engineering professional development course. A limitation of purposive sampling is that participants are not randomly sampled so they may not be representative of a larger group from which a researcher would want to form generalizations (Krathwohl, 2009). Even so, purposive sampling is common in educational research and is valuable when a researcher seeks participants with specific characteristics within distinct contexts.

Procedures. Participants took the Advancing STEM Instruction through Engineering Design course. The engineering course was a form of intervention to address the problem of elementary teachers' lacking content knowledge and PCK to teach engineering, which in turn accounts for low levels of confidence in teachers to teach engineering. Within the review of the literature section of Chapter 2, I made the argument that professional development that focuses on content knowledge, pedagogical skills, and teacher self-efficacy has been shown to improve teacher self-efficacy and positively influence teaching practices. Thus, I explained the goals and content within the engineering design professional development course in the following section.

Overview of the engineering design professional development. The engineering design course took place in two parts: (a) a one-week summer session, and (b) a one-day follow-up session during the school year with opportunities for individual mentoring. Prior to the summer session, the instructors met to discuss, negotiate, and 
create the course assessments and agenda. Although the course had been taught the previous year, the PMSP required the additional teaching of engineering PCK and culturally responsive pedagogy. Because Yu, Luo, Sun, and Stobel (2012) completed a study that included a K-6 teacher competency model specifically listing engineering PCK, their study was discussed for incorporation. Likewise, Gay's (2002) strategies for culturally responsive teaching were discussed for inclusion. After a couple of days of planning, a final agenda was created (see Appendix A). Within the one-week summer session, the goals for participants were to: (a) increase their pedagogical content knowledge and confidence in teaching the engineering aspects of the NGSS by

- describing how disciplinary core ideas in NGSS progress across grades K-8;

- identifying similarities and differences between science and engineering practices;

- providing an example of an engineering design process model from the Engineering is Elementary curriculum;

- discussing the positive view of making mistakes and identifying failure points that is inherent to the process of engineering design;

- giving examples to illustrate the meaning of technology and engineering;

- illustrating how science and engineering drive each other forward;

- providing examples of how to combine the three dimensions of the NGSS;

- planning an engineering lesson based on the 5E instructional model. 
(b) describe culturally responsive teaching strategies they could use when teaching engineering with a diverse group of students, and (c) communicate opportunities for good jobs that require STEM education.

In the summer course, teachers engaged in tinkering and engineering design lessons to observe good models of engineering instruction. Included was an explanation of how all lessons aligned with specific standards within NGSS. Teacher strategies were woven throughout the course; ones that teachers could use to assess student understandings, misconceptions, and learning progressions. For example, Bybee et al. (2006) 5 E Instructional Model and Keeley's (2011) formative assessment probes were presented as effective research-based strategies. These strategies are known to help support development of engineering PCK (Yu et al., 2012). The summer 2014 course represented the second time the course had been taught. As previously mentioned, new to the 2014 course was the teaching of culturally responsive teaching strategies. This addition came as a result of the Oregon Hub grant which required recipients to engage underrepresented groups of students. Also new to the 2014 course was that time was allotted on the last day for teachers to collaboratively create engineering lessons that aligned with NGSS and could be taught during the 2014 to 2015 school year.

The second part of the course involved a one-day workshop to share participant engineering instructional experiences and furnish teachers with engineering lessons that promote culturally responsive pedagogy. An agenda for the workshop (see Appendix B) was planned in January 2015 and taught in early February. A week prior to the workshop, teachers were asked to bring in engineering lessons taught thus far in the 
school year and any examples of student work. At the beginning of the workshop, teachers shared their teaching of engineering experiences with the purpose of inspiring each other to teach more engineering. Also, teachers shared student work and discussed the impact on student learning. The majority of the day teachers engaged in engineering design challenges so they could once again experience good examples of engineering instruction. For example, teachers worked through a windmill activity that combined an inquiry activity with an engineering design lesson. Afterwards, teachers collected materials to organize kits to be used in the classroom. Teachers were shown several new examples of engineering lessons and then they were offered individual mentoring to accomodate implementation of lessons. Such support would be differentiated upon the specific needs and wants of each teacher. For example, co-teaching and planning an engineering lesson would be available, if requested. Throughout the day, additional ideas and strategies to promote culturally responsive teaching were considered and demonstrated.

Importantly, the aformentioned components of the engineeering course contained the five critical features of Desimone's (2009) teacher professional development conceptual framework. The first component is content focus which is clearly taught during the summer course. The second feature is active learning, which is provided by having teachers engage in authentic tinkering and engineering challenges. The third feature is coherence which means that the course content aligns with school, district, and state goals (NGSS standards). Implementing engineering should not be in conflict with school goals. Therefore, teachers will be shown how well engineering can be integrated 
into other subjects so as not to take away time spent on school goals relating to reading and math instruction. The fourth feature often neglected in professional development courses is duration. In other words, teachers need time to make changes in instructional practice. For this reason, individual communication and offers of mentoring were used to encourage implementation of lessons. Likewise, the follow-up session was used to make teachers accountable for teaching their engineering lesson and to boost motivation. Sandholtz and Ringstaff (2013) applied Desimone's framework to their own professional development course and insisted time given to teachers to support local instructional demands was vital to making sustained changes in teacher practices. The last feature of Desimone's (2009) framework is collective participation. Participants in the course were encouraged to co-create lessons, share lessons, and especially to share their experiences in teaching engineering with one another.

Phase one. Being an explanatory sequential mixed methods study, this investigation took part in two intentionally consecutive phases (see Figure 3.1). In Phase One, teachers participated in a one-week summer workshop. Prior to the workshop, registered teachers received an email that asked them to bring a laptop, tablet, or Smartphone on the first and last days of the course. At the beginning of the first day of the summer course, I reviewed the purpose of the study and invited teachers to participate. An informed consent form was passed out in which teachers indicated they agreed or did not agree to participate (see Appendix C). The informed consent form assured that participation was voluntary and participants could withdraw at any time. If a participant changed their mind mid-way through the course, they could opt out at any 
point. Also, the informed consent form made participants aware that a subset of teachers would be chosen to take part in an interview some time during the school year. Teachers who agreed to participate in the study were given class time to complete the online survey. The survey was titled Teacher Demographic Survey (see Appendix D). Teachers were also given class time to complete a pencil and paper pre-assessment titled $E D$ Course Assessment (see Appendix E).

On the last day of the workshop, teachers were given time to complete the Teacher Self-Efficacy Survey (TSES) that consisted of a retrospective pre and post-test measuring teacher self-efficacy (see Appendix F). The TSES was a modified version of Tschannen-Moran and Hoy's (2001) instrument. The survey was developed and administered through the Qualtrics software program that is available to PSU students. The Teacher Self-efficacy Survey was used to determine if there were changes in teacher self-efficacy as a result of the course intervention. Participants were likewise given time to complete a pencil and paper post-assessment, which was the same instrument titled $E D$ Course Assessment. Pre and post ED Course Assessment results were used to measure if there were changes in teacher content and PCK to teach engineering.

Phase two. Once data from Phase One had been collected, teacher self-efficacy data was statistically analyzed. Partial results from the self-efficacy scores were used to identify a subset of participants to take part in a semi-structured interview. Interview questions (see Appendix G) served to contribute additional evidence for changes in teacher self-efficacy and identify sources of teacher self-efficacy. Interviews took approximately 30 to 45 minutes. Interviews were conducted in the winter of 2015 and 
after teachers have had experiences teaching engineering lessons with their students. Earlier in Chapter 2, when critiquing the construct self-efficacy as a theoretical framework, I mentioned the challenges of time and elusiveness of self-efficacy. Bandura (1997) stated self-efficacy is content-specific, and as such, can fluctuate while initially forming. In time, if self-efficacy strengthens, it remains more constant. Woolfolk-Hoy and Spero's (2005) research reflected this occurrence as they found preservice elementary teachers' self-efficacy decreased between the end of student teaching and the end of the first year of teaching. Clearly, time was a factor. Even Guskey (1986) stated that only after teachers saw change in student learning outcomes, did their beliefs change. Taking this information into consideration, my study offered teacher mentoring into the school year to assist teachers in implementation. Time was given for teachers to teach engineering lessons so they could experience success in applying new content and PCK (Palmer, 2011). In doing so, teachers would have a broader range of experiences from which to reflect upon and describe what aspects of their experiences influenced selfefficacy.

Phase Two also included teachers taking part in a one-day follow-up workshop in the winter of 2015. At the beginning of the workshop, teachers shared their progress and experiences in teaching engineering. Teachers wore name tags to facilitate the ability to take notes on the Observational Notes form (see Appendix H). Notes were not collected on individuals who declined participation. The form contained 'happenings' and 'what does it mean?' sections. Happenings consisted of statements/phrases, feelings and expressions, actions, and descriptions from participants randomly written during the 
workshop. The 'what does it mean?' section was written 24 hours later as time was needed to help the researcher reflect. Notes within the 'what does it mean?' section was to capture broader meanings expressed by the participants.

Towards the end of the workshop, teachers participated in the ED Course Postpost Survey (see Appendix I). This survey was administered orally and audiotaped. Only question two was analyzed as part of this study. Question two asked: "Can you share what you did (referring to the teaching of an engineering lesson)? Can you share how your students responded to the engineering lesson and describe any interesting impacts (outcomes) for students?" The question was intended to supply more evidence to explain why teacher self-efficacy changed.

Maintaining data. Data and records from both phases of the study were maintained in the researcher's home office for a minimum of three years. Data collected from the Qualtrics software (TSES and Teacher Demographic Survey), and the ED Course Assessment were shared with PMSP's research and assessment director. PMSP required this data because it is part of the STEM common measurement system and is needed to provide feedback for the STEM hub grant (Saxton et al., 2014). A separate IRB was approved to collect this data.

Instruments and measures. In Table 3.1, I review the five instruments used in this study and identify the constructs that each measure. Table 3.1 includes the number of items within each instrument and identifies the time within the engineering professional development at which each instrument is administered. Proceeding table 3.1 is a description of each instrument and rationale for their selection. 
Table 3.1

Instruments Selected and Constructs Measured

Phase One (quan)

\begin{tabular}{llcl}
\hline Instrument & Construct Measured & Items & Time Administered \\
\hline $\begin{array}{l}\text { Teacher Demographic } \\
\text { Survey }\end{array}$ & Teacher demographics & 6 & August 2014 \\
ED Course Assessment & $\begin{array}{l}\text { Teacher content and } \\
\text { Pedagogical content } \\
\text { Knowledge }\end{array}$ & 9 & $\begin{array}{l}\text { August 2014 } \\
\text { (pre and post) }\end{array}$ \\
$\begin{array}{l}\text { Teacher self-efficacy } \\
\text { TSES }\end{array}$ & 33 & $\begin{array}{l}\text { August 2014 } \\
\text { (retro pre and post) }\end{array}$ \\
$\begin{array}{l}\text { Phase Two (QUAL) } \\
\begin{array}{l}\text { ED Course Post post } \\
\text { Survey }\end{array}\end{array}$ & $\begin{array}{l}\text { Sources of self-efficacy } \\
\text { Observational notes }\end{array}$ & 1 & February 2015 \\
$\begin{array}{l}\text { Semi-structured } \\
\text { Interviews }\end{array}$ & $\begin{array}{l}\text { Teacher self-efficacy and } \\
\text { Sources of self-efficacy }\end{array}$ & 10 & February 2015 \\
\hline
\end{tabular}

Teacher demographic survey. The Teacher Demographic Survey (see Appendix D) survey consisted of six items to identify demographic information such as teacher characteristics (gender, ethnicity, current teaching grade, highest obtained educational level, and years of teaching experience) and school characteristics (Title I status). Because of the limited diversity among the participants due to a small sample size, I examined if there was any association between changes in teacher self-efficacy and teacher or school characteristics. I chose to do so to determine if teacher or school characteristics had an influence on teacher self-efficacy.

ED course assessment. The ED Course Assessment (see Appendix E) was a survey created by the three co-instructors of the Advancing STEM Instruction through 
Engineering Design course. The assessment contained nine items of open-ended questions to evaluate content and PCK of teachers within the context of engineering. Pre and post differences were measured using instructor made rubrics (see Appendix J). To review, the Portland Metro STEM Partnership (PMSP) had already established three core professional development outcomes and measures: (a) pedagogical content knowledge, (b) instructional practices, and (c) teacher self-efficacy (Saxton et al., 2014). I was asked to measure teacher content and PCK by the director of PMSP research and assessment. Evaluating the effectiveness of the professional development course and measuring PCK was a requirement under the grant money PMSP received from the state of Oregon. Another reason I included a measure for teacher content and PCK was that Palmer (2006) asserted that a teacher had to improve in these areas before being able to strengthen selfefficacy.

TSES. The TSES instrument (see Appendix F) used in my study was a modified version of Tschannen-Moran and Hoy's (2001) Teacher Sense of Self-efficacy Scale (TSES). As previously stated, the TSES was administered as a retrospective pre and post-test. Using a retrospective pretest has been found to reduce response shift bias (Drennan \& Hyde, 2008). Response shift bias refers to the tendency of students to change their perception during an educational intervention as they realize they underestimated or overestimated their prior content knowledge. Tschannen-Moran and Hoy's (2001) original instrument was designed to measure three subscales of teacher selfefficacy: (a) efficacy for instructional strategies, (b) efficacy for classroom mangement, and (c) efficacy for student engagement. It is a nine-point Likert scale instrument 
consisting of 24 items. Tschannen-Moran and Hoy (2007) found the TSES to have a reliability of .93 ; with a .87 reliability for the subscale of instructional strategies, .88 for the subscale of classroom management, and .84 for the subscale of student engagement. I selected the TSES instrument because it was adopted by the PMSP as a common tool to measure teacher self-efficacy for all professional development courses. Also, I used the TSES instrument because I contend it aligns well with Bandura's theory and has strength in reliability. Bandura (1977) viewed self-efficacy as a motivational construct. Tschannen-Moran and Hoy (2001) incorporated this key element when they defined teacher self-efficiacy as "a judgement of his or her capabilities to bring about desired outcomes of student engagement and learning, even among those students who may be difficult or unmotivated" (p. 783). I also prefer the TSES because it is worded in such a way that it focuses on current rather than past teacher performance and therefore can provide real-time data to answer my second research question. While the STEBI selfefficacy instrument continues to be used, I chose not to use it because of its reported problem in measuring the PSTE subscale of self-efficacy (Tschannen-Moran \& Hoy, 2001).

For the purposes of this and the PMSP's study, the TSES was modified in two ways. First, the context of teaching engineering was added to the questions. For example, within the subscale of efficacy for student engagement, a question is asked, “How much can you do to foster student creativity?" This question was modified to read, "How much can you do to foster student creativity in engineering?" Second, a fourth subscale was added to measure efficacy for culturally responsive teaching. An example 
of a question within this subscale was: "To what extent can you use examples that are familiar to students from diverse cultural backgrounds in engineering?" This subscale was incorporated into all PMSP courses as a way to assess the integration of culturally responsive teaching strategies. Adding a fourth subscale increased the item number from 24 to 33 .

Observational notes. Observational notes (see Appendix H) are simply field notes written randomly by the researcher during the one-day workshop. I selected this method because I feel the informal setting will allow teachers to act and express themselves in a genuine way. Maxwell (2013) pointed out that qualitative researchers "should always include whatever informal data-gathering strategies are feasible, including hanging out, casual conversations, and incidental observations" (p. 88). Notes included perceptions of participants engineering experiences, their feelings and actions, how their self-efficacy was affected, and why. I included actions taken by participants because sometimes they provide meaning not expressed in words. The notes also provided a second method for identifying evidence of sources of teacher self-efficacy.

ED course post-post survey. The ED Course post-post Survey (see Appendix I) was administered toward the end of the one day follow-up workshop conducted in February of 2015. Teachers were encouraged prior to the workshop to bring and share student work from an engineering lesson for this portion of the workshop. The survey consisted of three open-ended questions that are intended to promote teacher reflection upon their experience teaching engineering and student outcomes from the lessons. Questions were asked orally and answers were audiotaped. The purpose of this survey 
was to provide a different yet additional method for revealing evidence of sources of teacher self-efficacy. As previously mentioned, triangulating data would contribute strength to my overall results.

Interview questions. After the TSES survey had been analyzed, a subset of teachers representing the top $30 \%$ in self-efficacy gains were asked to participate in an interview. While it is true that all four subscales of the TSES instrument were measured and analyzed, it is important to note that only two of the four TSES subscales were used to ascertain the top $30 \%$ in self-efficacy gains. The two TSES subscales used were: efficacy for instructional strategies and efficacy for student engagement. The rationale for focusing on these two subscales was that they are most closely tied to content or engineering self-efficacy. The reason efficacy for culturally responsive teaching was not included was because these factors hold greater potential to be affected by school and teacher characteristcs. The reason efficacy for classroom management was not included was because this topic was not addressed or taught within the professional development class.

The purpose of the interviews was to provide supporting evidence of the TSES outcomes and to identify aspects of the professional development and any other factors that influenced teacher self-efficacy. Because the literature suggested time influences self-efficacy and development of mastery experiences (when teachers experience success in actually teaching engineering to students), I conducted interviews after teachers had a chance to teach an engineering lesson. The interview consisted of 10 open-ended questions (see Appendix G); one having to do with a teacher's motivation to participate 
in the course, three having to do with changes in self-efficacy, and six having to do with sources of self-efficacy. The questions were developed in a funnel-shaped format such that they begin asking general questions and end with asking specific questions.

It is important to note that the word confidence was used to represent self-efficacy in the interview questions. The reason for using confidence was because it is a more commonly understood word and many teachers do not understand the meaning of selfefficacy (Palmer, 2011). While Bandura would argue that confidence and self-efficacy are not identical in meaning, Palmer (2011) set a precedence in his own research by using the word confidence when conducting interviews.

Role of the researcher. I acknowledge that I hold specific bias in favor of teaching engineering at the elementary level. Having taught science in the classroom for 20 years, I have numerous experiences teaching engineering lessons. Over the years, I have been amazed at the power of engineering design challenges to engage and motivate students. For example, most middle school teachers would agree it is difficult to hold student attention the last two weeks of school as students look forward to summer break. Several years in a row, I purposely allocated this time to an engineering activity in which students designed a rollercoaster that adhered to specific criteria. While working on this project, my students wanted to come in to my classroom before school, during lunch, and after school to work on their coasters. I witnessed students consumed in flow experience. Csikszentmihalyi (1988) described flow experience as when an individual experiences a strong feeling of enjoyment accomplishing an activity and become so immersed in their work that they are oblivious to what is going on outside of the activity itself. Because of 
my personal experiences in teaching engineering, I have been become a tremendous advocate of teaching more engineering in the classroom. In addition, I believe engineering promotes creativity, problem-solving, negotiation, and other $21^{\text {st }}$ century skills. These skills will benefit students and society no matter what career a student decides to follow.

Another personal experience influencing my view of engineering professional development is that I took an internship position with the Director of Assessment at the Portland Metro STEM Partnership. My situation allowed me to observe and participate in several days of the Advancing STEM through Engineering Design course held during the 2013 through 2014 school year. I witnessed elementary teachers enthusiastically jumping into engineering activities. During such occasions, I formed the opinion that it might be easier to incentivize teachers to teach engineering than science because engineering is so open-ended. With science practices, inquiry is designed to guide one to an already scientifically agreed upon answer. In contrast, engineering practices are more open-ended and allow for multiple correct solutions. In other words, an engineering solution has no one right answer. I argue that inherent element of engineering practices will appear less intimidating to elementary teachers and once teachers recognize that fact, they will feel more comfortable and confident teaching engineering.

Because of my position of bias toward the teaching of engineering, I had to consider ways to overcome this bias. In reflection, I recognized that my experiences in teaching engineering were within being a middle school teacher. As such, my main role was to teach science. Elementary teachers, on the other hand, have the responsibility to 
teach multiple subjects. Juggling these subjects and growing professionally in each of these subjects is a challenging endeavor. Therefore, I strove to actively listen to the participants in my study and be empathetic toward their views.

Furthermore, I acknowledge my dual role in this study because I represented both the researcher and an instructor/mentor within the engineering professional development course. As such, I needed to be aware of the effect of reciprocity on the results of my study. After all, I have embraced Bandura's (1986) notion of reciprocal determinism as the theoretical framework grounding this study. To review, Bandura (1986) stated that people function as a result of three interacting factors: (a) environmental, (b) behavior, and (c) cognitive and other factors, including self-efficacy beliefs. I planned to act as a mentor for participants and through my assistance teachers may feel obligated towards me. Did participants feel obligated to tell me what they think I want to hear? Such a response could affect the trustworthiness of my data.

Harrison, MacGibbon, and Morton (2001) explored the challenges of reciprocity within qualitative research. These researchers insisted that examining reciprocity meant addressing issues of power between the researcher and research participants. Therefore, I was cautious to how participants perceived and responded to my actions. I tried to circumvent untrustworthy responses by continually impressing upon participants the importance of my study to gather and reflect genuine influences on teacher self-efficacy. While the issue of reciprocity can be problematic, there are benefits to be mentioned. Reciprocity has the potential to influence teachers to the extent that they ask for help and 
are encouraged to take risks. Like engineering, there are trade-offs, and I think in this case the benefits outweigh the disadvantages.

Data collection and analysis. One benefit of employing the pragmatic paradigm is that a researcher can combine both quantitative and qualitative methods (Creswell \& Plano-Clark, 2011; Morgan, 2007). This also means a researcher can apply different types of data analysis (Creswell, 2009). The most important consideration is whether or not data analysis sufficiently answers each of the research questions. Thus, I review the three research questions for this study, the instruments used to answer them, and describe the specific data analysis applied to each (see Figure 3.2). Research question one uses the ED Course Assessment instrument to provide pre and post information related to teacher engineering content and PCK. The pre and post assessments were quantitatively scored using an instructor made rubric. Total mean scores and standard deviations were calculated for the pre and post assessments. This data was statistically analyzed using a paired-sample $t$-test. According to Field (2013), a paired-sample $t$-test is a "test using the $t$-statistic that establishes whether two means collected from the same sample differ significantly" (p. 880). In other words, I calculated the mean score for the pre content and PCK assessment and compared it with the mean score from the same sample of participants for the post content and PCK assessment.

Research question two involved using the TSES and Teacher Demographic Survey instruments to gather pre, retro pre and post self-efficacy data. Total means scores and standard deviations were calculated for the retro pre and post surveys. A 
Research Question

Instrument

Data Analysis

1. How did the
professional
development program
affect elementary
teachers' content and
pedagogical content
knowledge to teach
engineering?

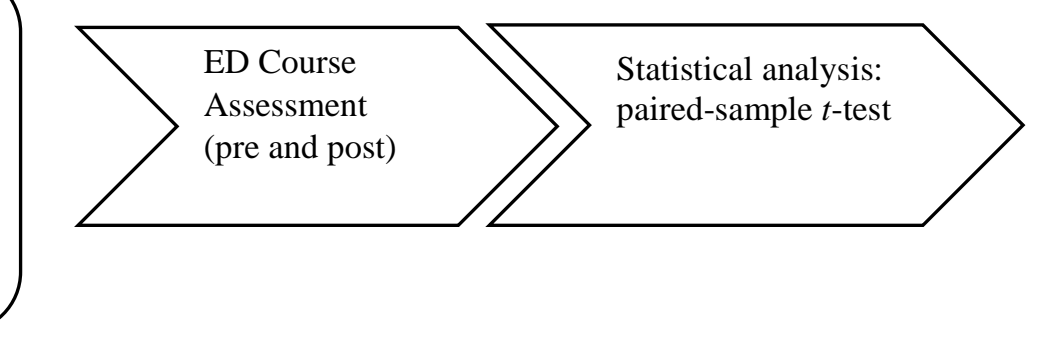

\section{How did the professional \\ development program affect elementary teachers' perceptions of self-efficacy to teach engineering?}

\section{After the engineering} professional development program, what aspects of the program or other factors did elementary teachers' identify as influencing their selfefficacy to teach engineering? 
teacher self-efficacy and teacher or school characteristics. I chose to do so to determine if teacher or school characteristics had an influence on teacher self-efficacy. Only interview question items two and three are planned for Phase Two to corroborate quantitative self-efficacy results. Interviews were audio-taped and transcibed. In-vivo coding, which means using exact words used by participants, was used to express language that supported changes in teacher self-efficacy (Creswell, 2013).

Research question three was more complicated because it relied on three qualitative instruments: (a) teacher interviews, (b) ED Course post-post Survey, and (c) observational notes. The purpose of all three of these instruments was to identify sources of teacher self-efficacy. The ED Course post-post Survey included one question, item two, having to do with sources of teacher self-efficacy (see Appendix I). Responses to this item, observational notes, and answers to interview questions (items one, and four through ten) were analyzed using thematic networks. Thematic networks have a twofold purpose: (a) to understand themes of an issue at different levels, and (b) to organize and visually display themes while showing interconnections between them (Attride-Stirling, 2001). Attride-Stirling (2001) stated there are six steps involved in implementing the thematic network analysis (see Figure 3.3). First, I devised a coding framework based upon theoretical interests (such as Bandura's four sources of self-efficacy) and recurring issues within the text. The coding framework was then used to dissect the text into pieces (such as passages, quotation, and single words). Second, I identified and refined themes across the data sources. The number of times a theme came up was recorded. Third, I organized and displayed themes into thematic networks (see Figure 3.4). According to 


\begin{tabular}{|c|c|}
\hline Step 1 & $\begin{array}{l}\text { Devise coding framework and use to dissect text } \\
\text { - Framework based on theory and recurring issues } \\
\text { - Dissect into passages, quotations, single words }\end{array}$ \\
\hline Step 2 & $\begin{array}{l}\text { Identify and refine themes } \\
\text { - Across all data sources } \\
\text { - Record of number of times theme comes up }\end{array}$ \\
\hline Step 3 & $\begin{array}{l}\text { Organize and display themes into thematic networks } \\
-\quad \text { Basic } \\
-\quad \text { Organizing } \\
\text { Global }\end{array}$ \\
\hline Step 4 & $\begin{array}{l}\text { Describe and explore the networks } \\
\text { - Relate back to original text } \\
\text { - Explore through thematic networks }\end{array}$ \\
\hline Step 5 & $\begin{array}{l}\text { Summarize the network } \\
\text { - Main themes } \\
\text { - Main patterns }\end{array}$ \\
\hline Step 6 & $\begin{array}{l}\text { Interpret patterns } \\
\text { - Return to theory } \\
\text { - Return to research question }\end{array}$ \\
\hline
\end{tabular}

Figure 3.3 Steps involved in the thematic network analysis (Attride-Stirling, 2001)

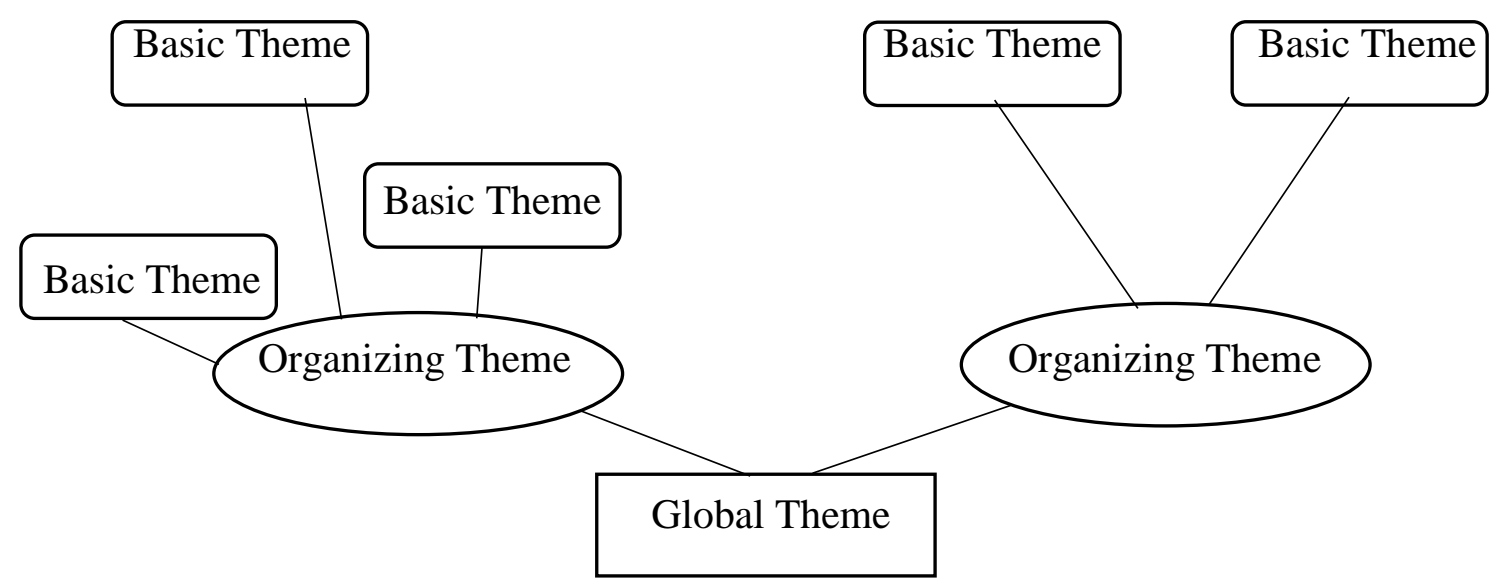

Figure 3.4 Example of a thematic network structure 
Attride-Stirling (2001), a thematic network "is developed from starting from the basic themes and working inwards toward a global theme" (p. 389). Fourth, I described and explored the networks. At this point, I went back to the original text and explored themes through the established networks. Fifth, I summarized the network by explaining main themes and patterns. Finally, for the sixth step, I interpreted the patterns. In doing so, I returned to the theoretical interests, purpose of my study, and research question to interpret results.

According to Creswell and Miller (2000), qualitative studies often use one or more strategies to ensure validity, such as triangulation, thick description, member checking, peer reviews, and external audits. These respected researchers defined validity as "how accurately the account represents participants' realities of the social phenomena and is credible to them" (Creswell \& Miller, 2000, p. 124). To answer research question three, I employed triangulation and member checking to foster validity. Implementing data triangulation means I put forward accuracy across two or more sources of data (Krathwohl, 2009). Accuracy can also be assessed through member checking. Member checking involved having my participants read the interview transcripts to make certain it accurately reflected their perceptions and experiences. Lincoln and Guba (1985) claimed member checking was the most important technique to establish credibility in a qualitative study.

\section{Summary}

In Chapter 3, I outlined the type of research methods to be used in my study. I selected an explanatory sequential mixed methods approach for my study because it 
aligned well with the chronological aspect of how teacher self-efficacy changes. The qualitative phase of this approach was particularly significant because it provided a deeper exploration of the influences responsible for forming and changing teacher selfefficacy.

I presented an overview of the engineering professional development course from which participants were purposively sampled. The engineering professional development was shown to follow Desimone's (2009) teacher professional development conceptual framework. I identified and detailed data collection instruments to be used in each of the two phases of my study. Phase One collected quantitative data to determine changes in teacher content, PCK, and self-efficacy toward engineering. In Phase Two, participants who demonstrate significantly positive changes in self-efficacy were interviewed to corroborate Phase One results and identify what aspects of their professional development experience influenced their self-efficacy. Additional evidence of sources of self-efficacy was gathered through a post-post survey and observational notes. Triagulation was applied to provide rich qualitative data.

I concluded Chapter 3 by communicating my dual role as both researcher and coinstructor of the engineering professional development course. I explained my bias and protocols put in place to reduce bias. Last, I sketched out the steps to analyze both quantitative and qualitative data collected within my study. Because validity can be problematic within qualitative research, I intentionally applied data triangulation and member checking to strengthen validity. The data analysis conducted for both phases of my study provided answers to my three research questions. 


\section{Chapter 4: Results/Analysis}

The purpose of this study was to investigate the effects of engineering professional development on elementary teacher's self-efficacy, content, and pedagogical content knowledge to teach engineering. Another goal of this study was to identify teachers' perceptions of what components or other factors surrounding the professional development intervention influenced their self-efficacy. In particular, if a teacher's selfefficacy was positively influenced, what were the sources of self-efficacy involved within their process of change? These ambitions were guided by the following three research questions:

1. How did the professional development program affect elementary teachers' content and pedagogical content knowledge to teach engineering?

2. How did the professional development program affect elementary teachers' perceptions of self-efficacy to teach engineering?

3. After the engineering professional development program, what aspects of the program or other factors did elementary teachers' identify as influencing their self-efficacy to teach engineering?

The ultimate aim of this study was to identify engineering professional development components that help improve elementary teacher's self-efficacy, content and pedagogical content knowledge to teach engineering. According to Desimone's (2009) conceptual framework guiding this study, effective engineering professional development focused on improving content and pedagogical skills can lead to changes in teacher practices such that teachers spend more time teaching engineering.

In Chapter 3, I provided an overview of the engineering professional development intervention and a description of the participants within this study. I explained methods chosen to answer my research questions, the rationale for their selection and protocols 
applied. Data collection instruments and data analysis procedures were made clear which also included justifications for use. In Chapter 4, I re-introduce the participants. I present and analyze data collected from various measures and then interpret the data to convey specific findings associated with the purpose of my study and research questions. Considering that my study was conducted in two phases, I organize and interpret my results chronologically through each of these phases. Last, I explain limitations of my study and overall analysis of data.

\section{Analysis of Data}

Participants. Ten elementary teachers participated in the engineering professional development course and gave consent to partake in this study. At the beginning of the first day of professional development, the Teacher Demographic Survey was administered. The intention of the survey was to collect teacher and school characteristics of the participants to consider possible correlations between characteristics and self-efficacy results. In Table 4.1, I summarized the survey data. As noted in Table 4.1, eight in ten of the participants were female and two in ten were male. Seven in ten of the participants identified them self as White, two in ten as Asian, and one in ten as Hispanic. Six in ten of the participants were currently employed in a Title I school while four in ten worked in a non-Title I school. In terms of current teaching contexts, six in ten of the participants taught in grades four through six and four in ten taught in grades $\mathrm{K}$ through three. It is interesting to note that nine in ten of the participants held a Master's degree and all participants were experienced teachers having more than six years of teaching in the classroom. 
Phase one. Employing Morgan's (2013) sequential contributions design, quant $\rightarrow$ QUAL, I collected quantitative data during phase one of my study. The objective of

Table 4.1

Teacher and School Characteristics of Participants

\begin{tabular}{ll}
\hline Characteristic & Number of Teachers $(N=10)$ \\
\hline Gender & Male $=(n=2)$ \\
Female $=(n=8)$ & \\
Ethnicity & White $=(n=7)$ \\
& Hispanic $=(n=1)$ \\
Asian $=(n=2)$ & \\
School Status & Title $1=(n=4)$ \\
& Not Title $1=(n=6)$ \\
Grade Taught & K - 3 $=(n=4)$ \\
& $4-6=(n=6)$ \\
Years Taught & $1-5$ years $=(n=0)$ \\
& $6-10$ years $=(n=4)$ \\
& $11-15$ years $=(n=3)$ \\
& $16-20$ years $=(n=2)$ \\
& $21+$ years $=(n=1)$ \\
Highest Degree Earned & BA or BS $=(n=1)$ \\
& MA or MS $=(n=9)$
\end{tabular}

phase one was to measure teacher self-efficacy, content and pedagogical content knowledge before and after participation in a one week engineering professional development course. Two instruments were administered: the ED Course Assessment, which measured teacher content and pedagogical content knowledge; and the TSES, which measured teacher self-efficacy. Both instruments were written specific to the context of understanding and the teaching of engineering. In the following sections, I 
communicate and interpret the results from these instruments through the construct they measure.

Teacher content and pedagogical content knowledge. Teachers' content knowledge increased significantly on the post test as a result of their participation in the one-week engineering professional development. Pretest and post test content knowledge scores were scaled variables with a score of 100 being the highest possible value. Scores were analyzed in SPSS to obtain grand means and standard deviations (see Table 4.2). When comparing pretest scores $(\mathrm{M}=0.53, \mathrm{SD}=0.15)$ to post-test scores $(\mathrm{M}=0.77, \mathrm{SD}$ $=0.17$, the mean change in content knowledge scores after the engineering professional development was $0.23(\mathrm{SD}=0.09)$. In other words, teachers' scores increased an average of 23 percentage points. Next, because two means from the same population were compared, a paired-sample $t$-test was performed (Field, 2014). Table 4.2 shows the results of the $t$-test in the fifth column, the degrees of freedom in the sixth column, and the corresponding $\mathrm{p}$-value in the seventh column $\left(t_{(9)}=8.07, \mathrm{p}<0.001\right)$. The $t$-test uses 0.05 (alpha level) as the conventionally accepted threshold in the social sciences. According to Field (2014), the critical threshold for a degree of freedom equal to nine is 2.26. Because the $t$-value is equal to 8.07 and greater than the critical threshold, the increases in content knowledge scores following engineering professional development were statistically significant. Further evidence is in the fact that the p-value is less than 0.001 which is less than the alpha level of 0.05 .

Likewise, teachers' pedagogical content knowledge had statistically significant increases as a result of their participation in the one-week engineering professional 
development. Pretest and post-test pedagogical content knowledge scores were also scaled variables with a score of 100 being the highest possible value. In Table 4.2, I reported the grand mean and standard deviation results. When comparing pretest scores

Table 4.2

Changes in Pre-post Measured Constructs after Engineering Professional Development

\begin{tabular}{lllllll}
\hline $\begin{array}{l}\text { Measured } \\
\text { construct }\end{array}$ & $\begin{array}{l}\text { Post-mean } \\
\text { (SD) }\end{array}$ & $\begin{array}{l}\text { Pre-mean } \\
(\mathrm{SD})\end{array}$ & $\begin{array}{l}\text { Mean diff } \\
(\mathrm{SD})\end{array}$ & $\mathrm{t}$ & df & $\begin{array}{l}\text { Sig. } \\
\text { (2-tailed) }\end{array}$ \\
\hline $\begin{array}{l}\text { Content } \\
\text { Knowledge }\end{array}$ & $0.77(0.17)$ & $0.53(0.15)$ & $0.23(0.09)$ & 8.07 & 9 & $<0.001$ \\
$\begin{array}{l}\text { Pedagogical } \\
\text { Content Know. }\end{array}$ & $0.78(0.09)$ & $0.61(0.11)$ & $0.17(0.08)$ & 7.12 & 9 & $<0.001$ \\
$\begin{array}{l}\text { Teacher Self- } \\
\text { Efficacy (TSES) }\end{array}$ & $7.74(0.89)$ & $6.38(0.81)$ & $1.36(0.77)$ & 5.61 & 9 & $<0.001$ \\
$\begin{array}{l}\text { TSES } \\
\text { Subscale A }\end{array}$ & $7.96(0.87)$ & $6.16(1.06)$ & $1.8(1.15)$ & 4.95 & 9 & 0.001 \\
$\begin{array}{l}\text { TSES } \\
\text { Subscale B }\end{array}$ & $7.79(0.86)$ & $5.95(0.91)$ & $1.84(0.89)$ & 6.54 & 9 & $<0.001$ \\
$\begin{array}{l}\text { TSES } \\
\text { Subscale C }\end{array}$ & $7.89(0.64)$ & $7.38(0.64)$ & $0.51(0.78)$ & 2.08 & 9 & 0.068 \\
$\begin{array}{l}\text { TSES } \\
\text { Subscale D }\end{array}$ & $7.33(1.58)$ & $6.02(1.34)$ & $1.31(0.74)$ & 5.61 & 9 & $<0.001$ \\
\hline
\end{tabular}

$(\mathrm{M}=0.61, \mathrm{SD}=0.11)$ to post-test scores $(\mathrm{M}=0.78, \mathrm{SD}=0.09)$, the mean change in pedagogical content knowledge scores after the engineering professional development was $0.17(\mathrm{SD}=0.08)$. That is, teachers' scores increased an average of 17 percentage points. In addition, table 4.2 shows in columns five through seven the results of the 
paired sample $t$-test, degrees of freedom, and p-value $\left(t_{(9)}=7.12, \mathrm{p}<0.001\right)$. Because the p-value is less than 0.001 , this indicates a statistically significant increase in teachers' pedagogical content knowledge as a result of the engineering professional development.

In sum, the positive changes in teacher content and pedagogical content knowledge after the engineering professional development addressed research question one. As a result of participating in the one-week engineering professional development class, elementary teachers' showed a statistically significant increase in their engineering content and pedagogical content knowledge. Because the overall purpose of the course and this study was to improve self-efficacy to teach engineering, these results align with Palmer's (2006) assertion that teacher self-efficacy would improve if content and pedagogical content knowledge were strengthened first. Now, I turn to the self-efficacy scores.

Teacher self-efficacy. In Chapter 3, I articulated the presence of four subscales within the TSES instrument. For purposes of clarity, I outline these subscales and identify them with a corresponding letter. Subscale A represents efficacy for student engagement, subscale B represents efficacy for instructional strategies, subscale C represents efficacy for classroom management, and subscale D represents efficacy for culturally responsive teaching strategies. Table 4.3 lists the four subscales and communicates the questions within the TSES instrument aligning with these components. When all four subscales of the TSES were analyzed, it was revealed that teachers' selfefficacy to teach engineering was significantly enhanced after the one-week engineering professional development experience. Because the TSES instrument used a nine-point 
Likert scale, data from the pretest and post-tests were labeled as ordinal values. Data from this instrument was analyzed in SPSS to obtain grand means and standard deviations and these results are shown in Table 4.2. Post-test scores $(\mathrm{M}=7.74, \mathrm{SD}=$ $0.89)$ were substantially higher than pretest scores $(\mathrm{M}=6.38, \mathrm{SD}=0.81)$. The mean

Table 4.3

Four Subscales of TSES and Alignment with Questions

Subscale A: Self-efficacy for Student Engagement

Q1: How much can you do to get through to the most challenging students in engineering design?

Q2: How much can you do to help your students think critically about engineering design?

Q4: How much can you do to motivate students who show low interest in engineering design school work?

Q6: How much can you do to get students to believe they can do well in engineering design school work?

Q9: How much can you do to help your students' value learning in engineering design?

Q12: How much can you do to foster student creativity in engineering design?

Q14: How much can you do to improve the understanding of a student who is under-preforming in engineering design?

Q22: How much can you assist families in helping their children do well in engineering design school work?

\section{Subscale B: Self-efficacy for Instructional Strategies}

Q7: How well can you respond to difficult questions from your students in engineering design?

Q10: How much can you gauge student comprehension of what you have taught in engineering design?

Q11: To what extent can you craft good questions for your students in engineering design?

Q17: How much can you do to adjust your lessons to the proper level for individual students in engineering design?

Q18: How much can you use a variety of assessment strategies in engineering design?

Q20: To what extent can you provide an alternative explanation or example when students are confused in engineering design?

Q23: How well can you implement alternative strategies in your classroom during engineering design lessons?

Q24: How well can you provide appropriate challenges for very capable students in engineering design?

\section{Subscale C: Self-efficacy for Classroom Management}

Q3: How much can you do to control disruptive behavior in the classroom, in general?

Q5: To what extent can you make your expectations clear about student behavior, in general?

Q8: How well can you establish routines to keep activities running smoothly, in general?

Q13: How much can you do to get children to follow classroom rules, in general?

Q15: How much can you do to calm a student who is disruptive, in general?

Q16: How well can you establish a classroom management system with each group of students, in general?

Q19: How well can you refocus students who are off-task to preserve the goals of your lesson, in general? 
Q21: How well can you respond to defiant students, in general?

\section{Subscale D: Self-efficacy for Culturally Responsive Strategies}

Q25: How well can you develop a community of learners when your class consists of students from diverse backgrounds when teaching engineering design?

Q26: How well can you use your students' cultural background to help make learning meaningful in engineering design?

Q27: To what extent can you revise materials to include a better representation of cultural groups in engineering design?

Q28: How well can you critically examine the curriculum to determine whether it reinforces negative cultural stereotypes in engineering design?

Q29: To what extent can you use examples that are familiar to students from diverse cultural backgrounds in engineering design?

Q30: How well can you explain new concepts using examples that are taken from your students' everyday lives in engineering design?

Q31: To what extent can you use the interests of your students to make learning meaningful for them in engineering design?

Q32: To what extent can you identify how ways your students' communicate at home may differ from your classroom/school communication norms in engineering design?

Q33: How well can you implement strategies to minimize the effects of the mismatch between your students' home culture and your classroom/school culture in engineering design?

difference was found to be $1.36(\mathrm{SD}=0.77)$. In short, teachers on average increased their self-efficacy by over one point on a scale of one to nine. These gains are statistically significant as shown by results in columns five through seven in Table $4.2\left(t_{(9)}=5.61, \mathrm{p}<\right.$ $0.001)$.

Furthermore, TSES results were disaggregated into the four subscales for data analysis. Outcomes are displayed in Table 4.2. Subscale A, efficacy for student engagement, mean scores increased $1.8(\mathrm{SD}=1.15)$ as post-test mean scores $(\mathrm{M}=7.96$, $\mathrm{SD}=0.87)$ rose when compared to pretest mean scores $(\mathrm{M}=6.16, \mathrm{SD}=1.06)$. Teacher self-efficacy for student engagement to teach engineering was significantly elevated as a result of the engineering professional development as indicated by the p-value being equal to 0.001. Similarly, efficacy for instructional strategies (subscale B) showed positively significant gains with a p-value less than 0.001 . When comparing pretest 
scores $(M=5.95, S D=0.91)$ to post-test scores $(M=7.79, S D=0.86)$, the mean change in subscale B scores was $1.84(\mathrm{SD}=0.89)$. Out of the four subscales, teacher selfefficacy for instructional strategies improved the most as a consequence of participation in the one-week engineering professional development.

While self-efficacy for classroom management (subscale C) changes in mean scores improved $(\mathrm{M}=0.51, \mathrm{SD}=0.78)$, the positive gains were not statistically significant as data analysis revealed the p-value to be equal to 0.068 . Post-test subscale $\mathrm{C}$ mean scores $(\mathrm{M}=7.89, \mathrm{SD}=0.64)$ rose slightly when compared to pretest mean scores $(\mathrm{M}=7.38, \mathrm{SD}=0.64)$. The fact that increases in self-efficacy for classroom management were not statistically significant was not a surprise because classroom management strategies were not a focus of the engineering professional development. Even so, TSES subscale data analysis finished on a high note as efficacy for culturally responsive teaching strategies mean scores demonstrated a significant growth with a pvalue less than 0.001 . When comparing pretest scores $(\mathrm{M}=6.02, \mathrm{SD}=1.34)$ to posttest scores $(\mathrm{M}=7.33, \mathrm{SD}=1.58)$, the mean change in subscale $\mathrm{D}$ scores was $1.31(\mathrm{SD}=$ 0.74). In other words, teachers on average increased their self-efficacy for culturally responsive teaching strategies by over one point on a scale of one to nine.

My conclusion, then, was that the one-week engineering professional development course significantly strengthened elementary teachers' self-efficacy to teach engineering. As such, these results address research question two of my study.

Correlational analysis of TSES. Previously written in Chapter 3 was the intention within this study to determine if there was an association between teacher and school 
characteristics and changes in teacher self-efficacy. The purpose of this analysis was to discount these characteristics as factors significantly impacting changes in teacher selfefficacy. Therefore, a linear multiple regression would be run in SPSS to model an association between two variables by fitting a linear equation to the data (Field, 2013). Unfortunately, due to the small sample size, this step was not possible. Instead, I describe the data results between variables by examining descriptive statistics (see Table 4.4). Descriptive statistics showed the breakdown of mean scores and standard deviations organized by various school and teacher characteristics.

Table 4.4

Descriptive Statistics of Changes in Self-efficacy Sorted by Teacher and School Characteristics

\begin{tabular}{ccc} 
Characteristic $\quad$ Mean Change in Self-efficacy & Standard Deviation \\
\hline Gender: Male $(\mathrm{n}=2)$ & 1.28 & 0.04 \\
Female $(\mathrm{n}=8)$ & 1.95 & 1.07 \\
Race: White $(\mathrm{n}=7)$ & 1.96 & 1.15 \\
Hispanic $(\mathrm{n}=1)$ & 1.25 & --- \\
Asian $(\mathrm{n}=2)$ & 1.63 & 0.53 \\
& & 0.31 \\
Years teaching: 6 to $10(\mathrm{n}=4)$ & 1.55 & 0.29 \\
11 to $15(\mathrm{n}=3)$ & 1.42 & 0.53 \\
16 to $20(\mathrm{n}=2)$ & 1.63 & --- \\
$21+(\mathrm{n}=1)$ & 4.5 & -- \\
& & 1.02 \\
Highest educational & 1.25 & 0.33 \\
level: BA/BS $(\mathrm{n}=1)$ & 1.88 & 1.28 \\
MA/MS $(\mathrm{n}=9)$ & 1.61 & \\
School status: Title I $(\mathrm{n}=4)$ & 1.96 & \\
Not Title I $(\mathrm{n}=6)$ & &
\end{tabular}


For example, the mean change in TSES scores was 1.28 for males and 1.95 for females. Some in both genders have scores that fall above as well as below their respective mean changes (the spread). The estimate of average spread is called the variance and the square root of the variance is called the standard variation. The standard variation was 0.04 for males and 1.07 for females. Because the standard deviation for males is a smaller number, this means there was a tighter distribution of change in TSES scores for males than for females. Considering these numbers, it appears that females had a slightly larger shift in self-efficacy than males.

When examining the remaining teacher and school characteristics, the descriptive statistics reveal that White participants had a slighter higher change in self-efficacy when compared to non-Whites. The teacher with the most years of teaching experience $(21+)$ had higher gains in self-efficacy compared to teachers with less than 20 years of teaching. Teachers earning a higher level of education improved self-efficacy slightly more. Last, teachers employed in a non-Title I school had a bit more of a change in self-efficacy compared to teachers working in a Title I school.

Phase two. Executing Morgan's (2013) sequential contributions design, quant $\rightarrow$ QUAL, I collected qualitative data during phase two of my study. An ED Course postpost Survey and Observational notes collected qualitative data during the one-day followup workshop in February 2015. Subsequently, I conducted interviews with a subset of three participants to collect the remaining qualitative data. It is meaningful to note that TSES results obtained in phase one were used to identify the subset of teachers to be interviewed in phase two of this study. The purpose of phase two was twofold: (a) to 
corroborate changes in self-efficacy, and (b) to explore sources of self-efficacy that were at play in bolstering self-efficacy to teach engineering. In the next sections, I communicate and explain the qualitative results associated with self-efficacy. Next, I convey and interpret sources of self-efficacy by the themes that were identified when qualitative data was examined through thematic network analysis. Last, I relate my results back to my research questions and purpose of the study.

Teacher self-efficacy. TSES data was examined to pinpoint the teachers producing the top $30 \%$ of gains in self-efficacy as a consequence of participating in the one-week engineering professional development. Because there was a total of ten participants, three teachers would qualify for interviews. Selection of these teachers was based upon having the highest mean changes in two of the four subscales of self-efficacy; efficacy for student engagement and efficacy for instructional strategies. These two subscales were selected because they are more content-specific than the other subscales. Individual mean changes in self-efficacy subscales A and B are shown in Table 4.5 and indicate that participants 2, 9, and 10 to have acquired the greatest gains in self-efficacy. For purposes of clarity, the following pseudonyms were assigned to the three participants: (a) Pamela - participant two, (b) Maria - participant nine, and (c) Rita participant 10. After the interviews were conducted, questions two and three of the Interview Questions (see Appendix G) were transcribed. Next, in-vivo coding was performed to extract exact language from the participants validating shifts in self-efficacy (Creswell, 2013). Comments from the three interviewed participants expressed weak 
self-efficacy before the engineering professional development and significant strengthening in self-efficacy after the professional development. Interviews

Table 4.5

Mean Changes in Self-efficacy for Instructional Strategies and Student Engagement Participant Pre Mean Post Mean Mean Difference Subscales A \& B Subscales A \& B Subscales A \& B

\begin{tabular}{llll}
\hline P1 & 5.13 & 6.38 & 1.25 \\
P2 & 4.38 & 8.88 & 4.5 \\
P3 & 7 & 8.75 & 1.75 \\
P4 & 6.06 & 7.5 & 1.44 \\
P5 & 5.31 & 6.75 & 1.44 \\
P6 & 6.5 & 7.75 & 1.25 \\
P7 & 7.13 & 8.44 & 1.31 \\
P8 & 7.19 & 8.44 & 1.25 \\
P9 & 5.63 & 7.63 & 2.0 \\
P10 & 6.25 & 8.25 & 2.0 \\
\hline
\end{tabular}

corroborated shifts in self-efficacy, but it is important to note all three teachers indicated they felt low on the scale prior to the intervention. The questions asked and the corresponding responses are reported in Table 4.6. For example, Pamela felt so confident after the engineering professional development the teacher expressed the desire to teach a similar workshop for fellow staff members. These remarks are cogent because they corroborate positive shifts in teacher self-efficacy as a result of the engineering professional development.

Sources of teacher self-efficacy. The reason for examining data through AttrideStirling's (2009) thematic network was to identify sources of self-efficacy perceived by 
participants as having positively influenced their self-efficacy to teach engineering.

Thematic network analysis examines themes across various data sets and classifies

themes into three levels: (a) basic, (b) organizing, and (c) global. Data from

Observational Notes, the ED Course post-post Survey, and Interview Questions were analyzed to identify themes and expose how themes are connected in a network. To

recap, Attride-Stirling (2009) explained that "a thematic network is developed starting

Table 4.6

Interview Responses to Questions 2 and 3

Question

Responses by Participants

2. How would you describe your confidence to teach engineering before the engineering PD?
Pamela: "So I feel like I could do engineering, I could teach it, but my confidence was just with those few lessons."

Maria: "Engineering? Probably low. Because I didn't really know exactly what that was."

Rita: "It's pretty low. Engineering is not my forte. It's newer. So I think the learning curve is pretty steep for me."

\begin{tabular}{|c|c|}
\hline Question & Responses by Participants \\
\hline \multirow[t]{3}{*}{$\begin{array}{l}\text { 3. How did the engineering PD } \\
\text { course affect your confidence } \\
\text { to teach engineering? }\end{array}$} & $\begin{array}{l}\text { Pamela: "After the class I feel like I could do...I } \\
\text { shouldn't even say this because then you'll } \\
\text { get me to do it...but I could do a class } \\
\text { teaching the staff. I just feel that confident." }\end{array}$ \\
\hline & $\begin{array}{l}\text { Maria: “A lot I would say. I didn't really do any } \\
\text { engineering before. I mean, I guess I did, } \\
\text { but I didn't know that's what it was." }\end{array}$ \\
\hline & $\begin{array}{l}\text { Rita: "Oh, definitely. Because you know how it } \\
\text { is like you build on whatever experiences } \\
\text { you have? So then, if you're, I'm going to } \\
\text { call it the base, the class, that is like my } \\
\text { foundation." }\end{array}$ \\
\hline
\end{tabular}


from the Basic themes and working inwards toward a Global theme" (p. 389). Basic themes are concepts characterized directly from the data. After establishing basic themes, I further grouped them according to the overarching main ideas they were expressing. These broader ideas are called organizing themes. Next, organizing themes were put together to present a concluding claim regarding a specific situation. Conclusive positions are known as global themes. Figure 4.1 displays the final thematic network, labeling global themes within rectangles, organizing themes within ovals, and basic themes extending from the ovals. Thematic network analysis identified the existence of two global themes: perceived sources of self-efficacy resulting from effective professional development and sources novel to engineering professional development. With regards to sources of self-efficacy resulting from effective professional development, it is noteworthy that participants expressed sources consistent with the four established by Bandura. In the following sections, I describe these four sources of self-efficacy as organizing themes and communicate evidence supporting these themes. Next, I report organizing themes revealed to be sources of self-efficacy unique to engineering professional development and provide evidence affirming their presence. All themes related to sources of self-efficacy from effective professional development and those unique to engineering professional development were explored to address research question three of this study.

Verbal persuasion as a source of self-efficacy fundamental to professional development. The organizing theme of verbal persuasion was expressed as a source of 
teacher self-efficacy resulting from effective professional development. Bandura (1997) characterized verbal persuasion as verbal feedback from other adults supporting the

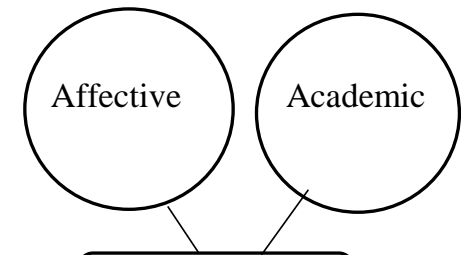

Student successes

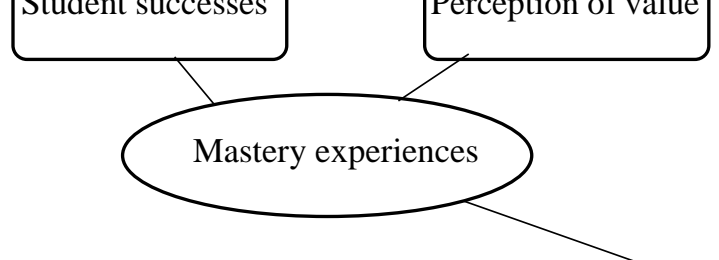

Sources of self-efficacy within professional development

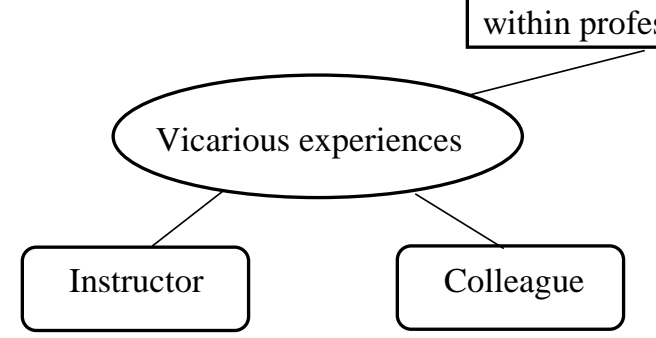

Sources of self-efficacy within engineering professional development

Less structure

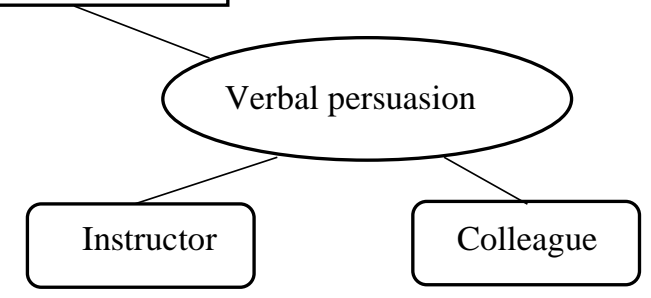

Emotional arousal
Feelings of familiarity
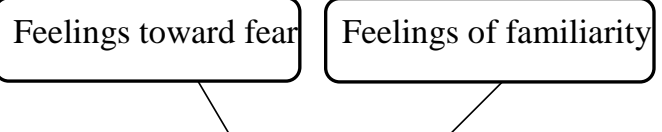

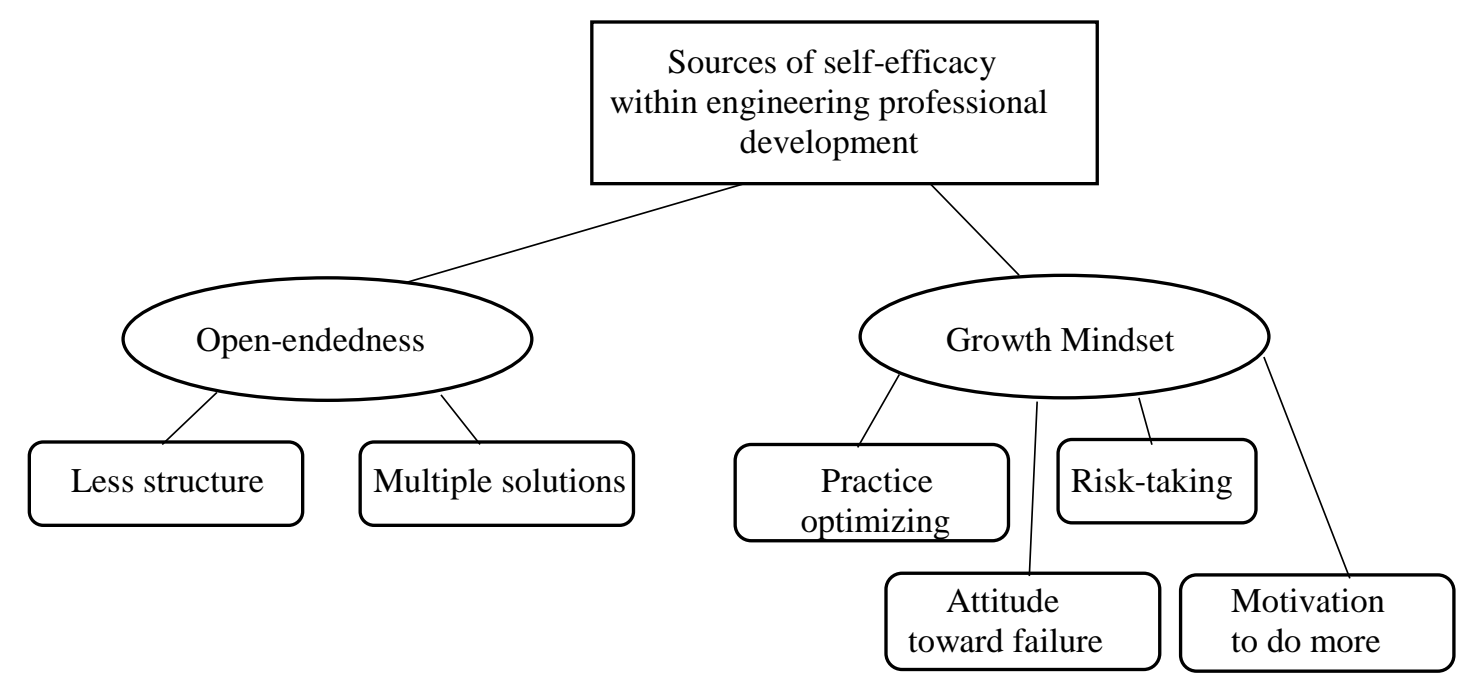

Figure 4.1 Final thematic network

notion that a person has the capacity to perform a specific task. Positive feedback is thought to be most effective when it is given by trusted and knowledgeable adults. I 
identified two basic themes within the three analyzed instruments: verbal persuasion from colleagues and verbal persuasion from the professional development instructors. During the coding process, I found 22 instances of verbal persuasion; eight from instructors and fourteen from colleagues. Evidence of these two types of verbal persuasion is recorded in Table 4.7. The majority of verbally persuasive comments from colleagues took place when teachers shared their experiences teaching engineering lessons during the one-day follow-up workshop. The remaining comments were made during the interviews.

Table 4.7

Evidence Supporting Verbal Persuasion as a Source of Self-efficacy Type of Verbal Persuasion Participant Comments

From colleague

Pamela: (referring to PD hands-on activities) "And as we were all talking about it we just kind of learned from each other. And then that built my confidence."

Maria: "Teachers Pay Teachers is great. Now I'll be waiting to see your name on it (referring to P2's engineering lessons)!"'

Rita: "So it helps to have another person in the same grade to, you know, to kind of bounce off lessons and ideas, things that work and will not work."

From instructor

Pamela: "The other major thing was when you encouraged me to get the Family Engineering book. That was huge for improving my confidence."

Rita: 'It's important to have people who are, you know, face to face and feel like you guys care. I mean, we feel that you care." 
Noteworthy is that teachers commented about the collaborative aspect of the professional development wherein teachers were able to exchange and encourage each other's ideas during hands-on engineering activities and sharing sessions. Pamela claimed that working and learning together to solve problems "built my confidence." Teachers felt particularly supported when collaborating with colleagues who shared a real desire to be part of the engineering professional development course and improve their teaching. For example, Pamela stated, "But my real enthusiasm came on the follow-up class. The people that were there were the people that really wanted to be there instead of just trying to get credits or because their district told them they had to take the course." Rita was excited about the collaboration created from having a follow-up workshop. Referring to the follow-up, Rita reported:

We didn't really email each other until right before this class. But, now that we had that second class, and I think the bonds are getting strong. And we're able to exchange ideas and things to tweak or try, I think that helps build confidence, you know, as a teacher.

Additionally, several examples of verbal persuasion from instructors were communicated as being supportive. Comments indicated teachers felt encouragement because the instructors were open to questions, provided helpful tips and resources, and appeared to care about the learning of the participants (see Table 4.7). Overall, teachers perceived supporting comments from both colleagues and instructors to have contributed to improving their confidence to engage in and teach engineering.

Vicarious experiences as a source of self-efficacy fundamental to professional development. Similarly, the organizing theme of vicarious experiences was perceived by teachers to be a source of self-efficacy positively influencing their self-efficacy to teach 
engineering. Bandura (1997) portrayed vicarious experiences as when a person observes another person, particularly an individual at a similar level of knowledge, competently performing a task. Coding across the three analyzed instruments revealed two basic themes of vicarious experiences: modelling of engineering lessons by instructors and observing colleagues. Evidence of these experiences is illustrated in Table 4.8. I coded

Table 4.8

Evidence Supporting Vicarious Experiences as a Source of Self-efficacy Type of Vicarious Experience Participant Comments

From colleague

Pamela: (After listening to P9 describe a successful experience and observing photos) "It was neat to see the pictures of it. Really, now it's like I want to do that."

Rita: "Then there's some YouTube videos. There's a teacher that did erosion in a tub and she had her kids video tape it and put it on YouTube. So, I thought, hey I can do that in class."

From instructor

Pamela: "So I got Legos wheels and axles because of how we learned to use those in our class last summer (referring to modelled lesson)."

Maria: "I did with my $2^{\text {nd }}$ graders the pollinator unit we did this summer. So, I basically followed that exactly how (instructor name) showed us."

Rita: "You showed many different ways to do engineering in the classroom. Plus, you also showed step-by-step how to do it. I think it makes me, it helps me to make it happen if someone has done it before that we trust. That I trust." 
15 examples of vicarious experiences with four being a result of observing colleagues and 11 having to do with instructor modelling. Teachers showed they experienced vicarious modelling from instructors when they shared that they taught the exact same engineering lessons demonstrated during professional development. Apparently, teachers felt more confident teaching lessons that were tried and tested by people considered to be experts. For instance, Rita stated:

And the experts...I call you the experts because you've been teaching for a while and you know what works so that helps me as a teacher to say, if they know this worked with other classes, then I know it should work in my class. So that's a boost. That's a big boost (referring to confidence).

Teachers conveyed vicarious experiences from colleagues when they described watching and learning from other teachers as they worked through engineering activities in the course. A couple of teachers searched for lessons on the Internet that included videos of teachers teaching engineering lessons. What appeared evident was that teachers observed both instructors and colleagues successfully teaching engineering which in turn seemed to raise their own confidence to the point that they wanted to try the lesson them self.

Emotional arousal as a source of self-efficacy fundamental to professional development. The organizing theme of emotional arousal was also declared as a source of self-efficacy shaping a teacher's confidence to teach engineering. Emotional arousal refers to a person's response to their own stress and fear when anticipating or performing a task (Bandura, 1997). Coding across the three analyzed data instruments exposed two basic themes within emotional arousal. The first basic theme consisted of a person's expressed feelings indicating fear or lack of fear toward teaching engineering. The second basic theme involved a person's feelings of familiarity with engineering as a 
result of time spent teaching it. Palmer (2010) claimed "repetitious familiarity" with teaching a topic to be an influential factor when considering emotional arousal (p. 580). When coding the data, Palmer's factor seemed to fit the feelings and actions of the teachers. Seven examples of emotional arousal were divulged by teachers, three referring to feelings of familiarity and four attributing to feelings toward fear of teaching engineering. Evidence of emotional arousal influencing teacher self-efficacy is displayed in Table 4.9. Teachers expressed that their feelings of fear toward teaching engineering were reduced when the course demonstrated to them that barriers could be reduced. Barriers included time to plan and teach engineering, access to resources, and equipment, and the ability to integrate engineering with other content areas. In addition, by the time the interviews were conducted teachers had experienced teaching two or more engineering lessons. At first glance, one might assume this theme of practice falls under the source of self-efficacy known as mastery experiences. While familiarity with Table 4.9

Evidence Supporting Emotional Arousal as a Source of Self-efficacy Type of Emotional Arousal Participant Comments Feelings toward fear Pamela: (Referring to confidence affecting teaching practices) "And, my teaching practices, I'm just, I'm not afraid to do anything anymore."

Rita: "An idea doesn't happen if you don't have the tools."

Feelings of familiarity

Pamela: (Referring to course) "So, because of this I am teaching more engineering. In fact, I'm probably spending too much time on engineering." 
teaching engineering overlaps into mastery experiences, I contend this basic theme differs because it focuses solely on one's feelings toward teaching more engineering. Comments from teacher interviews showed an increase in time spent teaching engineering in their classrooms which was accompanied with feelings of pride toward these changes. In fact, one teacher commented to another how much the professional development course appeared to change them. The changed teacher replied, "Well, yeah, I kind of have. But it's all for the good!" My conclusion, then, is that the professional development course reduced barriers to teach engineering which caused teachers to make time to teach it. Once teachers experienced teaching several lessons, a familiarity with the process of teaching engineering took hold which lead to feelings of fear to be replaced by feelings of confidence.

\section{Mastery experiences as a source of self-efficacy fundamental to professional}

development. Not surprisingly, teachers presented substantial recognition to mastery experiences as being a source of self-efficacy to teach engineering. Mastery experiences represented the fourth organizing theme. Bandura (1997) defined mastery experiences as authentic successes in performing a task. The term mastery implies knowledge that grows. Comments from teachers supported the notion that the professional development advanced their knowledge of engineering. For example, Rita declared, "You know how it is like you build on whatever experiences you have? I'm going to call it the base, like that class (referring to the course), that is like my foundation." Maria, a first grade teacher added, "What boosted my confidence was gaining knowledge... knowing things so I feel better able to talk about it with the kids." Palmer (2009) defined these examples 
as cognitive content mastery; a nuanced form of mastery experience because it "involves success in understanding something rather than success in doing something” (p. 339).

Teachers made 54 references that identified mastery experiences as a source of teacher self-efficacy. Two aspects of mastery experiences developed into basic themes. Student success was the first basic theme which accounted for thirty-seven of the fiftyfour references. Two sub-categories of student success developed that grouped successes into those being academic and those being affective. Evidence of student affective and academic successes positively improving teacher self-efficacy is shown in Table 4.10. Notable is that all teachers reported their confidence was boosted when they witnessed student success with regard to affective factors. Affective successes included enhanced student engagement, feelings of joy toward school, motivation to engage in more engineering tasks, and improved confidence to problem-solve. For instance, Rita, a fourth grade teacher admitted having doubts prior to teaching an engineering lesson. Not only did Rita's doubt shift to confidence, but she was surprised by the effect of the lesson on students:

It's their reaction to it. When I was explaining it and demonstrating, you know, it was still pretty bland, meaning their expressions were like, I wasn't sure if they were going to get into it. But once they got into their groups, and here are your materials, and they were actually having conversations with each other, then that piqued my interest because I was thinking, oh, they're having conversations. And I thought it's the quality of the conversation, you know. They're problem-solving. So I thought, wow, it wasn't as boring as I thought it could be. I mean I wasn't sure. I had never tried.

In particular, all teachers made comments about their student's heightened level of engagement during engineering activities and their desire to engage in more. Maria proclaimed, "Yeah, now they're like...can you bring out that stuff again because they just 
want to make pollinators again." Pamela stated that after a series of connected

engineering lessons with Legos, students were "loving school" and female students were "convincing their parents to buy them Legos. And their parents are saying to me, I never thought she would like Legos."

Likewise, student academic success connected to mastery experiences was described as a tremendous source of teacher self-efficacy (see Table 4.10). Academic Table 4.10

Evidence of Student Successes Supporting Mastery Experiences as a Source of Self-efficacy Type of Student Success Participant Comments

Affective Rita: (referring to engineering lesson) Then they tested it and it actually worked out better than I thought 'cause they were excited to do it. They were working together. Next, each group presented, they were such good listeners... oh, I was so thrilled. They were asking really good questions about what you would do differently next time. I found that very encouraging."

Academic

Pamela: (referring to motivation to read after Lego engineering lessons)"Yeah, now they're ordering books on Legos. Reading books a little above their level. And, then there's this little boy, he's just been so struggling to learn to read. He's reading the Lego Idea book. And, I couldn't get him to stop reading it at rug discussion time. And I said, do you want to borrow that book? He looked at me, and he said, can I? Now, he's picking up books all the time. So things like this are happening all the time. That's what improves my confidence." 
successes consisted of a better understanding of the engineering design process as well as scientific and engineering practices. Teachers also observed that their students achieved an assortment of skills such as problem solving, creativity, active listening, cooperation, and negotiation by engaging in engineering lessons. Students experienced deeper learning, which lead to better retention, questioning, and making connections to their everyday lives. Teachers asserted their self-confidence was especially amplified when previously unmotivated students became motivated to engage in more reading and writing as a result of an engineering lesson. For example, Pamela, a first grade teacher talked about difficulty in getting boys in the class to write. Yet, when asked to write results from an engineering activity, the boys were motivated to write. Pamela conveyed a strong sense of self success due to influencing student academic success:

These two boys now are writing full pages because they have something important to them that they want to share. And they want to document it. We just tested them on their reading level and both of them jumped in the last three weeks so it has made a huge impact on the kids.

Maria remarked about the meaningful connections students were making after learning from an engineering lesson. Maria was so delighted with such an experience, she professed:

Even a couple of months later this article had come up on Moby Max...on reading one and it was about how bees were dying and they were like: AHHHH! Look at this article! (mimicked their voices). Oh, that's great. Because then they're making connections with their outside world, which is what we want, you know. Because then you know they're retaining the information.

The second basic theme associated with mastery experiences was characterized as perception of value. Perception of value represented 17 of 54 references of mastery experiences. Evidence of perception of value positively effecting teacher self-efficacy is 
displayed in Table 4.11. Perception of value overlapped a bit with student success because clearly teachers perceive value when their students are successful. However, teachers associated additional values in building engineering experiences. For instance, all teachers appreciated that the teaching of engineering aligned with district and school goals. Maria stated:

It used to be our district was really focusing on reading and math and it was kind of like they were wanting us to cut out other subject areas. But now the district is really with the Common Core Standards and everything pushing towards adding those subjects back in.

A couple of teachers saw value in engineering as a vehicle in which to integrate content areas, thereby having the time to fit in science and allowing students to make connections across content areas. Maria described engineering as the hook to engage students and

Table 4.11

Evidence of Perception of Value Supporting Mastery Experiences as a Source of Self-efficacy

Participant Comments

Maria: "So I wanted to build a curriculum that was using more of the other standards, using the science and social studies standards as a basis for themes. And the I would pull in all of the literature and math and art that would supplement that. Like the pollinator lesson. It's like the engineering is the centerpiece and I add other content pieces to it. And that way I feel like I'm able to hit everything. And the kids seem more engaged."

Rita: "I'm hoping to do more engineering activities or more investigations that are, that can also be part of writing and the literacy and the math. So it is more integrated. So we're hitting all these learning targets all At once so it is not like an isolated activity. It is better for students if What you are doing as a teacher makes sense." 
pull in other content areas (see Table 4.11). It was striking that all teachers talked about how they loved the part within the professional development course in which they were exposed to the concept of learning progressions. Learning progressions are core science and engineering concepts spread across the K-12 curriculum that build upon each other so students can advance in their scientific thinking (NRC, 2007a). Specifically, teachers expressed value in understanding where science learning was headed next so they could better address how concepts should be taught at their own grade level. Maria confessed, "I liked seeing the whole thing (referencing learning progressions). I know I couldn't use every single piece of it for my classroom, but I think it did help for my own personal knowledge."

To summarize this section on mastery experiences as a source of self-efficacy, I discovered that student successes from engineering lessons combined with a teacher perceived value in teaching those lessons was a significant source of self-efficacy for teachers. All the teachers spent lots of time during their interviews expressing this point and they did so with enthusiasm. In fact, it was interesting that every teacher mimicked the excited voices of their students as they related their stories of student success and the depth of beneficial outcomes. Clearly, the organizing theme of mastery experiences is a powerful source of teacher self-efficacy to teach engineering.

Open-endedness as a source of self-efficacy inherent to engineering professional development. Within the section of Chapter 3 titled, Role of the researcher, I wrote about my own personal experiences teaching engineering. I commented that it might be easier to incentivize teachers to teach engineering than science because engineering is so open- 
ended. I was pleased to find that open-endedness was revealed to be a source of teacher self-efficacy and therefore an organizing theme novel to engineering professional development. Nine references were made to open-endedness as a source of teacher selfefficacy. When coding teacher comments, two basic themes or aspects of openendedness were identified: less structure and having multiple solutions. Evidence of open-endedness as a source of teacher self-efficacy is laid out in Table 4.12. The fact that engineering problems can have several different and yet excellent solutions were vocalized by a teacher. Furthermore, teachers declared their confidence grew because engineering lessons had less structure, opened up new questions and thus new lessons. For example, Rita explained this aspect of engineering by stating, "When we say do engineering design, it's open to anything." Pamela added, "And the way that you teach, you leave it open-ended enough that we can take what you got and then extend it, change it, build on it." In short, from their experiences in the engineering professional development, teachers came to understand the open-endedness of the engineering design process and that appeared to free them, empower them and help them gain confidence.

Growth mindset as a source of self-efficacy inherent to engineering professional development. In Chapter 3, I overviewed the content of material covered within the engineering professional development course (see Appendix A). One important aspect of the engineering design process is that a person learns from their mistakes or failures. Applying trial-and-error is a helpful tool within this iterative process of learning. Within the professional development, the instructors presented various strategies for developing this thinking at different grade levels. For example, within a kindergarten lesson, 
teachers were told to use if, then statements to recognize mistakes and promote trial-anderror. Cultivating this type of thinking was revealed to have an enormous influence on

Table 4.12

Evidence of Open-endedness as a Source of Self-efficacy

Aspect of Open-endedness Participant Comments

Less structure

Pamela: "So after teaching the lesson, my confidence grew. Because at first I thought I just had to teach the lesson. I didn't realize that the discussions that they had after the lesson would build on the next lessons."

Maria: "I think it's made me a better teacher. I like teaching more in this format rather than being required to teach some arbitrary textbook at a certain day, a certain time. It's not really natural learning. It totally boosted my confidence and feeling like, I don't know, this sounds silly, but giving you more power or control."

Rita: (Referring to engineering lessons) "Like I mentioned they brought up these questions. So I myself would have to be more open and more open to their ideas, and it's kind of thrilling to feel that way."

Multiple solutions

Pamela: (Referring to working with others on engineering activities during PD) "And everybody worked together, and I guess what helped my confidence was seeing that nobody had any better answers than I did. And neither would my kids. They would learn by doing it."

teacher self-efficacy. At first, I had difficulty identifying this organizing theme. Luckily, network analysis required me to employ a recursive, not linear process of analysis across 
data sets (Braun \& Clarke, 2006). In time, recurrent issues appeared to connect with ideas expressed by researchers that I wrote about when discussing the significance of failure within the engineering design process (in Chapter 1). Re-reading Pawlina and Stanford's (2011) article lead me to label these issues as growth mindset; my second organizing theme inherent to engineering professional development. When a person has a growth mindset, this means they believe intelligence is malleable and "making mistakes is an opportunity to do something different and learn" (Pawlina \& Stanford, 2011, p. 33).

Because engineering professional development cultivated a growth mindset for teachers, it was recognized as an important source of self-efficacy. Thirty-two references related to growth mindset were coded and four basic themes were established: (a) attitude toward failure, (b) practice troubleshooting or optimizing, (c) risk-taking behavior, and (d) motivation to do more engineering. Evidence of each of these four basic themes are shown in Table 4.13. Comments from teachers indicated they embraced a positive attitude toward failure and making mistakes which was taught in the professional development as an inherent part of the engineering design process. Rita indicated enjoyment of this way in which lessons were taught in the class. Rita declared, "It was structured, structured in a way that you have time to try things out. You can make mistakes and it is okay." Amazingly, teachers reported passing this attitude on to their students when they taught engineering lessons. Rather than focusing on failures in a negative way, teachers explained to their students that failure points showed where their designs could be fixed. For instance, Maria described how students became frustrated 
Table 4.13

Evidence of Growth Mindset as a Source of Self-efficacy

Aspect of Growth Mindset Participant Comments

Attitude toward failure Rita: "We were able to do it ourselves in class and discuss it so we were able to make mistakes and reassemble."

Practice optimizing

Maria: "And I really like that it was we, as the teachers, did the whole thing as if we were were students. I think that is more helpful for me for my own memory of, like, retaining that experience and of how to do it in my classroom. And the also you're able to figure out all the kinks to how it would work and how you would change it."

Risk-taking behaviors

Rita: "I had them set their own parameters for their criteria which was the first time I let do that."

Motivation to do more

Pamela: "I never wanted Legos until I took this engineering class. I never wrote the grant until I took the engineering class... because I really liked that lesson" (taught in class)

with failure when trying to design functional pollinators. Maria explained:

We ended up having to do this a few times because what ended up happening is that they started building them for design like for look and what they were finding out was that the ones they built for style were not effective. So, then we had a big conversation about, well, why did some of these work and why some didn't work. And, then we did it again and when we did it the second time they were much more effective with creating something that would work.

A positive attitude toward failure is typically accompanied by the active practice of attempting to fix mistakes and optimize designs. Thus, the physical act of optimizing was revealed as a basic theme within fostering a growth mindset. Teachers expressed 
that taking an active role in fixing failure points during engineering lessons improved their confidence. For instance, Pamela recounted:

And so, for me, as I was doing the activities, I was formulating my own hypothesis. And changing it as we went. And that helped me to learn more than anything, and that gave me the confidence. By going through it hands-on, I'm more likely to do it with my kids, and I'm more likely to have questions that are going to be more pertinent to them in their own mind thinking it through.

The third basic theme identified was risk-taking behavior. Because the three interviewed teachers developed a growth mindset, they begin to take more risks. Teachers took more risks within and outside the act of teaching. Pamela said the class made her so confident she felt she could teach the class to other teachers. Rita implemented risks with an engineering lesson by allowing the criteria in an engineering activity to be more open-ended and as a result noticed the students taking more risks. Finally, the fourth basic theme exposed was motivation to do more engineering. Embracing a growth mindset appeared to operate like a catalyst. In other words, developing a growth mindset seemed to speed up teacher motivation to teach engineering. All teachers began to talk about doing more engineering lessons in the future and actively pursued additional resources to do so. Pamela applied for and received a grant to buy engineering materials (see Table 4.13). Maria convinced her principal to buy engineering resources and materials. During the one-day follow-up workshop teachers shared engineering lessons. All the teachers asked each other for copies of the activities so they could replicate shared lessons with their own students. Overall, because the engineering professional development experience cultivated a 
growth mindset in teachers, I contend that the motivational aspect of self-efficacy was further reinforced, which further strengthened self-efficacy.

\section{Limitations of Study}

While there are exciting findings within this study, it would be remiss not to mention limitations. First, the TSES instrument used self-reporting to measure teacher self-efficacy. Pajares (1992) claimed self-reporting instruments used to measure teacher self-efficacy hold inherent problems. For this reason, qualitative data was gathered to corroborate self-reported quantitative data. Also, the TSES instrument was not administered a third time, at the end of the school year and after the follow-up workshop. Tschannen-Moran and McMaster (2009) indicated that teachers implementing changes to practice can experience an "implementation dip in self-efficacy" (p. 232). Additional testing of teacher self-efficacy or a longitudinal study may provide a more comprehensive picture of changes in self-efficacy. Second, three teachers in the engineering professional development course declined to participate in the study. Did that mean that teachers who agreed to participate were more pro-engineering and therefore more open to improving self-efficacy? Therefore, I included an interview question asking teachers what motivated them to take the engineering course. None of the teachers reported attending the professional development because they felt pro-engineering. The common reason for attendance was that teachers felt they lacked the preparation to teach engineering.

Last, a limitation to this study was that it had a small sample size $(N=10)$. According to Krathwohl (2009), larger sample sizes are preferable because the standard error decreases and makes it easier to generalize results. However, as stated in Chapter 3 , 
the intention of this study was not to generalize, but rather to inform other researchers searching for similar solutions. After all, Morgan's (2007) notion of transferability guides the intention of this study. In Chapter 3, I also referenced research from Dolle et al. (2013) addressing small sample sizes in educational research. They recommended creating networked improvement communities to improve educational practices and starting small before implementing broad systemic changes. Similarly, Borko (2004) endorsed small scale professional development because it should provide evidence of positive effects on teaching knowledge and practices before growing in scale. Large scale studies are important, but they should be conducted only after "well-designed interventions with demonstrated effectiveness already exist”' (Borko, 2004, p. 12). Мy study serves as a small scale intervention initiating first steps in improving teacher selfefficacy to teach engineering.

\section{Summary}

In conclusion, data analyses revealed that elementary teachers' self-efficacy, content, and pedagogical content knowledge improved significantly after the one-week engineering professional development. Although self-efficacy data were self-reported, this study included the collection of qualitative data to confirm shifts in teacher selfefficacy. Teachers' voices and actions provided evidence supporting positive changes in self-efficacy to teach engineering.

I used data analyses to identify sources of self-efficacy. In Phase Two of this study, I tried to determine what aspects of the engineering professional development or other factors teachers' perceived as improving their self-efficacy to teach engineering. 
Qualitative results divulged sources of self-efficacy that came from effective professional development. Evidence showed sources of self-efficacy to echo Bandura's four sources: (a) verbal persuasion, (b) vicarious experiences, (c) emotional arousal, and (d) mastery experiences. Comments from teachers verified the existence of all four sources unquestionably influencing teacher self-efficacy. While thematic network analysis does not purport to establish hierarchy of themes, the process does recommend keeping a record of the number of quotations containing themes (Attride-Stirling, 2009). Based upon the number of comments reflecting a theme and from the level and depth of enthusiasm expressed by teachers, it became apparent that mastery experiences were the most influential source of self-efficacy. It is important to note that teachers felt particularly strengthened in self-efficacy when unmotivated or struggling students achieved academic successes related to an engineering lesson.

The emergent aspect of Phase Two allowed for unique sources of self-efficacy to surface. Fortunately, evidence affirmed sources of teacher self-efficacy that were novel to engineering professional development. Teacher comments confirmed that two inherent aspects of the engineering design process they had been taught positively influenced their self-efficacy. The first aspect of the engineering design process is its open-endedness. Working on problems that potentially had several good solutions appeared to make them more receptive to diverse ideas and less focused on finding one correct answer. In a similar fashion, evidence revealed changes in teachers' mindsets as a consequence of engineering professional development. Teachers cultivated a growth 
mindset, which appeared to catalyze the motivational aspect of self-efficacy in such a way as to improving self-efficacy at a faster rate. 


\section{Chapter 5: Conclusion}

The overarching purpose of this study was twofold: (a) to investigate the effects of engineering professional development on elementary teachers' content knowledge, pedagogical content knowledge, and self-efficacy beliefs to teach engineering, and (b) to identify specific sources within the professional development that seemed to influence self-efficacy. I based this study upon a review of the literature indicating that a substantial amount of elementary teachers believe themselves to be inadequately prepared to teach science and engineering. The literature review seemed to confirm that holding inadequate beliefs effects a teacher's self-efficacy, which in turn effects a teacher's behavior. While the construct of self-efficacy has been investigated within the context of STEM and science professional development, my review of the literature indicated there were no studies on teacher self-efficacy conducted within the context of engineering professional development. Therefore, the following research questions propelled my study:

1. How did the professional development program affect elementary teachers' content and pedagogical content knowledge to teach engineering?

2. How did the professional development program affect elementary teachers' perceptions of self-efficacy to teach engineering?

3. After the engineering professional development program, what aspects of the program or other factors did elementary teachers' identify as influencing their self-efficacy to teach engineering?

Even though my study will augment the research by examining teacher self-efficacy within the context of engineering professional development, an additional objective was to identify sources of self-efficacy. I deemed it important to include this element to extract sources of self-efficacy strengthening teacher self-efficacy so these sources could 
be reinforced within subsequent professional development and be recommended practices for others involved with teaching engineering professional development.

In Chapter 4, I analyzed both quantitative and qualitative data collected from this study. I presented and interpreted results. Additionally, I described limitations stemming from implemented methods and data analysis. In Chapter 5, I synthesize results from the previous chapter and compose conclusions through the theoretical and conceptual frameworks established within the literature review. In addition, meanings exposed from results of this study are situated and explained in broader educational contexts. The synthesis of findings and how they are situated in a larger context will be organized by

the three research questions that guide this study. Finally, I express implications of these results on educational policy and practices as well as recommendations for further research.

\section{Synthesis of Findings}

Research question one. How did the professional development program affect elementary teachers' content and pedagogical content knowledge to teach engineering? The aim of research question one was to measure the effect of engineering professional development on elementary teachers' content and pedagogical content knowledge (PCK) to teach engineering. In Chapter 4, I reported quantitative evidence demonstrating elementary teachers' exhibited a statistically significant increase in engineering content and pedagogical content knowledge as a result of their participation in engineering professional development. Because the teaching of engineering is a new dimension of content within the NGSS, the course instructors thought it was important for teachers to develop a basic foundation of content and PCK specific to the engineering design 
process. Likewise, Desimone (2009) insisted a focus on content was a critical feature in producing effective professional development. Desimone's (2009) ideas are outlined in her professional development conceptual framework which guided this study. Another aspect of Desimone's (2009) conceptual framework was to incorporate a research-based theory that establishes an explanation of how professional development can influence teacher beliefs and learning. The researcher of this study desired a theory that would not only explain effects of professional development on teacher beliefs and learning, but would also have the potential to create enduring changes in teacher practices. Therefore, Bandura's $(1977,1982,1986)$ social cognitive theory was selected as the theoretical framework underlying this study. Bandura's (1986) work suggested that an environmental factor such as an engineering professional development experience could affect the beliefs of a teacher, and in turn, influence a teacher's behavior in teaching engineering. In Chapter 2, I presented well-established evidence in the literature that showed effective science professional development must include a focus on content and PCK (Appleton, 2008; Desimone, 2009; Guskey, 2003; Heck et al., 2006; Heller et al., 2010; Mundry, 2005; NRC, 2007b; Wilson, 2013). Fewer studies have investigated and recommended the inclusion of content and PCK within the context of engineering professional development (Duncan et al., 2011; Hsu et al., 2010; Yoon et al., 2013). The results in this study strongly support findings from these former investigations in concluding that the integration of engineering content and PCK within professional development is imperative in the process of changing teacher understandings of engineering. 
Unfortunately, a review of the literature found no studies verifying an association between teacher content knowledge, PCK, and self-efficacy within the context of engineering professional development. However, within the context of science professional development, Park and Oliver (2008) insisted that when teacher self-efficacy was increased, teachers were motivated to enact their understandings. Although this study did not aim to find an association between content knowledge, PCK, and selfefficacy to teach engineering, a bit of evidence was revealed to suggest possible interaction between these elements. When exploring sources of teacher self-efficacy in this study (research question three), evidence of Palmer's (2009) cognitive content mastery was recognized as a source boosting confidence to teach engineering. Palmer (2006) claimed content and PCK were pre-requisites for enhancing self-efficacy within mastery experiences. In sum, I contend that incorporating engineering content and PCK within engineering professional development is essential to improving teacher understandings, beliefs, and practices to teach engineering.

Research question two. How did the professional development program affect elementary teachers' perceptions of self-efficacy to teach engineering? The intention of research question two was to measure the effects of engineering professional development on elementary teachers' perception of self-efficacy to teach engineering. In Chapter 4, I presented both quantitative and qualitative evidence associated with research question two. Results from this study found that elementary teachers' self-efficacy to teach engineering showed statistically significant gains as a consequence of their engineering professional development experience. Accordingly, these results help fill a 
gap in the literature by reporting positive changes in teacher self-efficacy within the context of engineering professional development. These results align with Bandura's (1986) theory in which he purported there is a reciprocal relationship between environmental factors, a person's beliefs, and behaviors. Bandura (1986) believed that self-efficacy is a motivational construct because it influences a person's effort and persistence, which in turn affects behavior. This belief matches up well with Desimone's (2009) conceptual framework which promotes the idea that professional development studies need to identify cause and effect relationships to evaluate their effectiveness. The results of this study revealed that an environmental influence of professional development had a direct effect on teachers' by improving their self-efficacy to teach engineering. Moreover, positive shifts in teacher self-efficacy, in turn, affected teacher behavior in that teachers were motivated to teach engineering. At the follow-up workshop, all participants communicated that they had taught one or more engineering lessons since the summer professional development course. Clearly, the strengthening of self-efficacy motivated teachers, which in turn influenced their behaviors such that they taught engineering.

Self-efficacy subscales and issues of equity. When self-efficacy results were disaggregated by subscales, teachers' demonstrated statistically significant improvements in self-efficacy for student engagement, for instructional strategies, and for culturally responsive strategies. Plus, teachers' showed positive gains in self-efficacy for classroom management. Notable is that teachers' showed statistically significant gains in selfefficacy for culturally responsive strategies in teaching engineering. According to Gay 
(2002), culturally responsive teaching strategies involves "using the cultural characteristics, experiences and perspectives of ethnically diverse students as conduits for teaching them more effectively" (p. 106). The instructors of the engineering professional development hoped for improvements in self-efficacy for culturally responsive strategies because they intentionally and explicitly taught culturally responsive teaching practices within the context of engineering lessons. In Chapter 1, I mentioned that individuals from minority groups are less likely to earn a bachelor degree in science and engineering (Museus et al. 2011). The professional development provided teachers with proper tools and strategies to acknowledge and link different cultures within engineering lessons. The rationale to include these strategies was to support teachers in engaging students from diverse backgrounds. As a consequence of doing so, elementary teachers' self-efficacy for culturally responsive strategies strengthened. Gay and Howard (2000) asserted that improving teacher beliefs toward culturally responsive pedagogy is important because it allows teachers to perceive difficulties as challenges to be mastered rather than as fears to be averted. These results are also meaningful because Bandura's (1986) reciprocal theory would suggest that positively shifting teacher self-efficacy for culturally responsive strategies would motivate teachers to include similar methods in their teaching of engineering and foster heightened interest for students in underrepresented minority groups. While these results are beyond the goals of this study, nonetheless they present a compelling possible outcome.

Research question three. After the engineering professional development program, what aspects of the program or other factors did elementary teachers' identify 
as influencing their self-efficacy to teach engineering? In Chapter 3, I stated that the results of research questions one and two would explain what happened to teacher content knowledge, PCK, and self-efficacy after participation in engineering professional development. While I consider these pieces of the study to be important, they were deemed secondary to the primary goal of this study which was to explore how teacher self-efficacy changed. Research question three aspired to identify factors surrounding the professional development experience that explained how teacher self-efficacy was enhanced. Maxwell (2013) emphasized that how questions are best answered through qualitative approaches. Thus, in Chapter 4, I reported qualitative evidence revealing sources of teacher self-efficacy to teach engineering. The bulk of qualitative evidence came from teacher interviews. Such a strategy was advocated by Desimone (2009) who stated that interviews are excellent for "understanding the complexities of professional development in a specific context, how beliefs and attitudes change, and the process through which teachers change their instruction" (p. 190). Distinguishing sources of selfefficacy would help revise and improve the engineering professional development course as well as recommend practices for educators and researchers conducting similar work. Moreover, Klassen et al. (2011) insisted there was an inadequate amount of investigations examining sources of teacher self-efficacy. Results from this study serve to help fill a gap in the literature.

This study concluded that sources of teacher self-efficacy derived from both effective professional development principles and practices novel to teaching the 
engineering design process. In the next two sections, I synthesize results addressing research question three and explain their meaning in broader contexts.

Sources of self-efficacy within effective professional development. Effective professional development principles were established through Desimone's (2009) endorsement of five critical features: (a) content focus, (b) active learning, (c) coherence, (d) duration, and (e) collective participation. The definition of these features and how they were applied to the engineering professional development were outlined in Chapters 2 and 3. The foremost finding of this study regarding sources of teacher self-efficacy from effective professional development was that all four of Bandura's sources were reported to be influential in explaining how self-efficacy changed. To review, Bandura (1986) described four sources of self-efficacy: (a) mastery experiences, (b) vicarious experiences, (c) verbal persuasion, and (d) emotional arousal. Below is a summary of the findings presented in Chapter 4 with regard to sources of self-efficacy from effective professional development:

- Verbal persuasion from colleagues and from the professional development instructors was exposed by teachers as a factor contributing to self-efficacy gains;

- Vicarious experiences observed from colleagues and the professional development instructors were expressed by teachers as a factor positively influencing self-efficacy;

- Although representing the least number of comments from teachers, emotional arousal was communicated as a factor influencing teacher self-efficacy;

- Teachers believed the professional development course reduced barriers to teaching engineering and in doing so reduced their fears to teach it;

- Mastery experiences were perceived by teachers to be a powerful factor associated with the strengthening of self-efficacy; 
- Success within mastery experiences influencing teacher self-efficacy were strongly tied to student successes (academic and affective successes);

- Teachers claimed mastery experiences to be more potent as a factor affecting selfefficacy when unmotivated or struggling students achieved academic successes related to an engineering lesson.

Now, I extend the significance of a few of the above findings within broader contexts. First, teaching engineering is perceived by teachers to be a new demand on their already overburdened set of responsibilities (Moore et. al, 2013). Bandura (1986) acknowledged that self-efficacy and its influence on behavior was complicated because of the existence of external factors. Lee and Houseal (2003) classified self-efficacy as an internal factor. A teacher's time was considered an external factor that had the potential to influence self-efficacy. For example, teachers may resist instructional changes when they perceive changes to negatively impact their time. Thus, Yasar et al. (2006) insisted that engineering professional development must address issues of time. Within the evidence of emotional arousal as a source of self-efficacy, teachers reported feeling less fearful toward teaching engineering because the professional development experience demonstrated how barriers to teaching engineering could be reduced. In particular, the teachers in this study perceived time to be a serious barrier in teaching engineering. I contend that when professional development reduces some barriers to teach engineering, teachers can focus on what they tend to gain in implementing changes. Also, in light of Bandura's work, I find that when fewer obstacles are perceived by teachers, they become more open to the incentives associated with changing their instructional practices.

Second, I concluded that teacher self-efficacy gains were most influenced by mastery experiences that involved academic and affective successes with students, 
especially when those students were formerly unmotivated or difficult to reach. Bandura (1977) defined two sub-groups of self-efficacy affecting behavior: personal self-efficacy and outcome expectancy. Outcome expectancy involves a teacher's perception that their behavior influences student outcomes. Bandura (1997) also stated success in mastery experiences to be the most influential source of self-efficacy because beliefs are "both products and constructors of experiences" (p. 82). Ramsey-Gassert et al. (1996) viewed mastery experiences as when teachers had positive experiences teaching science. Yet, are all teacher successes or outcomes with students equal in their effect on self-efficacy? I argue Bandura's (1997) definition of mastery experiences as a source of self-efficacy falls short because he did not identify different kinds of success or suggest how different kinds of success are influencing self-efficacy. Perhaps this explains why TschannenMoran and Hoy (2001) extended Bandura's definition when they claimed teacher selfefficacy was a "judgement of his or her capabilities to bring about desired outcomes of student engagement and learning, even among those students who may be difficult or unmotivated" (p. 783). In my own experience as a teacher, I found a teachers' success is not simply a function of perceived individual performance. The key to a successful performance must include the positive reaction and feedback from students. Were the students engaged? Moreover, were previously unmotivated students more engaged? Did students personally connect to what they learned? Did engagement in engineering activities situated in real-life contexts foster deeper learning? Were students motivated by the success of the teacher's performance to achieve in other content areas? These questions affirm Tschannen-Moran and Hoy's (2001) interpretation of teacher self- 
efficacy. In short, the findings of this study suggest mastery experiences that bring about positive outcomes in previously unmotivated or hard to reach students represents a powerful source of teacher self-efficacy.

In addition, results from this study confirm that effective professional development must grant time for teachers to experience success in teaching new content that is accompanied by student success. Rockland et al. (2010) criticized one-time, shortterm interventions to improve teacher beliefs and practices within the context of STEM professional development. They claimed these approaches were not effective because teachers needed to experience success with their students. Therefore, I assert that the reason mastery experiences has been associated with being the most influential source of teacher self-efficacy is because enough time is provided for teachers to receive positive feedback from students. Interestingly, improved student learning is a component within Desimone's (2009) path model. According to this model, strengthening teacher selfefficacy leads to changes in teacher practices, which leads to improved student learning. While the model accommodates a back-and-forth influence between self-efficacy, teacher practices, and student outcomes, I maintain the model omits an important feature. In figure 5.1, I extend Desimone's (2009) path model to include the powerful feedback loop between improved student learning for previously unmotivated students and teacher selfefficacy. A feedback loop might also explain why Guskey (1986) believed that changes in teacher self-efficacy did not precede, but instead followed changes in classroom practices. The revised path model supports the findings in this study that when a teacher's mastery experience is accompanied by subsequent student successes, 
particularly those of previously unmotivated students, teacher self-efficacy is strengthened to a higher degree.

\section{Sources of self-efficacy novel to engineering professional development.}

Bandura (1986) professed that teacher self-efficacy is content-specific. In Chapter 3, I provided an overview of the content taught within the engineering design course. One essential component of the course was to describe and demonstrate the iterative methodology inherent within teaching the engineering design process. When examining

Desimone's original path model:

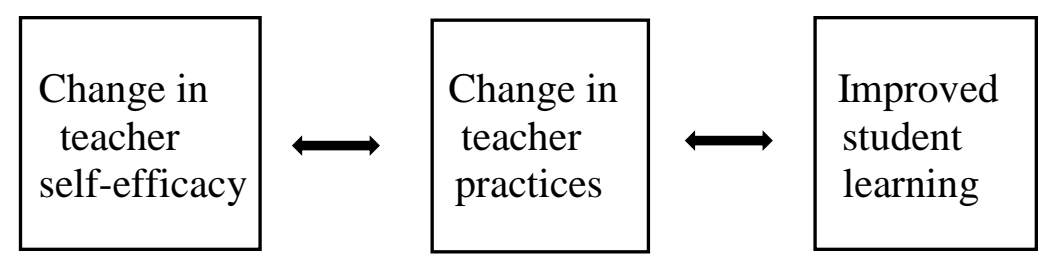

Revised version of Desimones's path model:

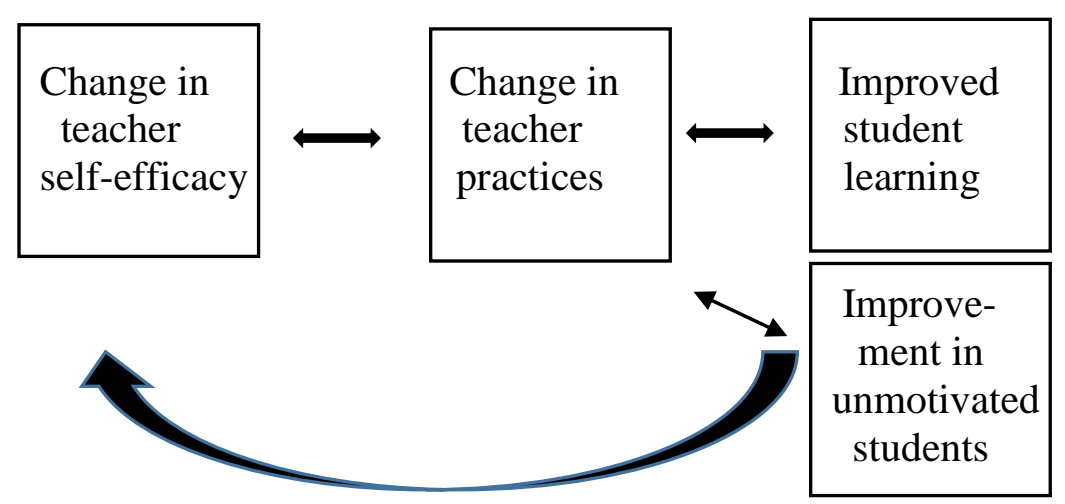

Figure 5.1 Webb's revision of Desimone's (2009) path model

sources of teacher self-efficacy, it became evident that there existed content-specific sources of self-efficacy. Below is a summary of the findings presented in Chapter 4 regarding sources of self-efficacy novel to engineering professional development: 
- The open-ended nature of the engineering design process was declared to be a source of teacher self-efficacy;

- Because the engineering professional development course encouraged teachers to embrace failure, make mistakes, and apply trial-and-error, teachers cultivated a growth mindset;

- Cultivating a growth mindset was perceived by teachers to be a source greatly enhancing their self-efficacy to teach engineering;

- Fostering a growth mindset reduced teachers' fears of failure and promoted the taking of risks to teach engineering;

- When teachers cultivated a growth mindset, their shift in this belief combined with and augmented shifts in self-efficacy beliefs. This enhancement of beliefs accelerated teachers' motivation to teach engineering.

Now, I elaborate the significance of the above findings within broader contexts.

First, the process of engineering design is more open-ended than scientific inquiry

(Cunningham \& Carlsen, 2014; Lammi \& Becker, 2013). For example, the act of solving an engineering problem may reveal several excellent solutions. This study found that because teachers were not pressured to come up with one right solution, teachers felt more confident to engage in the engineering design process. Of course, this perception of the engineering design process being more open-ended is new to many teachers. Pajares (1992) viewed newly acquired teacher beliefs to be more susceptible to change than beliefs held over a longer period of time. Because the teaching of engineering and its inherent open-endedness is relatively new to elementary teachers, I argue teacher beliefs related to engineering are more vulnerable to being changed. Furthermore, I believe the open-ended nature of the engineering design process should be explicitly taught in professional development because it represents a persuasive source of self-efficacy to teach engineering. 
The most surprising finding within this study was that teachers reported the engineering professional development experience cultivated a growth mindset, which in turn, influenced their self-efficacy and motivation to teach engineering. In fact, teachers expressed a significant number of comments indicating that growth mindset was a dominant source explaining how their self-efficacy improved. According to Dweck (2006), there are two types of mindsets: fixed and growth. A fixed mindset is when a person believes their intelligence is not able to change. People with a fixed mindset tend to fear challenges, have no regard for effort, and view failures as negative setbacks. A growth mindset is when a person believes their intelligence is malleable and therefore can change through effort and practice. People with a growth mindset "view challenging work as an opportunity to learn and grow" (Dweck, 2010, p. 16). They seek out learning, value effort, and embrace their weaknesses. As a result, people with a growth mindset tend to persevere through challenges and handle setbacks better than people with fixed mindsets. As Pawlina and Stanford (2011) stated, people with a growth mindset believe that "making mistakes is an opportunity to do something different and learn" (p. 33).

Most thought-provoking is that these growth mindset beliefs were reinforced within the professional development program when instructors taught the process of engineering design. As previously mentioned in Chapter 4, as teachers engaged in engineering lessons during the professional development, the instructors encouraged the use trial-and-error, embracing mistakes, and viewing failure points as places to improve. The instructors talked about how productive failure is a valuable and essential part of the engineering design process (Kapur \& Bielaczyc, 2012; Trueman, 2013). The instructors 
shared stories describing how Thomas A. Edison kept detailed lab journals documenting his process in creating successful inventions (Wills, 2007). Edison's journals revealed he relied heavily on trial-and-error. Edison attributed all of his successes on his positive view of failure. Edison saw failure as a positive force because it provided him with direction and motivation (Wills, 2007).

In a similar way, Dweck (2006) claimed that people with a growth mindset perceive failures as "motivating and informative" (p. 99). Evidence in Chapter 4 revealed that teachers perceived acquiring a growth mindset from participation in the engineering professional development, which in turn greatly influenced their motivation. Self-efficacy is also viewed as a motivational construct influencing a person's effort, persistence, and thus behavior (Bandura, 1986). Because both self-efficacy and a growth mindset are beliefs that influence a person's motivation, I argue the reciprocal relationship between Bandura's (1986) three interacting elements were speed up as a result of engineering professional development. In Figure 5.2, I present a revised visual representation of Bandura's three interacting elements of social cognitive theory. When growth mindset is included as a belief, the interactions among the three elements are sped up as noted by the two arrows acting between the three elements. In other words, growth mindset acts like a catalyst in accelerating the interactive relationship between a person's environmental factors, beliefs, and behaviors.

In conclusion, I identified sources of self-efficacy explaining how teacher selfefficacy changed in this study. As expected, teachers acknowledged all four of Bandura's sources as factors influencing their self-efficacy. While mastery experiences 
were revealed to be a considerable source of self-efficacy, this study extended this understanding. Mastery experiences accompanied with student successes, particularly from formerly unmotivated or difficult to reach students, was the most powerful source of Bandura's original three elements of social cognitive theory:

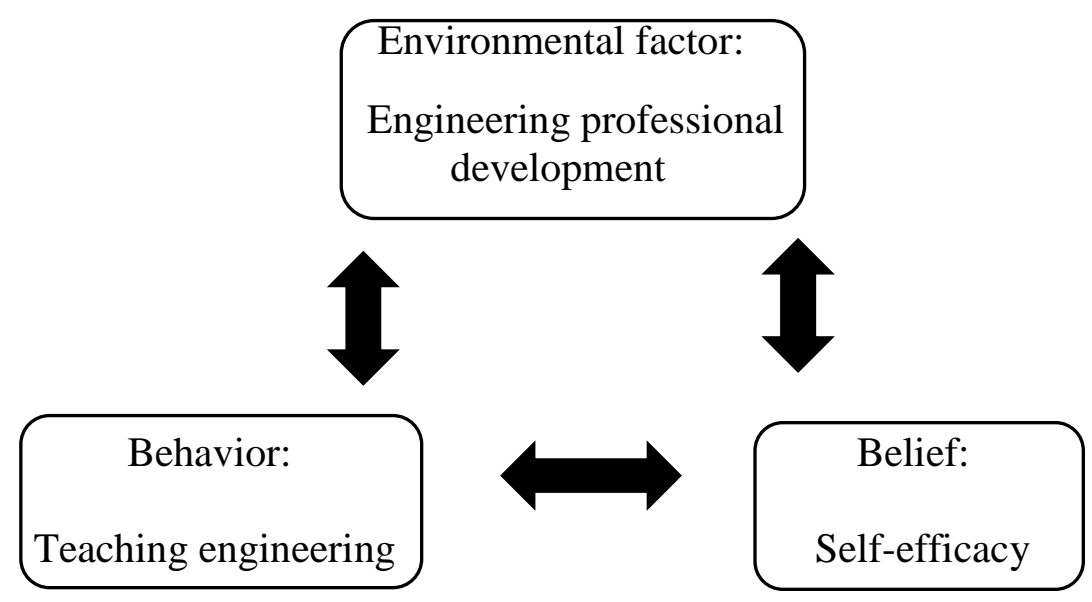

Revised version of Bandura's three elements of social cognitive theory:

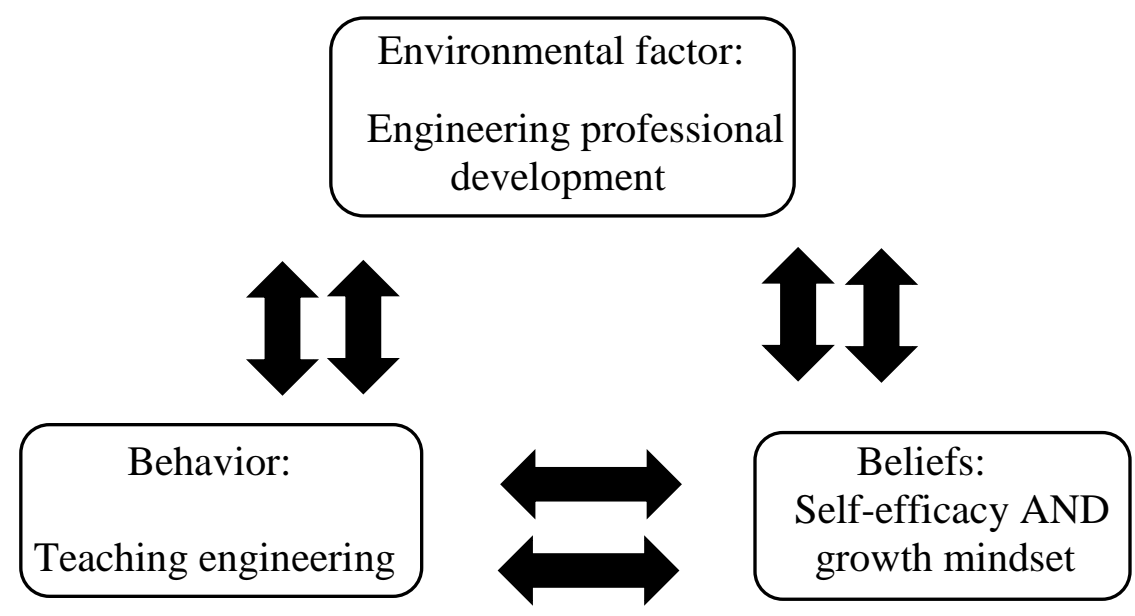

Figure 5.2 Webb's revision of Bandura's (1986) three elements of social cognitive theory teacher self-efficacy. Another compelling finding in this study was the identification of content-specific sources of teacher self-efficacy. The open-ended nature of and inherent value toward embracing failure and applying trial-and-error within the engineering design 
process were found to be significant sources of teacher self-efficacy. Notable is the finding that characteristics within teaching the engineering design process cultivated a growth mindset which appeared to boost the effect of the professional development experience on teachers' self-efficacy, motivation, and classroom practices.

\section{Implications}

This study has several implications regarding policy and practice in engineering professional development programs. Although the small sample size of this study makes it unwise to make generalizations, the positive shifts in teacher self-efficacy provided validation that the engineering professional development experience strengthened selfefficacy for the participants in this study. I argue that elements exist within the engineering professional development that resonated with elementary teachers and therefore represent potential features that could likewise positively influence other teachers to teach engineering. First, Desimone's (2009) critical features used to implement professional development are effective and should be replicated within the context of engineering professional development. Second, Bandura's (1986) wellestablished four sources of self-efficacy should be supported within the professional development experience. Third, the open-ended nature, views toward failure, and applying trial-and-error within the engineering design process should be explicitly taught to cultivate a growth mindset in professional development participants. Educational policy should support the creation of small scale engineering interventions that include measuring their effectiveness before replicating programs on a larger scale. In addition, it is important to note that all three of the above mentioned findings will contribute toward filling gaps in the literature because self-efficacy and especially sources of self- 
efficacy have not been examined within the context of engineering professional development.

Sustainability is a popular buzz word in education today. With regards to the practice of teacher engineering professional development, the concept of sustainability raises an important question: How does professional development foster enduring changes in teacher self-efficacy and instructional practices? I believe a central feature in creating sustained change involves a focus on teacher self-efficacy because of its effect on motivation and subsequent links to effort and performance. I also contend time is an important feature within engineering professional development. Interventions should continue to work with and support teachers through their implementation phase. Once teachers experience mastery and especially in the form of positive feedback from students, I assert that self-efficacy has the potential to sustain. Tschannen-Moran and McMaster (2009) examined sources of teacher self-efficacy within a professional development intervention promoting a new reading strategy. They addressed the problem of implementation dips in self-efficacy, whereby teacher self-efficacy can increase immediately after an intervention, but decrease during the implementation phase. This point supports the finding of this study that engineering professional development should continue within the implementation phase.

One limitation within this study was that self-efficacy was quantitatively measured only before and after the one-week course. Qualitative evidence suggested that self-efficacy endured because teachers were supported during implementation. Further studies should be conducted that quantitatively measure teacher self-efficacy to teach 
engineering at intervals beyond a one-week intervention. Also, inservice elementary teachers were the subjects of this study. Future studies should be conducted on the effects of engineering education taught within methods courses on preservice teachers' self-efficacy to teach engineering.

A significant implication from this study was the discovery that teaching inherent elements of the engineering design process cultivated a growth mindset for participants within the professional development, which was found to be a tremendous source of selfefficacy. Further research should be conducted on whether or not the teaching of the engineering design process can help cultivate growth mindsets in P-12 students.

Dweck's (2006) study with college students suggests such research could hold significant implications within STEM education. Dweck (2006) investigated the effects of a growth versus fixed mindset on females taking a Calculus class. She found the females with a disposition of a growth mindset felt a greater sense of belonging and persistence when faced with challenges compared to females with a fixed mindset. Challenges included stereotype threat, which Steele (1997) described as when a person is in a situation where they perceive themselves to be treated or judged by a stereotype. Dweck's (2006) study focused on the stereotype that males perform better in math than females. Pawlina and Stanford (2011) added that developing a growth mindset helps children foster coping skills and resiliency. Clearly, growth mindset is a belief influencing motivation, which in turn effects a person's effort, resiliency, and persistence. As such, can cultivating a growth mindset in underrepresented minority groups be a crucial key to helping students 
be more resilient through barriers and persist in STEM learning and careers? I strongly assert that further research should explore this question.

\section{Summary}

Engineering is a new dimension of content within the NGSS (NGSS, 2013). As such, P-12 teachers working in states that have adopted the NGSS will be required to teach engineering. Yet, review of the literature showed that elementary teachers feel inadequately prepared to teach science let alone engineering. This situation demands solutions to better prepare elementary teachers to teach engineering. Well-established research points to professional development as a key part in solving a problem such as this (Desimone, 2009; Guskey, 1986). The intention of engineering professional development is to create sustainable changes in teacher practices such that elementary teachers feel confident to teach engineering. Thus, the aim of this study was to examine the construct of self-efficacy within the context of engineering professional development. The rationale was based upon evidence showing self-efficacy to be a motivational construct that can influence teacher efforts and behaviors. It is striking that the construct of self-efficacy or sources of self-efficacy have not been investigated within the context of engineering professional development. The results of this study confirm that a focus on content knowledge, pedagogical content knowledge, and self-efficacy are powerful elements to be part of and studied further within the context of engineering professional development. 


\section{References}

Antonio, A. L., Chang, M. J., Hakuta, K., Kenny, D A., Levin, S., \& Milem, J. F. (2004). Effects of racial diversity on complex thinking in college students. Psychological Science, 15(8), 507-510. doi: 10.1111/j.0956-7976.2004.00710.x

Appleton, K. (2008). Developing science pedagogical content knowledge through mentoring elementary teachers. Journal of Science Teacher Education, 19, 523545. doi: 10.1007/s10972-008-9109-4

Attride-Stirling, J. (2001). Thematic networks: An analytic tool for qualitative research. Qualitative Research, 1(3), 385-405.

Baker, D., Krause, S., Yasar, S., Roberts, C., \& Robinson-Kurpius, S. (2007). An intervention to address gender issues in a course on design, engineering, and technology for science educators. Journal of Engineering Education, 96(3), 213226.

Bandura, A. (1977). Self-efficacy: Toward a unifying theory of behavioral change. Psychological Review, 84, 191-215.

Bandura, A. (1982). Self-efficacy mechanism in human agency. American Psychologist, 37, 122-147. doi: 10.1037/0003-066X.37.2.122

Bandura, A. (1986). Social foundations of thought and action: A social cognitive theory. Englewood Cliffs, NJ: Prentice-Hall.

Bandura, A. (1997). Self-efficacy: The exercise of control. New York, NY: Freeman. 
Banilower, E. R., Smith, P. S., Weiss, I. R., Malzahn, K. A., Campbell, K. M., \& Weis, A. M. (2013). Report of the 2012 national survey of science and mathematics education. Chapel Hill: NC: Horizon Research. Retrieved from http://www.horizon-research.com/2012nssme/wp-content/uploads/2013/02/2012NSSME-Full-Report1.pdf

Bautista, N. U. (2011). Investigating the use of vicarious and mastery experiences in influencing early childhood education majors' self-efficacy beliefs. Journal of Science Teacher Education, 22, 333-349. doi: 10.1007/s10972-011-9232-5

Borko, H. (2004). Professional development and teacher learning: Mapping the terrain. Educational Researcher, 33(8), 3-15.

Braun, V., \& Clarke, V. (2006). Using thematic network analysis in psychology. Qualitative Research in Psychology, 3(2), 77-101. doi: 10.1191/1478088706qp0630a

Brophy, S., Klein, S., Portsmore, M., \& Rogers, C. (2008). Advancing engineering education in P-12 classrooms. Journal of Engineering Education, 97, 369-387. doi: 10.1002/j.2168-9830.2008.tb00985.x

Brown, D. B., Alford, B. L., Rollins, K. B., Stillisano, J. R., \& Waxman, H. C. (2013). Evaluating the efficacy of mathematics, science, and technology teacher preparation academies in Texas. Professional Development in Education, 39(5), 656-677. doi: 10.1080/19415257.2012.729221.

Brown, R., Brown, J., Reardon, K., \& Merrill, C. (2011). Understanding STEM: Current perceptions. Technology and Engineering Teacher, 70(6), 5-9. 
Bybee, R. W. (2009). K-12 engineering education standards: Opportunities and barriers. Workshop on Standards for K-12 Engineering Education. Washington, DC: National Academies Press.

Bybee, R. W. (2011). Scientific and engineering practices in K-12 classrooms: Understanding a framework for K-12 science education. Science Scope, 35(4), 3439.

Bybee, R.W., Taylor, J. A., Gardner, A., Van Scotter, P., Powell, J. C., Westbrook, A., \& Landes, N. (2006). The BSCS 5E instructional model: Origins and effectiveness. Colorado Springs, CO: Biological Sciences Curriculum Study.

Capobianco, B. M., \& Joyal, H. (2008). Practical strategies for incorporating professional development experiences in the classroom. Science and Children, 45(8), 22-26.

Carr, R. L., Bennett, L. D., \& Strobel, J. (2012). Engineering in the K-12 STEM standards of the 50 U.S. states: An analysis of presence and extent. Journal of Engineering Education, 101(3), 1-26.

Chang, M. J., Eagan, M. K., Lin, M. H., \& Hurtado, S. (2011). Considering the impact of racial stigmas and science identity: Persistence among biomedical and behavioral science aspirants. The Journal of Higher Education, 82(5), 564-596.

Creswell, J. W. (2009). Research design: Qualitative, quantitative, and mixed methods approaches ( $3^{\text {rd }}$ ed.). Thousand Oaks, CA: Sage.

Creswell, J. W. (2013). Qualitative inquiry and research design: Choosing among five approaches $\left(3^{\text {rd }}\right.$ ed.). Thousand Oaks, CA: Sage. 
Creswell, J. W., \& Miller, D. L. (2000). Determining validity in qualitative inquiry. Theory into Practice, 39(3), 124-130.

Creswell, J. H., \& Plano-Clark, V. L. (2011). Designing and conducting mixed methods research. Thousand Oaks, CA: Sage.

Csikszentmihalyi, M. (1988). The flow experience and its significance for human psychology. In M. Csikszentmihalyi \& I. S. Csikszentmihalyi (Eds.), Optimal experience: Psychological studies of flow in consciousness (pp. 15 - 35). New York, NY: Cambridge University Press.

Culver, D. E. (2012). A qualitative assessment of preservice elementary teachers' formative perceptions regarding engineering and $K-12$ engineering education (Master's thesis). Retrieved from http://lib.dr.iastate.edu/etd. (Paper 12888)

Cunningham, C. M., \& Carlsen, W. S. (2014). Teaching engineering practices. Journal of Science Teacher Education, 25, 197-210. doi: 10.1007/s10972-014-9380-5

Darling-Hammond, L., \& Adamson, F. (2013). Developing assessments of deeper learning: The costs and benefits of using tests that help students learn. Stanford, CA: Stanford University, Stanford Center for Opportunity Policy in Education.

Daugherty, J. L. (2012). Infusing engineering concepts: Teaching engineering design. Publications. Paper 170. Retrieved from http://digitalcommons.usu.edu/ncete_publications/170

Desimone, L. M. (2009). Improving impact studies of teacher's professional development: Toward better conceptualizations and measures. Educational Researcher, 38, 181-199. doi: 10.3102/0013189X0833114 
Dolle, J. R., Gomez, L. M., Russell, J. L., \& Bryk, A. S. (2013). More than a network: Building professional development communities for educational improvement. National Study of Education Yearbook, 112(2), 443-463.

Drennan, J., \& Hyde, A. (2008). Controlling response shift bias: The use of the retrospective pre-test design in the evaluation of a master's programme. Assessment and Evaluation in Higher Education, 33(6), 699-709.

Duncan, D., Diefes-Dux, H., \& Gentry, M. (2011). Professional development through engineering academies: An examination of elementary teachers' recognition and understanding of engineering. Journal of Engineering Education, 100(3), 520539.

Dweck, C. S. (2006). Mindset: The new psychology of success. New York, NY: Random House.

Dweck, C. S. (2010). Even geniuses work hard. Educational Leadership, 68(1), 16-20.

Enochs, L. G., \& Riggs, I. M. (1990). Further development of an elementary teaching belief instrument: A preservice elementary scale. School Science and Mathematics, 90(8), 694-705.

Ferrini-Mundy, J. (2013). Driven by diversity. Science, 340(6130), 278.

Field, A. (2013). Discovering statistics using SPSS (3 ${ }^{\text {rd }}$ ed.). London, England: Sage.

Friedman, T. L. (2005). The world is flat. New York, NY: Farrar, Straus and Giroux.

Fulp, S. L. (2002). The status of elementary school science teaching. Chapel Hill, NC: Horizon Research. Retrieved from http://www.horizon-research.com/reports/20 02/2000survey/elem_sci.php 
Gay, G., \& Howard, T. C. (2000). Multicultural teacher education for the $21^{\text {st }}$ century. The Teacher Educator, 36(1), 1-16, doi: 10.1080/08878730009555246.

Gay, G. (2002). Preparing for culturally responsive teaching. Journal of Teacher Education, 53(2), 106-116. doi: 10.1177/0022487102053002003

Gibson, S., \& Dembo, M. (1984). Teacher efficacy: A construct validation. Journal of Educational Psychology, 76, 569-582.

Guba, E. G., \& Lincoln, Y. A. (2005). Paradigmatic controversies, contradictions, and emerging confluences. In N, K. Denzin \& Y. S. Lincoln (Eds.), The Sage handbook of qualitative research ( $3^{\text {rd }}$ ed.) (pp.191-215). Thousand Oaks, CA: Sage.

Guskey, T. R. (1986). Staff development and the process of teacher change. Educational Researcher, 15(5), 5-12.

Guskey, T. R. (2003). What makes professional development effective? Phi Delta Kappan, 84(10), 748-750.

Haney, J. J., Lumpe, A. T., Czerniak, C. M., \& Egan, V. (2002). From beliefs to actions: The beliefs and actions of teachers implementing change. Journal of Science Teacher Education, 13, 171-187. doi: 10.1023/A:1016565016116

Harlow, D. B. (2014). An investigation of how a physics professional development course influenced the teaching practices of five elementary school teachers. Journal of Science Teacher Education, 25, 119-139. Doi: 10.1007/s10972-013$9346-2$ 
Harrison, J., MacGibbon, L., Morton, M. (2001). Regimes of trustworthiness in qualitative research: The rigors of reciprocity. Qualitative Inquiry, 7, 323-345.

Heck, D. J., Rosenberg, S. L., \& Crawford, R. A. (2006). LSC teacher questionnaire study: A longitudinal analysis of data collected between 1997 and 2006. Chapel Hill, NC: Horizon Research.

Heller, J. I., Shinohara, M., Miratrix, L., Hesketh, S. R., \& Daehler, K. R. (2010, March). Learning science for teaching: Effects of professional development on elementary teachers, classrooms, and students. Paper presented at the Society for Research on Education Effectiveness Conference, Washington, DC. Abstract retrieved from http://www.files.eric.ed.gov/fulltext/ED514193.pdf

Henson, R. K. (2002). From adolescent angst to adulthood: Substantive implications and measurement dilemmas in the development of teacher efficacy research. Educational Psychologist, 37, 137-150.

Henson, R. K., Kogan, L. R., \& Vacha-Haase, T. (2001). A realiability generalization study of the teacher efficacy scale and related instruments. Educational and Psychological Measurement, 61, 404-420.

Hsu, M., Cardella, M., \& Purzer, S. (2010, June). Assessing elementary teachers’ design knowledge before and after introduction of a design process model. Paper presented at the 2010 American Society for Engineering Education Conference, Louisville, KY.

Johnson, H., \& Cotterman, M. (2013, November). Collaborative efforts to put the 'E' back in STEM. NSTA Reports, p. 3. 
Katehi, L., Pearson, G., \& Feder, M. (2009). Engineering in K-12 education: Understanding the status and improving the prospects. Washington, DC: The Academies Press.

Kapur, M., \& Bielaczyc, K. (2012). Designing for productive failure. The Journal of the Learning Sciences, 21, 45-83. doi: 10.1080/10508406.2011.591717

Keeley, P. (2011). With a purpose. Science and Children, 48(9), 22-25.

Kieffer, K. M., \& Henson, R. K. (2000, April). Development and validation of the sources of self-efficacy inventory (SOSI): Exploring a new measure of teacher efficacy. Paper presented at the Annual Meeting of the National Council on Measurement in Education, New Orleans, LA.

Kim, K. H. (2011). The creativity crisis: The decrease in creative thinking scores on the Torrance Tests of Creative Thinking. Creativity Research Journal, 23, 285-295. doi: 10.1080/10400419.2011.627805

Klassen, R. M., Tze, V. M. C., Betts, S. M., \& Gordon, K. A. (2011). Teacher efficacy research 1998-2009: Signs of progress or unfulfilled promise? Educational Psychological Review, 23, 21- 43. doi: 10.1007/s10648-010-9141-8

Krathwohl, D. R. (2009). Methods of educational and social science research: The logic of methods ( $3^{\text {rd }}$ ed.). Long Grove, IL: Waveland Press.

Lakshmanan, A., Heath, B. P., Perlmutter, A., \& Elder, M. (2011). The impact of science content and professional learning communities on science teaching efficacy and standards-based instruction. Journal of Research in Science Teaching, 48(5), 534551. 
Lammi, M., \& Becker, K. (2013). Engineering design thinking. Journal of Technology Education, 24(2), 55-77.

Laskey, D., \& Yoon, S. (2011). Making space for the act of making: Creativity in the engineering design classroom. Science Educator, 20(1), 34-43.

Lee, C. A., \& Houseal, A. (2003). Self-efficacy, standards, and benchmarks as factors in teaching elementary school science. Journal of Elementary Science Education, 15(1), 37-56.

Lincoln, Y. S., \& Guba, E. G. (1985). Naturalistic inquiry. Beverly Hills, CA: Sage.

Liu, W., Carr, R. L., \& Strobel, J. (2009). Extending teacher professional development through an online learning community: A case study. Journal of Educational Technology Development and Exchange, 2(1), 99-112.

Lord, M. (2011). Gimme an E.... Prism, 20(6), 33-34.

Mativo, J. M., \& Park, J. H. (2012). Innovative and creative K-12 engineering strategies: Implications of preservice teacher survey. Journal of STEM Education, 13(5), 2629.

Maxwell, J. A. (2013). Qualitative research design: An interactive approach ( $\left.{ }^{\text {rd }} \mathrm{ed}.\right)$. Thousand Oaks, CA: Sage.

McMurrer, J. (2008). Instructional time in elementary schools: A closer look at changes for specific subjects. Washington, DC: Center on Education Policy. doi: 10.3200/AEPR.109.6.23-28 
Melguizo, T., \& Wolniak, G. C. (2012). The earnings benefits of majoring in STEM fields among high achieving minority students. Research in Higher Education, 53, 383-405. doi: 10.1007/s11162-011-9238-2

Mendoza-Diaz, N. V., \& Cox, M. F. (2012). An overview of the literature: Research in P12 engineering education. Advances in Engineering Education, 3(2), 1-37.

Mendoza-Diaz, N. V., Cox, M. F., \& Adams, S. G. (2013). Elementary educator's perceptions of design, engineering, and technology: An analysis by ethnicity. Journal of STEM Education, 14(3), 13-21.

Milner, A. R., Sondergeld, T. A., Demir, A., Johnson, C. C., \& Czerniak, C. M. (2012). Elementary teachers' beliefs about teaching science and classroom practice: An examination of pre/post NCLB testing in science. Journal of Science Teacher Education, 23, 111-132. doi: 10.1007/s10972-011-9230-7

Mintzes, J. J., Marcum, B., Messerschmidt-Yates, C., Mark, A. (2013). Enhancing selfefficacy in elementary science teaching with professional learning communities. Journal of Science Teacher Education, 24, 1201-1218. doi: 10.1007/s10982-0129320-1

Moman-Powell, A. D., \& Brown-Schild, V. B. (2011). The inflence of a two-year professional development institute on teacher self-efficacy and use of inquirybased instruction. Science Educator, 20(2), 47-53. 
Moore, T. J., Tank, K. M., Glancy, A. W., Kersten, J. A., \& Ntow, F. D. (2013, June). The status of engineering in the current $K-12$ state science standards (Research to practice). Paper presented at the $120^{\text {th }}$ American Society for Engineering Education Conference and Exposition, Atlanta, GA.

Morgan, D. L. (2007). Paradigms lost and pragmatism regained: Methodological implications of combining qualitative and quantitative methods. Journal of Mixed Methods Research, 1, 48-76.

Morgan, D. L. (2013). Integrating qualitative and quantitative methods: A pragmatic approach. Thousand Oaks, CA: Sage.

Mundry, S. (2005). Changing perspectives in professional development. Science Educator, 14(1), 9-15.

Museus, S. D., Palmer, R. T., Davis, R. J., \& Maramba, D. C. (2011). Racial and ethnic minority students' success in STEM education. Hoboken, NJ: Jossey-Bass.

Nadelson, L. S., Callahan, J., Pyke, P., Hay, A., Dance, M., \& Pfiester, J. (2013). Teacher STEM perception and preparation: Inquiry-based STEM professional development for elementary teachers. The Journal of Educational Research, 106(2), 157- 168. doi: 10.1080/00220671.2012.667014

Nadelson, L. S., \& Farmer, C. (2012, Summer). Developing standards for teaching engineering. NSTA Reports, p. 3.

Nadelson, L. S., Seifert, A., Moll, A. M., Coats, B. (2012). I-STEM summer institute: An integrated approach to teacher professional development in STEM. Journal of STEM Education, 13(2), 69-83. 
National Research Council. (1996). National Science Education Standards. Washington, DC: National Academy Press.

National Research Council. (2007a). Ready, set, SCIENCE! : Putting research to work in K-8 science classrooms. Washington, DC: The National Academies Press.

National Research Council. (2007b). Rising above the gathering storm: Energizing and emplying America for a brighter economic future. Washington, DC: National Academies Press.

National Research Council. (2011). Successful K-12 STEM education: Identifying effective approaches in science, technology, engineering, and mathematics. Washington, DC: The National Academies Press.

National Research Council. (2012). A framework for K-12 science education: Practices, crosscutting concepts, and core ideas. Committee on a Conceptual Framework for New K-12 Science Education Standards. Board on Science Education, Division of Behavioral and Social Sciences and Education. Washington, DC: The National Academy Press.

NGSS Lead States. (2013). Next generation science standards: For states, by states. Washington, DC: The National Academies Press.

Pajares, M. F. (1992). Teachers' beliefs and educational research: Cleaning up a messy construct. Review of Educational Research, 62(3), 307-332.

Palmer, D. H. (2006). Sources of self-efficacy in a science methods course for primary teacher education students. Research in Science Education, 36, 337-353. doi: $10.1007 / \mathrm{s} 11165-005-9007-0$ 
Palmer, D. H. (2011). Sources of efficacy information in an inservive program for elementary teachers. Science Education, 95, 577-600. doi: 10.1002/sce.20434

Park, S., \& Oliver, J. S. (2008). Revisiting the conceptualisation of pedagogical content knowledge (PCK): PCK as a conceptual tool to understand teachers as professionals. Research in Science Education, 38, 261-284. doi: 10.1007/s11165007-9049-6

Pawlina, S., \& Stanford, C. (2011). Preschoolers grow their brains: Shifting mindsets for greater resilency and better problem-solving. Young Children, 66(5), 30-35.

Pecore, J. L., Kirchgessner, M. L., \& Carruth, L. L. (2013). Changes in science content knowledge and attitudes toward science teaching of educators attending a zoobased neuroscience professional development. The Clearing House, 86(6), 238245. doi: $10.1080 / 00098655.2013 .826527$

Petty, E. R. (1983). Engineering curricula for encouraging creativity and innovation. European Journal of Engineering Education, 8(1), 29-43. doi: 10.1080/03043798308903541

Plano-Clark, V. L., \& Creswell, J. W. (2010). Understanding research: A consumer's guide. Boston, MA: Pearson.

Posnanski, T. J. (2002). Professional development programs for elementary science teachers: An analysis of teacher self-efficacy beliefs and a professional development model. Journal of Science Teacher Education, 13, 189-220. 
Pratt, H. (2012). The NSTA reader's guide to a framework for $k$-12 science education: Practices, crosscutting concepts, and core ideas. Arlington, VA: National Science Teachers Association Press.

President's Council of Advisors on Science and Technology, STEM Undergraduate Education Working Group, Gates, S. J., Handelsman, J., Lepage, G. P., \& Mirkin. (2012). Engage to Excel: Producing one million additional college graduates with degrees in science, technology, engineering, and mathematics. President's Council of Advisors on Science and Technology. Retrieved from http://www.whitehouse.gov/sites/default/files/microsites/ostp/pcast-engage-toexcel-final_2-25-12.pdf

Ramsey-Gassert, L., Shroyer, M. G., \& Staver, J. R. (1996). A qualitative study of factors influencing science teaching self-efficacy of elementary level teachers. Science Education, 80, 283-315. doi: 10.1002/(SICI)1098-237X(199606)80:3<283::AIDSCE2>3.0.CO;2-A

Riggs, I., \& Enochs, L. (1990). Toward the development of an elementary teacher's science teaching efficacy belief instrument. Science Education, 74, 625-637. doi: $10.1002 /$ sce. 3730740605

Rockland, R., Bloom, D. S., Carpinelli, J., Burr-Alexander, L., Hirsch, L. S., \& Kimmel, H. (2010). Advancing the "E" in K-12 STEM education. Journal of Technology Studies, 36(1), 53-64. 
Ross, J., \& Bruce, C. (2007). Professional development effects on teacher efficacy: Results of randomized field trial. The Journal of Educational Research, 101(1), 50-60. doi: 10.3200/JOER.101.1.50-60

Sanders, D. (2014, May). Revealing the creative side of engineering. NSTA Reports, 25(9), 3.

Sanders, M. (2009). STEM, STEM education, STEMmania. The Technology Teacher, 69(4), 20-26.

Sandholtz, J. H., \& Ringstaff, C. (2011). Reversing the downward spiral of science instruction in K-2 classrooms. Journal of Science Teacher Education, 22, 513533. doi: 10.1007/s 10972-011-9246-Z

Sandholtz, J. H., \& Ringstaff, C. (2013). Assessing the impact of teacher professional development on science instruction in the early elementary grades in rural US schools. Professional Development in Education, 39, 678-697. doi: $10.1080 / 19415257.2012 .751044$

Saxton, E., Burns, R., Holveck, S., Kelley, S., Prince, D., Rigelman, N., \& Skinner, E. A. (2013). A common measurement system for K-12 STEM education: Adopting an educational evaluation methodology that elevates theoretical foundations and systems thinking. Studies in Educational Evaluation, 40(1), 1-18.

Shulman, L. S. (1987). Knowledge and teaching: Foundations of the new reform. Harvard Educational Review, 57(1), 1-22. 
Sinclair, B. B., Naizer, G., \& Ledbetter, C. (2011). Observed implementation of a science professional development program for K-8 classrooms. Journal of Science Teacher Education, 22, 579-594.

Southerland, S. A., Sowell, S., \& Enderle, P. (2011). Science teachers' pedagogical discontentment: Its sources and potential for change. Journal of Science Teacher Education, 22, 437-457. doi: 10.1007/s10972-011-9242-3

Steele, C. M. (1997). A threat in the air: How stereotypes shape intellectual identity and performance. American Psychologist, 52(6), 613-629.

Stouffer, W. B., Russell, J. S., \& Olivia, M. G. (2004). Making the strange familiar: Creativity and the future of engineering education. Proceedings of the 2004 American Society for Engineering Education Annual Conference and Exposition, Salt Lake City, UT.

Sun, Y., Boots, N., \& Strobel, J. (2012, June). EEE (Elementary engineering education) adoption and expertise development model: Conceptualizing, assessing, and tracking elementary teachers' EEE adoption and EEE expertise development. Paper presented at the 2012 American Society for Engineering Education Annual Conference and Exposition, San Antonio, TX.

Supovitz, J. A., \& Turner, H. M. (2000). The effects of professional development on science teaching practices and classroom culture. Journal of Research on Science Teaching, 37(9), 963-980. 
Tornkvist, S. (1998). Creativity: Can it be taught? The case of engineering education. European Journal of Engineering Education, 23(1), 5-12. doi: $10.1080 / 0304379980230102$

Trueman, R. J. (2013). Productive failure in STEM education. Journal of Educational Technology Systems, 42(3), 199-214.

Tschannen-Moran, M., Woolfolk-Hoy, A., \& Hoy, W. K. (1998). Teacher efficacy: Its meaning and measure. Review of Educational Research, 68(2), 202-248.

Tschannen-Moran, M., \& Hoy, A. W. (2001). Teacher efficacy: Capturing an elusive construct. Teaching and Teacher Education, 17(7), 783- 805.

Tschannen-Moran, M., \& Woolfolk-Hoy, A. (2007). The differential antecedents of selfefficacy beliefs of novice and experienced teachers. Teaching and Teacher Education, 23, 944-956. doi: 10.10016/j.tate.2006.05.003

Tschannen-Moran, M., \& McMaster, P. (2009). Sources of self-efficacy: Four professional development formats and their relationship to self-efficacy and implementation. The Elementary School Journal, 110(2), 228-245.

U.S. Department of Commerce, Economics and Statistics Administration. (2011). STEM: Good jobs now and for the future (ESA Issue Brief No. 03-11). Retrieved from http://www.esa.doc.gov/sites/default/files/reports/documents/stemfinaljuly14_1.p df

Vasquez, J. A., Sneider, C., \& Comer, M. (2013). STEM lesson essentials: Integrating science, technology, engineering, and mathematics. Portsmouth, NH: Heinemann. 
Vogt, W. P., Gardner, D C., \& Haeffele, L. M. (2012). When to use what research design. New York, NY: Guilford Press.

Wills, I. (2007). Instrumentalizing failure: Edison's invention of the carbon microphone. Annals of Science, 64(3), 383-409, doi: 10.1080/00033790601160515.

Wilson, S. M. (2013). Professional development for science teachers. Science, 340(6130), 310-313.

Woolfolk-Hoy, A., \& Spero, R. B. (2005). Changes in teacher efficacy during the early years of teaching: A comparison of four measures. Teaching and Teacher Education, 21, 343-356.

Wojnowski, B. S., \& Pea, C. H. (Ed.). (2014). Models and approaches to STEM professional development. Arlington, VA: National Science Teachers Association Press.

Yasar, S., Baker, D., Robinson-Kurpius, S., Krause, S., \& Roberts, C. (2006). Development of a survey to assess K-12 teachers' perceptions of engineers and familiarity with teaching design, engineering, and technology. Journal of Engineering Education, 95(3), 205-216.

Yoon, S. Y., Diefes-Dux, H., \& Strobel, J. (2013). First-year effects of an engineering professional development program on elementary teachers. American Journal of Engineering Education, 4(1), 67-83.

Yu, J. H., Luo, Y., Sun, Y., \& Strobel, J. (2012). A conceptual K-6 teacher competency model for teaching engineering. Procedia-Social and Behavioral Sciences, 56, 243-252. 


\title{
Appendix A
}

\section{Advancing STEM Instruction through Engineering Design Agenda}

\author{
(Revised 7/29/14) \\ Summer Term 2014: 3 PSU Graduate Credits \\ 2014-15 School Year Follow-Up Sessions: 1 PSU graduate credit \\ August 18-22 (Monday - Friday) 9:00 AM - 4:00 PM \\ Location: Intel STEM Center, 18624 NW Walker Rd. Beaverton, OR 97006
}

Course Description: The purpose of the course is to provide learning experiences in the practices of engineering design as applied to a select number of core ideas in science as described in the Next Generation Science Standards (NGSS). Participants will learn the vertical progression of the standards and practices along with detailed grade level specific engineering design embedded lessons. A key part of the course will be learning how to instruct and assess student progress towards the engineering components of the standards. Teachers will learn strategies, including culturally responsive practices, to support all students in becoming STEM curious, capable, and confident in their everyday lives. Also, different types of engineering careers will be presented so teachers may encourage students toward such careers.

\section{Goals for the course are that the participants are able to:}

1) Increase their pedagogical content knowledge and confidence in teaching the engineering aspects of the NGSS by:

- Describing how disciplinary core ideas in the NGSS progress across grades K8.

- Identifying similarities and differences between science and engineering practices.

- Providing an example of an engineering design process model from the Engineering is Elementary curriculum.

- Giving examples to illustrate the meaning of technology and engineering.

- Illustrating how science and engineering drive each other forward.

- Providing examples of how to combine the three dimensions of the NGSS.

- Planning an engineering lesson based on the $5 \mathrm{E}$ instructional model.

2) Describe culturally responsive teaching strategies they can use when teaching engineering with a diverse group of students.

3) Communicate opportunities for good jobs that require STEM education. 


\section{Day 1 Engineering and the Science of Ecosystems}

Crosscutting Concept: Systems

Goals for the Day-Participants are able to:

1) Increase their pedagogical content knowledge and confidence in teaching the engineering aspects of the NGSS by:

- Describing how disciplinary core ideas in the NGSS progress across grades K8.

- Identifying similarities and differences between science and engineering practices.

- Providing an example of an engineering design process model from the Engineering is Elementary curriculum

- Giving examples to illustrate the meaning of technology and engineering.

2) Describe culturally responsive teaching strategies they can use when teaching engineering with a diverse group of students.

\section{9:00 Introductions / Consent forms / Pre-Test}

10:00 Overview of the week / Goals of course Why Engineering?

\section{0:15 Technology in a Bag Challenge: What is technology? What is engineering?}

Participants discuss "What comes to mind when you hear the word technology?" "What might your students think of when they hear that word?" Then they work in pairs to choose an object from a bag and discuss: What is this technology? What does it do or what problem does it solve? How else could you use it? What materials are used to make your technology? What other materials could be used to make this technology? What are the benefits of one material over another? How does the shape and material of your object contribute to its function?

Define technology as anything human-made, used to solve a problem or to fulfill a desire. Technology can be an object, a system, or a process.

Discuss the engineering design process, and the EiE curriculum.

10:45 Break

\section{1:00 Ecosystems: Second Grade - Design a Pollinator}

Participants discuss crosscutting concept of a system, using the example of a juice pouch.

Engineering Challenges: 1) Design a device that replicates the pollination function of an animal. 2) Design a device that replicates the seed dispersal function of an animal. 
Performance Expectation:

2-LS2-2. Develop a simple model that mimics the function of an animal in dispersing seeds or pollinating plants.

\section{What are Performance Expectations and why should we care?}

Noon Lunch

\section{1:00 Ecosystems: Fifth Grade - Food Cart Ecosystem}

Engineering Challenge: Draw an ecosystem of a food cart that includes plants, animals, and decomposers. Plans should include systems in place to deal with hygiene, safety, and recycling or reuse of materials.

Performance Expectations:

5-LS1-1. Support an argument that plants get the materials they need for growth chiefly from air and water. [Clarification Statement: Emphasis is on the idea that plant matter comes mostly from air and water, not from the soil.]

5-LS2-1. Develop a model to describe the movement of matter among plants, animals, decomposers, and the environment. [Clarification Statement: Emphasis is on the idea that matter that is not food (air, water, decomposed materials in soil) is changed by plants into matter that is food. Examples of systems could include organisms, ecosystems, and the Earth.] [Assessment Boundary: Assessment does not include molecular explanations.]

\section{1:45 Ecosystems: Middle School - Travis Creek}

Engineering Challenge: Teachers view overhead map of Travis Creek and familiarize themselves with its problematic features, specifically when there are heavy rains. In groups of 2-3, teachers will work together to decide how to modify the area surrounding the creek (at least two different modifications). Teachers use copies of the map and markers to illustrate their design. Then share with each other. Teachers pick one design to create using cardboard, Popsicle sticks, clay, sponges, and tape.

Performance Expectation:

MS-LS2-5. Evaluate competing design solutions for maintaining biodiversity and ecosystem services. [Clarification Statement: Examples of ecosystem services could include water purification, nutrient recycling, and prevention of soil erosion. Examples of design solution constraints could include scientific, economic, and social considerations.]

\section{2:45 Listening to Student Ideas}

View "Minds of Our Own: Lessons from Thin Air" video. Reflect on the importance of listening to our students ideas, so as to recognize barriers to learning. Note connection between physical science (in this case understanding that air has weight) and life science (photosynthesis). Discuss "evaluative 
listening" vs. "interpretive listening. ” Discuss definition of culturally responsive teaching and the importance of listening to different perspectives of students.

Review how the activities provide a good example of systems and system models.

3:30 Reflection: What did we learn today about how core ideas of ecosystems progress through the grade levels? About the progression of practices? About crosscutting concepts?

3:45 Evaluation of the day's activities (plus-delta cards)

4:00 Workshop ends 


\section{Day 2 Engineering and the Science of Waves and Communication}

Crosscutting Concept: Patterns, Structure \& Function, Influence of Technology on Society

\section{9:00 Response to yesterday's evaluations}

Goals for the Day—Participants are able to:

1) Increase their pedagogical content knowledge and confidence in teaching the engineering aspects of the NGSS by:

- Describing how disciplinary core ideas in the NGSS progress across grades K8.

- Identifying similarities and differences between science and engineering practices.

- Giving examples to illustrate the meaning of technology and engineering.

- Illustrating how science and engineering drive each other forward.

- Planning an engineering lesson based on the 5E instructional model.

2) Describe culturally responsive teaching strategies they can use when teaching engineering with a diverse group of students.

\section{9:15 Waves and Their Applications: First Grade - Good Vibrations}

Instructor introduces the 5E instructional model, pointing out how we have used it in prior lessons: Engage, Explore, Explain, Elaborate, and Evaluate (reflect and assess).

Participants view video about sound and discuss how vibrations create sounds. Also discuss properties of sound waves, including pitch and volume. They then work in teams plan and carry out investigations to determine the effects of different materials on "paper cup telephones," and share their findings.

Engineering Challenge: Apply data from all of the teams who studied the effects of different materials to design a telephone system between two tree houses.

Performance Expectations:

1-PS4-1. Plan and conduct investigations to provide evidence that vibrating materials can make sound and that sound can make materials vibrate. [Clarification Statement: Vibrating materials that make sound could include tuning forks and plucking a stretched string. Examples of how sound can make matter vibrate could include holding a piece of paper near a speaker making sound and holding an object near a vibrating tuning fork.]

1-PS4-4. Use tools and materials to design and build a device that uses light or sound to solve the problem of communicating over a distance.* [Clarification Statement: Examples of devices could include a light source to send signals, paper 
cup and string "telephones," and a pattern of drum beats.] [Assessment Boundary: Assessment does not include technological details for how communication devices work.]

\section{0:15 The 4E x 2 Model and Culturally Responsive Teaching Strategies}

Reflect on previous activities, noting how they incorporate the $5 \mathrm{E}$ model for sequencing STEM lessons.

Review list of culturally responsive teaching strategies. Teachers share the demographic background of their students and discuss specific strategies they could implement.

10:30 Break

\section{0:45 Waves and Their Applications: Fourth Grade - Properties of Waves}

Create waves with Slinky's, ropes, water, and other media and develop a model (drawing) of how waves with different wavelengths and amplitudes cause objects to move.

"View" an object in complete darkness, and with gradually increasing amounts of light, and see how the object appears to change. They then draw a ray of light from where it leaves its source to where it enters their eye. The use their model to explain how we see.

Discuss why sound and light are considered to be waves.

Performance Expectations:

4-PS4-1. Develop a model of waves to describe patterns in terms of amplitude and wavelength and that waves can cause objects to move. [Clarification Statement: Examples of models could include diagrams, analogies, and physical models using wire to illustrate wavelength and amplitude of waves.] [Assessment Boundary: Assessment does not include interference effects, electromagnetic waves, non-periodic waves, or quantitative models of amplitude and wavelength.]

4-PS4-2. Develop a model to describe that light reflecting from objects and entering the eye allows objects to be seen. [Assessment Boundary: Assessment does not include knowledge of specific colors reflected and seen, the cellular mechanisms of vision, or how the retina works.]

Noon Lunch

1:00 Waves and Their Applications: Fourth Grade - Sending Pictures with Light

Participants learn about how SETI scientists decided to decipher messages from other worlds by assuming that mathematics would be a common language, so that 
messages could be sent based on the idea that a repeating message that had a number of characters what is a product of two prime numbers could be interpreted.

Engineering Challenge: Participants design and send messages using a 5 x 7 grid, using flashlights to send the message over a distance.

Performance Expectation:

4-PS4-3. Generate and compare multiple solutions that use patterns to transfer information. [Clarification Statement: Examples of solutions could include drums sending coded information through sound waves, using a grid of 1's and 0's representing black and white to send information about a picture, and using Morse code to send text.]

\section{3:00 Waves and Their Applications: Middle School - Digital Vs. Analog}

Learn how to write binary numbers - the "language" of computers.

View a binary image display up-close.

Performance Expectation:

MS-PS4-3. Integrate qualitative scientific and technical information to support the claim that digitized signals (sent as wave pulses) are a more reliable way to encode and transmit information. [Clarification Statement: Emphasis is on a basic understanding that waves can be used for communication purposes. Examples could include using fiber optic cable to transmit light pulses, radio wave pulses in wifi devices, and conversion of stored binary patterns to make sound or text on a computer screen.] [Assessment Boundary: Assessment does not include binary counting. Assessment does not include the specific mechanism of any given device.]

3:30 Reflection: What did we learn today about how core ideas of waves and communication progress through the grade levels? About the progression of practices? About crosscutting concepts?

\section{3:45 Evaluation of the day's activities}

\section{4:00 Workshop ends}




\section{Day 3 Engineering and the Science of Astronomy}

Crosscutting Concepts: Patterns, and Systems and System Models

And Interdependence of Engineering, Technology, and Science

\section{9:00 Response to yesterday's evaluations}

Goals for the Day_Participants are able to:

1) Increase their pedagogical content knowledge and confidence in teaching the engineering aspects of the NGSS by:

- Illustrating how science and engineering drive each other forward.

- Describing how disciplinary core ideas in the NGSS progress across grades K-8.

- Identifying similarities and differences between science and engineering practices.

- Giving examples to illustrate the meaning of technology and engineering.

- Illustrating how science and engineering drive each other forward.

2) Describe culturally responsive teaching strategies they can use when teaching engineering with a diverse group of students.

\section{9:15 Progression of Disciplinary Core Ideas in the NGSS}

Instructor hands out Appendix E of the NGSS and explains how to use it. Focus on the progression of core ideas in astronomy.

\section{9:30 Earth's Place in the Universe: First Grade - Observing the Sky}

Participants trace the shadow of a gnomon (vertical rod) for an hour or two around noontime (outdoors if skies are clear, inside with a lamp if it's cloudy) and discuss how to use what they learned to make a sundial. Participants also discuss how to help first graders note changes in daily motion in the sky, as well as the amount of sunlight over a year's time.

Engineering Challenge: How can we use these findings to make a sundial to tell time?

1-ESS1-1. Use observations of the sun, moon, and stars to describe patterns that can be predicted. [Clarification Statement: Examples of patterns could include that the sun and moon appear to rise in one part of the sky, move across the sky, and set; and stars other than our sun are visible at night but not during the day.] [Assessment Boundary: Assessment of star patterns is limited to stars being seen at night and not during the day.]

1-ESS1-2. Make observations at different times of year to relate the amount of daylight to the time of year. [Clarification Statement: Emphasis is on relative 
comparisons of the amount of daylight in the winter to the amount in the spring or fall.] [Assessment Boundary: Assessment is limited to relative amounts of daylight, not quantifying the hours or time of daylight.]

10:15 Break

\section{0:30 Earth's Place in the Universe: Fifth Grade - Earth in the Solar System}

Participants view and then discuss video "A Private Universe," that illustrates even top students may not understand astronomical phenomena at a deep level.

Participants discuss their responses to a series of Probes, including:

1 Is the Earth Really Round?

2 Where Do People Live?

3 Falling Through the Earth

4 What Causes Night and Day?

8 No Shadow

19 Earth or Moon Shadow?

20 Moon Phase and Solar Eclipse

35 Is the Sun a Star?

Performance Expectations:

5-PS2-1. Support an argument that the gravitational force exerted by Earth on objects is directed down. [Clarification Statement: "Down" is a local description of the direction that points toward the center of the spherical Earth.] [Assessment Boundary: Assessment does not include mathematical representation of gravitational force.]

5-ESS1-1. Support an argument that differences in the apparent brightness of the sun compared to other stars is due to their relative distances from Earth. [Assessment Boundary: Assessment is limited to relative distances, not sizes, of stars. Assessment does not include other factors that affect apparent brightness (such as stellar masses, age, stage).]

5-ESS1-2. Represent data in graphical displays to reveal patterns of daily changes in length and direction of shadows, day and night, and the seasonal appearance of some stars in the night sky. [Clarification Statement: Examples of patterns could include the position and motion of Earth with respect to the sun and selected stars that are visible only in particular months.] [Assessment Boundary: Assessment does not include causes of seasons.]

\section{1:15 Earth's Place in the Universe: Middle School - The Universe}


Participants engage in a series of activities in which they collect data on daily motion and on the relationship between the Earth, Moon, and Sun over one full lunar cycle and use their bodies to model daily motion, moon phases and eclipses, and the changing constellations with the seasons. (The starting question is "What's my astrological sign, and why can't I see it on my birthday?")

Performance Expectation:

MS-ESS1-1. Develop and use a model of the Earth-sun-moon system to describe the cyclic patterns of lunar phases, eclipses of the sun and moon, and seasons. [Clarification Statement: Examples of models can be physical, graphical, or conceptual.]

Noon Lunch

\section{1:00 Interdependence of Science, Engineering, and Technology}

Participants engage in building a microscope and a telescope; observe how these tools are similar and different, and how they illustrate the interactions of science, engineering, and technology.

Crosscutting Concepts

K-2 Connections Statements

- Science and engineering involve the use of tools to observe and measure things.

\section{3-5 Connections Statements}

- Science and technology support each other.

- Tools and instruments are used to answer scientific questions, while scientific discoveries lead to the development of new technologies.

\section{3-5 Connections Statements}

- Science and technology support each other.

- Tools and instruments are used to answer scientific questions, while scientific discoveries lead to the development of new technologies.

6-8 Connections Statements

- Engineering advances have led to important discoveries in virtually every field of science and scientific discoveries have led to the development of entire industries and engineered systems.

- Science and technology drive each other forward.

3:30 Reflection: What did we learn today about how core ideas of Earth's place in the universe progress through the grade levels? About the progression of practices? 


\author{
About crosscutting concepts? \\ 3:45 Evaluation of the day's activities \\ 4:00 Workshop ends
}




\title{
Day 4 Engineering and the Science of Forces and Interactions
}

\author{
Crosscutting Concepts: Cause and Effect \\ 9:00 Response to yesterday's evaluations \\ Goals for the Day-Participants are able to: \\ 1) Increase their pedagogical content knowledge and confidence in teaching the \\ engineering aspects of the NGSS by: \\ - Describing how disciplinary core ideas in the NGSS progress across \\ grades K-12. \\ - Providing examples of how to combine the three dimensions of the NGSS. \\ - Illustrating how science and engineering drive each other forward.
}

\section{9:15 Forces and Interactions: Kindergarten - Pushes and Pulls}

Teachers use ramps, Playdoh, index cards, paper, and marbles to create an obstacle course that directs the direction of the marble as it rolls down the ramp. Teachers reflect on the experience; discuss problems that arose, how they fixed the problem, and what they did to be successful.

Performance Expectations:

K-PS2-1. Plan and conduct an investigation to compare the effects of different strengths or different directions of pushes and pulls on the motion of an object. [Clarification Statement: Examples of pushes or pulls could include a string attached to an object being pulled, a person pushing an object, a person stopping a rolling ball, and two objects colliding and pushing on each other.] [Assessment Boundary: Assessment is limited to different relative strengths or different directions, but not both at the same time. Assessment does not include noncontact pushes or pulls such as those produced by magnets.]

K-PS2-2. Analyze data to determine if a design solution works as intended to change the speed or direction of an object with a push or a pull. [Clarification Statement: Examples of problems requiring a solution could include having a marble or other object move a certain distance, follow a particular path, and knock down other objects. Examples of solutions could include tools such as a ramp to increase the speed of the object and a structure that would cause an object such as a marble or ball to turn.] [Assessment Boundary: Assessment does not include friction as a mechanism for change in speed.]

\section{0:00 Forces and Interactions: Third Grade - Action at a Distance}

Next, teachers are given materials (popsicle sticks, straws, wheels, axles, tape, pennies, string, index cards, timers, and measuring tape) and asked to design a 
car. The car is to roll down the ramp. Teams must specify the criteria, constraints, and explain how they built it and justify any design changes. Emphasis is on how changes to design result in different effects. (If...then.. statements). Reflection: How much time did you spend designing vs. modifying? Discussed introduction at $3^{\text {rd }}$ grade to introduce action-at-a-distance.

Performance Expectations:

3-PS2-1. Plan and conduct an investigation to provide evidence of the effects of balanced and unbalanced forces on the motion of an object. [Clarification

Statement: Examples could include that an unbalanced force on one side of a ball can make it start moving and that balanced forces pushing on a box from both sides will not produce any motion at all.] [Assessment Boundary: Assessment is limited to one variable at a time: number, size, or direction of forces. Assessment does not include quantitative force size, only qualitative and relative. Assessment is limited to gravity being addressed as a force that pulls objects down.]

3-PS2-4. Define a simple design problem that can be solved by applying scientific ideas about magnets. [Clarification Statement: Examples of problems could include constructing a latch to keep a door shut and creating a device to keep two moving objects from touching each other.]

10:30 Break

\section{0:45 How is engineering design related to science inquiry?}

- Reflecting on the morning activities

- Science and engineering practices from the NGSS

\section{1:00 Forces and Interactions: Middle School-Electromagnets}

Participants experiment with electromagnets to determine the factors that increase the strength of the electromagnets. They record and graph their results. Finally, they apply the results of their experiments to design an electromagnet that will pick up 1 ton of scrap iron and steel.

Performance Expectations:

MS-PS2-3. Ask questions about data to determine the factors that affect the strength of electric and magnetic forces. [Clarification Statement: Examples of devices that use electric and magnetic forces could include electromagnets, electric motors, or generators. Examples of data could include the effect of the number of turns of wire on the strength of an electromagnet, or the effect of increasing the number or strength of magnets on the speed of an electric motor.] [Assessment Boundary: Assessment about questions that require quantitative answers is limited to proportional reasoning and algebraic thinking.] 
MS-PS2-5. Conduct an investigation and evaluate the experimental design to provide evidence that fields exist between objects exerting forces on each other even though the objects are not in contact. [Clarification Statement: Examples of this phenomenon could include the interactions of magnets, electrically-charged strips of tape, and electrically-charged pith balls. Examples of investigations could include first-hand experiences or simulations.] [Assessment Boundary: Assessment is limited to electric and magnetic fields, and limited to qualitative evidence for the existence of fields.]

Noon Lunch

1:00 Forces and Interactions: Middle School - Electromagnets (continued)

1:30 Forces and Interactions: High School - Motors \& Generators

Participants build an electric motor using copper wire, paperclips, push pins, furniture slides, and batteries. They then take apart motors to see how they are constructed inside. Finally they use the motors as generators to produce an electric current.

Performance Expectation:

HS-PS2-5. Plan and conduct an investigation to provide evidence that an electric current can produce a magnetic field and that a changing magnetic field can produce an electric current. [Assessment Boundary: Assessment is limited to designing and conducting investigations with provided materials and tools.]

3:30 Reflection: What did we learn today about how core ideas of forces and interactions progress through the grade levels? About the progression of practices? About crosscutting concepts?

\section{3:45 Evaluation of the day's activities}

\section{4:00 Workshop ends}




\section{Day 5 Careers in Engineering \& Technology}

\section{9:00 Response to yesterday's evaluations}

Goals for the Day-Participants are able to:

1) Increase their pedagogical content knowledge and confidence in teaching the engineering aspects of the NGSS by:

- Describing how core disciplinary ideas in the NGSS progress across grades K8.

- Identifying similarities and differences between science and engineering practices.

- Giving examples to illustrate the meaning of technology and engineering.

- Illustrating how science and engineering drive each other forward.

- Providing examples of how to combine the three dimensions of the NGSS.

- Planning an engineering lesson based on the 5E instructional model.

2) Describe culturally responsive teaching strategies they can use when teaching engineering with a diverse group of students.

3) Communicate opportunities for good jobs that require STEM education.

9:15 Careers in Engineering \& Technology - Work Opportunities at Solar World and Dragonfly $T V$

\section{9:45 Classroom Planning}

Teachers reflect on the week's activities and plan their STEM program for the year, using questions such as:

- What is your assignment this coming year?

- Using the NGSS, what STEM units will you be teaching?

- What resources do you have to make a detailed plan?

- What resources do you still need?

10:30 Break

\section{0:45 School-wide Planning}

Discuss family engineering. Teachers engage in "Five Points" activity.

Noon Lunch

1:00 Planning time (continued)

Teachers continue to design their plans for next year.

\section{2:00 Post-Test and Teacher Efficacy Survey}




\section{Appendix B}

\section{Follow-Up Agenda}

8:00 - 8:15 am: Eat and greet. Registration forms.

8:15 - 9:00 am: Lesson share

Discuss lesson you brought connected to original course

1. Compass activity.

2. Share with a partner

3. Familiarize with the charts on Culturally Responsive Teaching and Lesson Planning

4. What aspects are already in the lesson?

5. How could this be made more culturally responsive by weaving some of these aspects into the lesson for the next time you teach it?

6. Whole group share

7. Discuss CRT strategy of using everyday materials with students; because it brings to bear materials from the students' own life experiences and opens the doors to engineering they could do with readily available materials. Galimoto by Karen Lynn Williams - story of a boy who collects wires and other discarded materials to make a toy.

\section{9:00 - 9:20 am: Share course lessons successes and challenges}

1. Divide into two groups: Numbers and Operation and STEM Lit together and Engineering separate

2. Discuss where you are at with lessons; share successes, challenges, and needs

9:20 - 9:30 am: Break

\section{9:30 - 11:00 am: Windmill Activity}

1. Discuss The Boy Who Harnessed the Wind by William Kamkwamba and Bryan Mealer and show TED Talk video.

2. Can I Harness the Wind? Activity

- Photos of windmills around the world- write what they know about windmills and how they work. Discuss.

- Compare and contrast photos and pictures from book - Why did the village need a windmill? What are the design features of a windmill? List.

- Brainstorm variables with windmills. Inquiry activity: select one variable to investigate. Show materials and Data Sheet.

- Add a math connection (For example: $3^{\text {rd }}$ grade - Describe and analyze 2-D shapes. Represent and solve problems involving multiplication and division 
(calculate average RPM). Solve problems involving measurement and estimation (measure time intervals in minutes). Represent and interpret data.

- Discuss and negotiate a design. Test and collect data. How make the design spin freely? How will you attach blades? How determine one rotation? How keep other variables constant (e.g. distance from fan)?

- Share results. Take information learned from group and improve your design. Test.

- Identify elements that represent CRT practices.

- Make own kit.

\section{1:00 - 11:30 pm: Diverse Assets of Students, Parents, and the Community}

1. Discuss tools to use to better understand your students', parents', and community assets.

2. Share own ideas of gathering this information.

\section{1:30 - 12:00 pm: Dr. Chris Emdin}

1. Show video

2. Five C's Discussion

3. Revisit the Compass

12:00 - 12:30 pm: Lunch

1:00 - 1:50 pm: Family Engineering and Assembly Line Activity

1. Discuss purpose and logistics of Family Engineering Night.

2. Activity from Family Engineering book: Assembly Line

3. Incorporate CRT - Teams come up with science name, made up name and Spanish name for parts.

1:50 - 2:00 pm: Break

2:00 - 2:30 pm: Trade Books and Lessons

1. Discuss CRT connected trade books to support various STEM lessons.

2. Teachers select lessons to own.

2:30 - 3:00 pm: Research Component Requirements 


\section{Appendix C}

\section{Teacher Consent Form}

You are invited to participate in a study conducted by Donna Webb, doctoral student from Portland State University (PSU) and co-instructor of the Advancing STEM Instruction through Engineering Design course, and the Portland Metro STEM Partnership (PMSP).

The purpose of this study is to evaluate the effects of the engineering professional development course on teacher content knowledge, pedagogical content knowledge, and self-efficacy. Your participation in the study will generate data to provide evidence of the impact of the course on teacher practices and student learning. Your responses will also help instructors to refine the course so it meets the needs of classroom teachers. This data will be used for both a doctoral dissertation and the Portland Metro STEM Partnership Hub grant.

Most of the data that will be gathered for this study may coincide with information that is required by your school, if your school is participating in the transformation of STEM teaching and learning. If you agree to participate, you will be asked to complete the following:

- Respond to surveys pertaining to your beliefs, knowledge and experiences as a teacher, your typical classroom activities, past professional development activities, and traits of your school.

- Participate in a 45-60 minute interview during the 2014-2015 school year that will be audio-taped (only a sub-set of teachers will be selected to participate in interviews).

- Observed during a debriefing session conducted during the 2014-2015 school year from which researcher notes will be collected.

You were selected as a participant for this research based on your registration for the Advancing STEM Instruction through Engineering Design course. Participation is completely voluntary and code numbers will be used rather than names to assure confidentiality. All information and data collected will be kept in a locked file cabinet and stored in the home office of Donna Webb and the office of the Center for Science Education at PSU for a period of three years.

You do not have to take part in this study; it will not affect your relationship with PSU or PMSP. You may withdraw from this study at any time. If you have concerns or problems about participating in this study or your rights as a research subject, please contact the Human Subjects Research review Committee, Office of Research and Strategic Partnerships, Market Center Building, 1600 SW $4^{\text {th }}$, Portland State University, (503) 725 3423. If you have questions about the study itself, please contact Donna Webb at (503) 297-3298, webbdonna18@gmail.com. The researcher will provide you with a copy of this form for your records. 
Please mark below whether you "Agree" or "Do not agree" to participate. Your mark in the checkbox "I agree" below indicated that you have read and understand the above information and agree to take part in this study.

I agree

I do not agree 


\section{Appendix D}

Teacher Demographic Survey

Please provide your name (last, first).

\section{Teacher Demographics - Please provide the following demographic information:}

1. Please describe the status of your current school:

a) Schoolwide Title I

b) No schoolwide Title I

2. Please indicate your gender:

a) Male

b) Female

3. Please describe your current teaching position:
a) Kindergarten
b) $1^{\text {st }}$
c) $2^{\text {nd }}$
d) $3^{\text {rd }}$
e) $4^{\text {th }}$
f) $5^{\text {th }}$
g) $6^{\text {th }}$
h) $7^{\text {th }}$
i) $8^{\text {th }}$

4. Please specify the number of years you have taught in any K-12 school setting:

5. Please indicate your ethnicity/race (chose all that apply):
a) American Indian or Alaska Native
b) Asian
c) Black or African American
d) Hispanic or Latino(a)
e) Native Hawaiian or Pacific Islander
f) White

6. Please indicate the highest degree you hold:
a) $\mathrm{BA}$ or $\mathrm{BS}$
b) MA or MS
c) $\mathrm{PhD}$ or $\mathrm{EdD}$
d) Other 


\section{Appendix E}

\section{ED Course Pre/Post Assessment}

Please provide your name (last, first).

1. Review and consider the words in the 'word bank' below. Then, write words (or practices) that are specific to scientific inquiry within the left side of the Venn diagram. Write words (or practices) that are specific to engineering design within the right side of the Venn diagram. Write words (or practices) common to both scientific inquiry and engineering design in the middle of the Venn diagram.

\begin{tabular}{llll}
\hline Apply & Design & Observe & Refine \\
Communicate & Discover & Optimize & Simulate \\
Conclude & Explain & Pattern & Solve \\
Construct & Human needs & Phenomena & Technology \\
Control & Hypothesize & Problem & Trade-offs \\
Create & Investigate & Prototype & Variables \\
Criteria & Model & Question & \\
\hline
\end{tabular}

\section{Scientific Inquiry Common to Both Engineering Design}

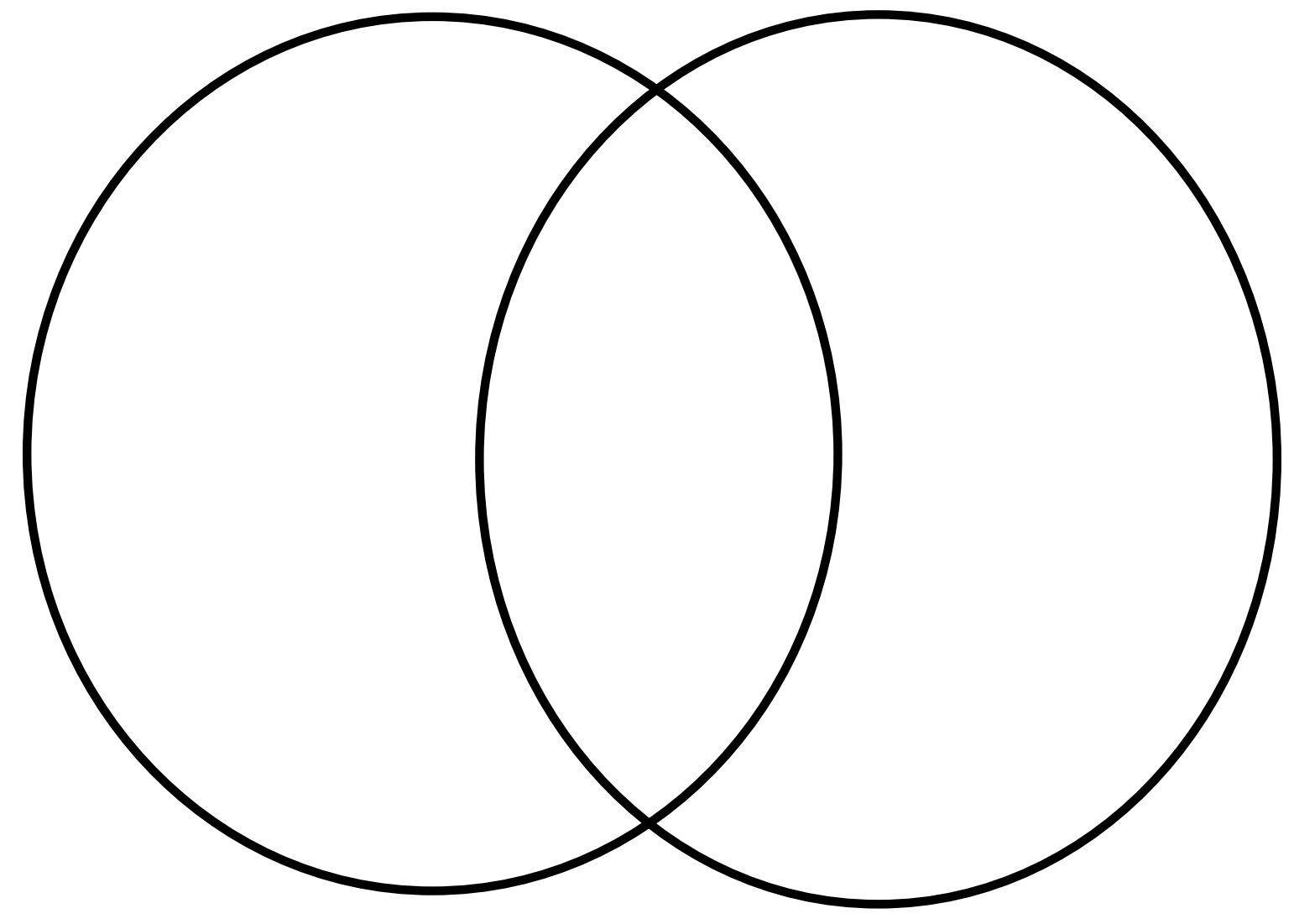


2. Explain your sorting rule (why you decided to sort the words the way you did). Give three examples (one word you placed under 'scientific inquiry,' one word you placed under 'engineering design,' and one word you placed under 'common to both.'

3. For the level that you teach, explain the engineering design process. 
4. Define technology in your own words.

5. What misconceptions do you think your students have with regards to the concept of technology?

6. How are science, engineering, and technology connected? 


\section{Engineering Scenarios}

INSTRUCTIONS: Read each teacher scenario and determine which teacher BEST represents the choices you would make in the given situation. Explain why you made that selction.

\section{SCENARIO \#1 - DEFINING A PROBLEM}

You are in the teacher's lounge to meet with colleagues that teach the same grade level. The meeting is to discuss an engineering design lesson all will teach. You have already agreed that students will design a sundial. In terms of approaching the design problem with students, each teacher discussed their most important consideration:

Teacher A - "It's all about having the right materials available and prepared for students, as well as clear instructions of how to use them so students have success."

Teacher B - " Yes, I give my students a variety of materials. But, that's not enough. I provide my students with specific criteria in making a sundial, such as it must be accurate to within 15 minutes and it can be moved from place to place."

Teacher C - "No, no, I have a better approach. I plan to provide a broader approach to the design challenge and allow students to come up with their own criteria. And, I'll give my students a variety of materials to use but they don't have to use them all."

Teacher D - "No, I disagree with all your approaches. Rather than providing a lot of up front instruction, I believe in free exploration. How else can you foster creativity in students?"

7. a. Which of these teachers do you agree with the most?

b. Explain why you made the choice you did: 


\section{SCENARIO \#2 - GENERATING IDEAS AND SKETCHING}

The following teachers have completed one day of instruction teaching a sundial engineering design lesson with their students. They meet after school to share their experiences.

Teacher A - "Wow! What a great lesson. My students immediately came up with fantastic solutions and we are already finished with the lesson."

Teacher B - "Well, my students need extra time. I made them come up with three different solutions in each group and they're still discussing them."

Teacher C - "Yeah, I had each of my student groups come up with different ideas, too. But, then I had them look back at the criteria to decide which solution was a better match."

Teacher D - "My groups of students came up with different solutions, but couldn't agree with one idea. So, I thought it would be best to let them create each solution to see how they worked. One group came up with 16 different sundials!"

Teacher E - "I'm just loving the creativity I'm seeing. My students have really gotten into decorating their sundials so my students need more time to express their creativity."

8. a. Which of these teachers do you agree with the most?

b. Explain why you made the choice you did: 


\section{SCENARIO \#3 - THE END OF THE LESSON}

Four of the teachers from scenario \#2 have finished the sundial engineering design lesson with their students. They meet after school to discuss the last day of instruction.

Teacher A - "I gave my students flashlights to test how well their sundials worked."

Teacher B - "Yes, my students used flashlights to test their su dials, too. But, we also tested the sundials in natural light. I had groups trade sundials with other groups and test within each context. I asked students to identify and write down weaknesses. Comments and sundials were given back to the original groups so they could improve their designs."

Teacher C - "Like Trevor, my students tested their sundials using a flashlight and natural light. But, each group tested their own designs. Then, they discussed and recorded how big they could make their sundial, yet still being able to meet the criteria of portability and accuracy. That way, I could extend understanding by discussing the concept of trade-offs, which was a great way to end the lesson."

Teacher D - "I think most of you are making the lesson too complicated. Each group of my students tested their sundials with flashlights and then we discussed how they would make changes next time around."

9. a. In your opinion, which teacher is doing the best job at moving students from a novice to an informed engineering designer?

b. Explain why you made the choice you did: 


\section{Appendix F}

\section{Teacher Self-Efficacy Survey}

This questionnaire is designed to help us gain a better understanding of the kinds of things that create difficulties for teachers in their school activities. Your answers are confidential.

Please respond to each of the questions by considering your current ability and the resources and opportunities currently available at your school.

\section{INSTRUCTIONS:}

For this survey we will ask you to undertake a reflective activity which involves a two part process:

1) Please read each question and reflect back on your classroom during the 2013-2014 school year. Mark the answer that best represents your past ability, resources, and opportunity to do each of the following next to where it says 'before this course.'

2) Next, please reflect on how you feel about your current ability now that you've completed this course. Please mark the answer that best represents your current ability now that you have completed this class next to where it says 'after this course.'

1. How much can you do to get through to the most challenging students in engineering design...

before this course:

\begin{tabular}{|c|c|c|c|c|c|c|c|c|c|}
\hline & $\begin{array}{c}\text { None at } \\
\text { all }\end{array}$ & & $\begin{array}{c}\text { Very } \\
\text { Little }\end{array}$ & & Some & & Quite & & A Great \\
Degree & & A Bit & & Deal \\
N/A & 1 & 2 & 3 & 4 & 5 & 6 & 7 & 8 & 9 \\
\hline
\end{tabular}

after this course:

\begin{tabular}{|c|c|c|c|c|c|c|c|c|c|}
\hline & $\begin{array}{c}\text { None at } \\
\text { all }\end{array}$ & & $\begin{array}{c}\text { Very } \\
\text { Little }\end{array}$ & & Some & & Quite & & A Great \\
Negree & & A Bit & & Deal \\
N/A & 1 & 2 & 3 & 4 & 5 & 6 & 7 & 8 & 9 \\
\hline
\end{tabular}


2. How much can you do to help your students think critically about engineering design... before this course:

\begin{tabular}{|c|c|c|c|c|c|c|c|c|c|}
\hline & $\begin{array}{c}\text { None at } \\
\text { all }\end{array}$ & & $\begin{array}{c}\text { Very } \\
\text { Little }\end{array}$ & & Some & & Quite & & A Great \\
Degree & & A Bit & & Deal \\
N/A & 1 & 2 & 3 & 4 & 5 & 6 & 7 & 8 & 9 \\
\hline
\end{tabular}

after this course:

\begin{tabular}{|c|c|c|c|c|c|c|c|c|c|}
\hline & $\begin{array}{c}\text { None at } \\
\text { all }\end{array}$ & & $\begin{array}{c}\text { Very } \\
\text { Little }\end{array}$ & & Some & & Quite & & A Great \\
Degree & & A Bit & & Deal \\
N/A & 1 & 2 & 3 & 4 & 5 & 6 & 7 & 8 & 9 \\
\hline
\end{tabular}

3. How much can you do to control disruptive behavior in the classroom, in general... before this course:

\begin{tabular}{|c|c|c|c|c|c|c|c|c|c|}
\hline & $\begin{array}{c}\text { None at } \\
\text { all }\end{array}$ & & $\begin{array}{c}\text { Very } \\
\text { Little }\end{array}$ & & Some & & Quite & & A Great \\
Deal & Degree & & A Bit & & 9 \\
N/A & 1 & 2 & 3 & 4 & 5 & 6 & 7 & 8 & 9 \\
\hline
\end{tabular}

after this course:

\begin{tabular}{|c|c|c|c|c|c|c|c|c|c|}
\hline & $\begin{array}{c}\text { None at } \\
\text { all }\end{array}$ & & $\begin{array}{c}\text { Very } \\
\text { Little }\end{array}$ & & Some & & Quite & & A Great \\
Deal & A Bit & & & \\
N/A & 1 & 2 & 3 & 4 & 5 & 6 & 7 & 8 & 9 \\
\hline
\end{tabular}

4. How much can you do to motivate students who show low interest in engineering school work...

before this course:

\begin{tabular}{|c|c|c|c|c|c|c|c|c|c|}
\hline & $\begin{array}{c}\text { None at } \\
\text { all }\end{array}$ & & $\begin{array}{c}\text { Very } \\
\text { Little }\end{array}$ & & Some & & Quite & & A Great \\
Deal & A Bit & & & \\
N/A & 1 & 2 & 3 & 4 & 5 & 6 & 7 & 8 & 9 \\
\hline
\end{tabular}

after this course:

\begin{tabular}{|c|c|c|c|c|c|c|c|c|c|}
\hline & $\begin{array}{c}\text { None at } \\
\text { all }\end{array}$ & & $\begin{array}{c}\text { Very } \\
\text { Little }\end{array}$ & & Some & & Quite & & A Great \\
Degree & & A Bit & & Deal \\
N/A & 1 & 2 & 3 & 4 & 5 & 6 & 7 & 8 & 9 \\
\hline
\end{tabular}


5. To what extent can you make your expectations clear about student behavior, in general... before this course:

\begin{tabular}{|c|c|c|c|c|c|c|c|c|c|}
\hline & $\begin{array}{c}\text { None at } \\
\text { all }\end{array}$ & & $\begin{array}{c}\text { Very } \\
\text { Little }\end{array}$ & & Some & & Quite & & A Great \\
N/A & 1 & 2 & 3 & 4 & 5 & 6 & 7 & 8 & 9 \\
\hline
\end{tabular}

after this course:

\begin{tabular}{|c|c|c|c|c|c|c|c|c|c|}
\hline & $\begin{array}{c}\text { None at } \\
\text { all }\end{array}$ & & $\begin{array}{c}\text { Very } \\
\text { Little }\end{array}$ & & Some & & Quite & & A Great \\
Negree & & A Bit & & Deal \\
N/A & 1 & 2 & 3 & 4 & 5 & 6 & 7 & 8 & 9 \\
\hline
\end{tabular}

6. How much can you do to get students to believe they can do well in engineering school work...

before this course:

\begin{tabular}{|c|c|c|c|c|c|c|c|c|c|}
\hline & $\begin{array}{c}\text { None at } \\
\text { all }\end{array}$ & & $\begin{array}{c}\text { Very } \\
\text { Little }\end{array}$ & & Some & & Quite & & A Great \\
Negree & & A Bit & & Deal \\
N/A & 1 & 2 & 3 & 4 & 5 & 6 & 7 & 8 & 9 \\
\hline
\end{tabular}

after this course:

\begin{tabular}{|c|c|c|c|c|c|c|c|c|c|}
\hline & $\begin{array}{c}\text { None at } \\
\text { all }\end{array}$ & & $\begin{array}{c}\text { Very } \\
\text { Little }\end{array}$ & & Some & & Quite & & A Great \\
Negree & & A Bit & & Deal \\
N/A & 1 & 2 & 3 & 4 & 5 & 6 & 7 & 8 & 9 \\
\hline
\end{tabular}

7. How well can you respond to difficult questions from your students in engineering design...

before this course:

\begin{tabular}{|c|c|c|c|c|c|c|c|c|c|}
\hline & $\begin{array}{c}\text { None at } \\
\text { all }\end{array}$ & & $\begin{array}{c}\text { Very } \\
\text { Little }\end{array}$ & & $\begin{array}{c}\text { Some } \\
\text { Degree }\end{array}$ & & $\begin{array}{c}\text { Quite } \\
\text { A Bit }\end{array}$ & & A Great \\
Deal \\
N/A & 1 & 2 & 3 & 4 & 5 & 6 & 7 & 8 & 9 \\
\hline
\end{tabular}

after this course:

\begin{tabular}{|c|c|c|c|c|c|c|c|c|c|}
\hline & $\begin{array}{c}\text { None at } \\
\text { all }\end{array}$ & & $\begin{array}{c}\text { Very } \\
\text { Little }\end{array}$ & & Some & & Quite & & A Great \\
Degree & & A Bit & & Deal \\
N/A & 1 & 2 & 3 & 4 & 5 & 6 & 7 & 8 & 9 \\
\hline
\end{tabular}


8. How well can you establish routines to keep activities running smoothly, in general... before this course:

\begin{tabular}{|c|c|c|c|c|c|c|c|c|c|}
\hline & $\begin{array}{c}\text { None at } \\
\text { all }\end{array}$ & & $\begin{array}{c}\text { Very } \\
\text { Little }\end{array}$ & & Some & & Quite & & A Great \\
Degree & & A Bit & & Deal \\
N/A & 1 & 2 & 3 & 4 & 5 & 6 & 7 & 8 & 9 \\
\hline
\end{tabular}

after this course:

\begin{tabular}{|c|c|c|c|c|c|c|c|c|c|}
\hline & $\begin{array}{c}\text { None at } \\
\text { all }\end{array}$ & & $\begin{array}{c}\text { Very } \\
\text { Little }\end{array}$ & & Some & & Quite & & A Great \\
Degree & & A Bit & & Deal \\
N/A & 1 & 2 & 3 & 4 & 5 & 6 & 7 & 8 & 9 \\
\hline
\end{tabular}

9. How much can you do to help your students value learning in engineering design... before this course:

\begin{tabular}{|c|c|c|c|c|c|c|c|c|c|}
\hline & $\begin{array}{c}\text { None at } \\
\text { all }\end{array}$ & & $\begin{array}{c}\text { Very } \\
\text { Little }\end{array}$ & & Some & & Quite & & A Great \\
Degree & & A Bit & & Deal \\
N/A & 1 & 2 & 3 & 4 & 5 & 6 & 7 & 8 & 9 \\
\hline
\end{tabular}

after this course:

\begin{tabular}{|c|c|c|c|c|c|c|c|c|c|}
\hline & $\begin{array}{c}\text { None at } \\
\text { all }\end{array}$ & & $\begin{array}{c}\text { Very } \\
\text { Little }\end{array}$ & & Some & & Quite & & A Great \\
Degree & & A Bit & & Deal \\
N/A & 1 & 2 & 3 & 4 & 5 & 6 & 7 & 8 & 9 \\
\hline
\end{tabular}

10. How much can you gauge student comprehension of what you have taught in engineering design...

before this course:

\begin{tabular}{|c|c|c|c|c|c|c|c|c|c|}
\hline & $\begin{array}{c}\text { None at } \\
\text { all }\end{array}$ & & $\begin{array}{c}\text { Very } \\
\text { Little }\end{array}$ & & Some & & Quite & & A Great \\
Deal & A Bit & & & \\
N/A & 1 & 2 & 3 & 4 & 5 & 6 & 7 & 8 & 9 \\
\hline
\end{tabular}

after this course:

\begin{tabular}{|c|c|c|c|c|c|c|c|c|c|}
\hline & $\begin{array}{c}\text { None at } \\
\text { all }\end{array}$ & & $\begin{array}{c}\text { Very } \\
\text { Little }\end{array}$ & & Some & & Quite & & A Great \\
Deal & A Bit & & & \\
N/A & 1 & 2 & 3 & 4 & 5 & 6 & 7 & 8 & 9 \\
\hline
\end{tabular}


11. To what extent can you craft good questions for your students in engineering design... before this course:

\begin{tabular}{|c|c|c|c|c|c|c|c|c|c|}
\hline & $\begin{array}{c}\text { None at } \\
\text { all }\end{array}$ & & $\begin{array}{c}\text { Very } \\
\text { Little }\end{array}$ & & Some & & Quite & & A Great \\
Deal & A Bit & & & \\
N/A & 1 & 2 & 3 & 4 & 5 & 6 & 7 & 8 & 9 \\
\hline
\end{tabular}

after this course:

\begin{tabular}{|c|c|c|c|c|c|c|c|c|c|}
\hline & $\begin{array}{c}\text { None at } \\
\text { all }\end{array}$ & & $\begin{array}{c}\text { Very } \\
\text { Little }\end{array}$ & & Some & & Quite & & A Great \\
Degree & & A Bit & & Deal \\
N/A & 1 & 2 & 3 & 4 & 5 & 6 & 7 & 8 & 9 \\
\hline
\end{tabular}

12. How much can you do to foster student creativity in engineering design... before this course:

\begin{tabular}{|c|c|c|c|c|c|c|c|c|c|}
\hline & $\begin{array}{c}\text { None at } \\
\text { all }\end{array}$ & & $\begin{array}{c}\text { Very } \\
\text { Little }\end{array}$ & & Some & & Quite & & A Great \\
Deal & A Bit & & Dree \\
N/A & 1 & 2 & 3 & 4 & 5 & 6 & 7 & 8 & 9 \\
\hline
\end{tabular}

after this course:

\begin{tabular}{|c|c|c|c|c|c|c|c|c|c|}
\hline & $\begin{array}{c}\text { None at } \\
\text { all }\end{array}$ & & $\begin{array}{c}\text { Very } \\
\text { Little }\end{array}$ & & Some & & Quite & & A Great \\
Degree & & A Bit & & Deal \\
N/A & 1 & 2 & 3 & 4 & 5 & 6 & 7 & 8 & 9 \\
\hline
\end{tabular}

13. How much can you do to get children to follow classroom rules, in general... before this course:

\begin{tabular}{|c|c|c|c|c|c|c|c|c|c|}
\hline & $\begin{array}{c}\text { None at } \\
\text { all }\end{array}$ & & $\begin{array}{c}\text { Very } \\
\text { Little }\end{array}$ & & Some & & Quite & & A Great \\
Deal & A Bit & & Dea \\
N/A & 1 & 2 & 3 & 4 & 5 & 6 & 7 & 8 & 9 \\
\hline
\end{tabular}

after this course:

\begin{tabular}{|c|c|c|c|c|c|c|c|c|c|}
\hline & $\begin{array}{c}\text { None at } \\
\text { all }\end{array}$ & & $\begin{array}{c}\text { Very } \\
\text { Little }\end{array}$ & & Some & & Quite & & A Great \\
Degree & & A Bit & & Deal \\
N/A & 1 & 2 & 3 & 4 & 5 & 6 & 7 & 8 & 9 \\
\hline
\end{tabular}


14. How much can you do to improve the understanding of a student who is underpreforming in engineering design...

before this course:

\begin{tabular}{|c|c|c|c|c|c|c|c|c|c|}
\hline & $\begin{array}{c}\text { None at } \\
\text { all }\end{array}$ & & $\begin{array}{c}\text { Very } \\
\text { Little }\end{array}$ & & Some & & Quite & & A Great \\
Degree & & A Bit & & Deal \\
N/A & 1 & 2 & 3 & 4 & 5 & 6 & 7 & 8 & 9 \\
\hline
\end{tabular}

after this course:

\begin{tabular}{|c|c|c|c|c|c|c|c|c|c|}
\hline & $\begin{array}{c}\text { None at } \\
\text { all }\end{array}$ & & $\begin{array}{c}\text { Very } \\
\text { Little }\end{array}$ & & $\begin{array}{c}\text { Some } \\
\text { Degree }\end{array}$ & & $\begin{array}{c}\text { Quite } \\
\text { A Bit }\end{array}$ & & A Great \\
Deal \\
N/A
\end{tabular}

15. How much can you do to calm a student who is disruptive, in general... before this course:

\begin{tabular}{|c|c|c|c|c|c|c|c|c|c|}
\hline & $\begin{array}{c}\text { None at } \\
\text { all }\end{array}$ & & $\begin{array}{c}\text { Very } \\
\text { Little }\end{array}$ & & Some & & Quite & & A Great \\
Degree & & A Bit & & Deal \\
N/A & 1 & 2 & 3 & 4 & 5 & 6 & 7 & 8 & 9 \\
\hline
\end{tabular}

after this course:

\begin{tabular}{|c|c|c|c|c|c|c|c|c|c|}
\hline & $\begin{array}{c}\text { None at } \\
\text { all }\end{array}$ & & $\begin{array}{c}\text { Very } \\
\text { Little }\end{array}$ & & $\begin{array}{c}\text { Some } \\
\text { Degree }\end{array}$ & & $\begin{array}{c}\text { Quite } \\
\text { A Bit }\end{array}$ & & A Great \\
Deal \\
N/A & 1 & 2 & 3 & 4 & 5 & 6 & 7 & 8 & 9 \\
\hline
\end{tabular}

16. How well can you establish a classroom management system with each group of students, in general...

before this course:

\begin{tabular}{|c|c|c|c|c|c|c|c|c|c|}
\hline & $\begin{array}{c}\text { None at } \\
\text { all }\end{array}$ & & $\begin{array}{c}\text { Very } \\
\text { Little }\end{array}$ & & $\begin{array}{c}\text { Some } \\
\text { Degree }\end{array}$ & & Quite & & A Great \\
A Bit & & & Deal \\
N/A & 1 & 2 & 3 & 4 & 5 & 6 & 7 & 8 & 9 \\
\hline
\end{tabular}

after this course:

\begin{tabular}{|c|c|c|c|c|c|c|c|c|c|}
\hline & $\begin{array}{c}\text { None at } \\
\text { all }\end{array}$ & & $\begin{array}{c}\text { Very } \\
\text { Little }\end{array}$ & & Some & & Quite & & A Great \\
Negree & & A Bit & & Deal \\
N/A & 1 & 2 & 3 & 4 & 5 & 6 & 7 & 8 & 9 \\
\hline
\end{tabular}


17. How much can you do to adjust your lessons to the proper level for individual students in engineering design...

before this course:

\begin{tabular}{|c|c|c|c|c|c|c|c|c|c|}
\hline & $\begin{array}{c}\text { None at } \\
\text { all }\end{array}$ & & $\begin{array}{c}\text { Very } \\
\text { Little }\end{array}$ & & Some & & Quite & & A Great \\
Negree & & A Bit & & Deal \\
& 1 & 2 & 3 & 4 & 5 & 6 & 7 & 8 & 9 \\
\hline
\end{tabular}

after this course:

\begin{tabular}{|c|c|c|c|c|c|c|c|c|c|}
\hline & $\begin{array}{c}\text { None at } \\
\text { all }\end{array}$ & & $\begin{array}{c}\text { Very } \\
\text { Little }\end{array}$ & & Some & & Quite & & A Great \\
N/A & 1 & 2 & 3 & 4 & 5 & 6 & 7 & 8 & 9 \\
\hline
\end{tabular}

18. How much can you use a variety of assessment strategies in engineering design... before this course:

\begin{tabular}{|c|c|c|c|c|c|c|c|c|c|}
\hline & $\begin{array}{c}\text { None at } \\
\text { all }\end{array}$ & & $\begin{array}{c}\text { Very } \\
\text { Little }\end{array}$ & & Some & & Quite & & A Great \\
N/A & 1 & 2 & 3 & 4 & 5 & 6 & 7 & 8 & 9 \\
\hline
\end{tabular}

after this course:

\begin{tabular}{|c|c|c|c|c|c|c|c|c|c|}
\hline & $\begin{array}{c}\text { None at } \\
\text { all }\end{array}$ & & $\begin{array}{c}\text { Very } \\
\text { Little }\end{array}$ & & Some & & Quite & & A Great \\
Degree & & A Bit & & Deal \\
N/A & 1 & 2 & 3 & 4 & 5 & 6 & 7 & 8 & 9 \\
\hline
\end{tabular}

19. How well can you refocus students who are off-task to preserve the goals of your lesson, in general...

before this course:

\begin{tabular}{|c|c|c|c|c|c|c|c|c|c|}
\hline & $\begin{array}{c}\text { None at } \\
\text { all }\end{array}$ & & $\begin{array}{c}\text { Very } \\
\text { Little }\end{array}$ & & Some & & Quite & & A Great \\
N/A & 1 & 2 & 3 & 4 & 5 & 6 & 7 & 8 & 9 \\
\hline
\end{tabular}

after this course:

\begin{tabular}{|c|c|c|c|c|c|c|c|c|c|}
\hline & $\begin{array}{c}\text { None at } \\
\text { all }\end{array}$ & & $\begin{array}{c}\text { Very } \\
\text { Little }\end{array}$ & & Some & & Quite & & A Great \\
N/A & 1 & 2 & 3 & 4 & 5 & 6 & 7 & 8 & 9 \\
\hline
\end{tabular}


20. To what extent can you provide an alternative explanation or example when students are confused in engineering design...

before this course:

\begin{tabular}{|c|c|c|c|c|c|c|c|c|c|}
\hline & $\begin{array}{c}\text { None at } \\
\text { all }\end{array}$ & & $\begin{array}{c}\text { Very } \\
\text { Little }\end{array}$ & & Some & & Quite & & A Great \\
N/A & 1 & 2 & 3 & 4 & 5 & 6 & 7 & 8 & 9 \\
\hline
\end{tabular}

after this course:

\begin{tabular}{|c|c|c|c|c|c|c|c|c|c|}
\hline & $\begin{array}{c}\text { None at } \\
\text { all }\end{array}$ & & $\begin{array}{c}\text { Very } \\
\text { Little }\end{array}$ & & Some & & Quite & & A Great \\
N/A & 1 & 2 & 3 & 4 & 5 & 6 & 7 & 8 & 9 \\
\hline
\end{tabular}

21. How well can you respond to defiant students, in general... before this course:

\begin{tabular}{|c|c|c|c|c|c|c|c|c|c|}
\hline & $\begin{array}{c}\text { None at } \\
\text { all }\end{array}$ & & $\begin{array}{c}\text { Very } \\
\text { Little }\end{array}$ & & Some & & Quite & & A Great \\
Negree & & A Bit & & Deal \\
N/A & 1 & 2 & 3 & 4 & 5 & 6 & 7 & 8 & 9 \\
\hline
\end{tabular}

after this course:

\begin{tabular}{|c|c|c|c|c|c|c|c|c|c|}
\hline & $\begin{array}{c}\text { None at } \\
\text { all }\end{array}$ & & $\begin{array}{c}\text { Very } \\
\text { Little }\end{array}$ & & Some & & Quite & & A Great \\
N/A & 1 & 2 & 3 & 4 & 5 & 6 & 7 & 8 & 9 \\
\hline
\end{tabular}

22. How much can you assist families in helping their children do well in engineering school work...

before this course:

\begin{tabular}{|c|c|c|c|c|c|c|c|c|c|}
\hline & $\begin{array}{c}\text { None at } \\
\text { all }\end{array}$ & & $\begin{array}{c}\text { Very } \\
\text { Little }\end{array}$ & & Some & & Quite & & A Great \\
N/A & 1 & 2 & 3 & 4 & 5 & 6 & 7 & 8 & 9 \\
\hline
\end{tabular}

after this course:

\begin{tabular}{|c|c|c|c|c|c|c|c|c|c|}
\hline & $\begin{array}{c}\text { None at } \\
\text { all }\end{array}$ & & $\begin{array}{c}\text { Very } \\
\text { Little }\end{array}$ & & Some & & Quite & & A Great \\
Negree & & A Bit & & Deal \\
N/A & 1 & 2 & 3 & 4 & 5 & 6 & 7 & 8 & 9 \\
\hline
\end{tabular}


23. How well can you implement alternative strategies in your classroom during engineering lessons...

before this course:

\begin{tabular}{|c|c|c|c|c|c|c|c|c|c|}
\hline & $\begin{array}{c}\text { None at } \\
\text { all }\end{array}$ & & $\begin{array}{c}\text { Very } \\
\text { Little }\end{array}$ & & Some & & Quite & & A Great \\
N/A & 1 & 2 & 3 & 4 & 5 & 6 & 7 & 8 & 9 \\
\hline
\end{tabular}

after this course:

\begin{tabular}{|c|c|c|c|c|c|c|c|c|c|}
\hline & $\begin{array}{c}\text { None at } \\
\text { all }\end{array}$ & & $\begin{array}{c}\text { Very } \\
\text { Little }\end{array}$ & & $\begin{array}{c}\text { Some } \\
\text { Degree }\end{array}$ & & $\begin{array}{c}\text { Quite } \\
\text { A Bit }\end{array}$ & & A Great \\
Deal \\
N/A
\end{tabular}

24. How well can you provide appropriate challenges for very capable students in engineering design...

before this course:

\begin{tabular}{|c|c|c|c|c|c|c|c|c|c|}
\hline & $\begin{array}{c}\text { None at } \\
\text { all }\end{array}$ & & $\begin{array}{c}\text { Very } \\
\text { Little }\end{array}$ & & Some & & Quite & & A Great \\
N/A & 1 & 2 & 3 & 4 & 5 & 6 & 7 & 8 & 9 \\
\hline
\end{tabular}

after this course:

\begin{tabular}{|c|c|c|c|c|c|c|c|c|c|}
\hline & $\begin{array}{c}\text { None at } \\
\text { all }\end{array}$ & & $\begin{array}{c}\text { Very } \\
\text { Little }\end{array}$ & & Some & & Quite & & A Great \\
Degree & & A Bit & & Deal \\
N/A & 1 & 2 & 3 & 4 & 5 & 6 & 7 & 8 & 9 \\
\hline
\end{tabular}

25. How well can you develop a community of learners when your class consists of students from diverse backgrounds when teaching engineering design...

before this course:

\begin{tabular}{|c|c|c|c|c|c|c|c|c|c|}
\hline & $\begin{array}{c}\text { None at } \\
\text { all }\end{array}$ & & $\begin{array}{c}\text { Very } \\
\text { Little }\end{array}$ & & Some & & Quite & & A Great \\
Degree & & A Bit & & Deal \\
N/A & 1 & 2 & 3 & 4 & 5 & 6 & 7 & 8 & 9 \\
\hline
\end{tabular}

after this course:

\begin{tabular}{|c|c|c|c|c|c|c|c|c|c|}
\hline & $\begin{array}{c}\text { None at } \\
\text { all }\end{array}$ & & $\begin{array}{c}\text { Very } \\
\text { Little }\end{array}$ & & Some & & Quite & & A Great \\
N/A & 1 & 2 & 3 & 4 & 5 & 6 & 7 & 8 & 9 \\
\hline
\end{tabular}


26. How well can you use your students' cultural background to help make learning meaningful in engineering design...

before this course:

\begin{tabular}{|c|c|c|c|c|c|c|c|c|c|}
\hline & $\begin{array}{c}\text { None at } \\
\text { all }\end{array}$ & & $\begin{array}{c}\text { Very } \\
\text { Little }\end{array}$ & & Some & & Quite & & A Great \\
Degree & & A Bit & & Deal \\
N/A & 1 & 2 & 3 & 4 & 5 & 6 & 7 & 8 & 9 \\
\hline
\end{tabular}

after this course:

\begin{tabular}{|c|c|c|c|c|c|c|c|c|c|}
\hline & $\begin{array}{c}\text { None at } \\
\text { all }\end{array}$ & & $\begin{array}{c}\text { Very } \\
\text { Little }\end{array}$ & & $\begin{array}{c}\text { Some } \\
\text { Degree }\end{array}$ & & $\begin{array}{c}\text { Quite } \\
\text { A Bit }\end{array}$ & & A Great \\
Deal \\
N/A
\end{tabular}

27. To what extent can you revise materials to include a better representation of cultural groups in engineering design...

before this course:

\begin{tabular}{|c|c|c|c|c|c|c|c|c|c|}
\hline & $\begin{array}{c}\text { None at } \\
\text { all }\end{array}$ & & $\begin{array}{c}\text { Very } \\
\text { Little }\end{array}$ & & Some & & Quite & & A Great \\
Degree & & A Bit & & Deal \\
N/A & 1 & 2 & 3 & 4 & 5 & 6 & 7 & 8 & 9 \\
\hline
\end{tabular}

after this course:

\begin{tabular}{|c|c|c|c|c|c|c|c|c|c|}
\hline & $\begin{array}{c}\text { None at } \\
\text { all }\end{array}$ & & $\begin{array}{c}\text { Very } \\
\text { Little }\end{array}$ & & Some & & Quite & & A Great \\
Degree & & A Bit & & Deal \\
N/A & 1 & 2 & 3 & 4 & 5 & 6 & 7 & 8 & 9 \\
\hline
\end{tabular}

28. How well can you critically examine the curriculum to determine whether it reinforces negative cultural stereotypes in engineering design...

before this course:

\begin{tabular}{|c|c|c|c|c|c|c|c|c|c|}
\hline & $\begin{array}{c}\text { None at } \\
\text { all }\end{array}$ & & $\begin{array}{c}\text { Very } \\
\text { Little }\end{array}$ & & Some & & Quite & & A Great \\
Degree & & A Bit & & Deal \\
N/A & 1 & 2 & 3 & 4 & 5 & 6 & 7 & 8 & 9 \\
\hline
\end{tabular}

after this course:

\begin{tabular}{|c|c|c|c|c|c|c|c|c|c|}
\hline & $\begin{array}{c}\text { None at } \\
\text { all }\end{array}$ & & $\begin{array}{c}\text { Very } \\
\text { Little }\end{array}$ & & Some & & Quite & & A Great \\
Dearee & & A Bit & & Deal \\
N/A & 1 & 2 & 3 & 4 & 5 & 6 & 7 & 8 & 9 \\
\hline
\end{tabular}


29. To what extent can you use examples that are familiar to students from diverse cultural backgrounds in engineering lessons...

before this course:

\begin{tabular}{|c|c|c|c|c|c|c|c|c|c|}
\hline & $\begin{array}{c}\text { None at } \\
\text { all }\end{array}$ & & $\begin{array}{c}\text { Very } \\
\text { Little }\end{array}$ & & Some & & Quite & & A Great \\
N/A & 1 & 2 & 3 & 4 & 5 & 6 & 7 & 8 & 9 \\
\hline
\end{tabular}

after this course:

\begin{tabular}{|c|c|c|c|c|c|c|c|c|c|}
\hline & $\begin{array}{c}\text { Not at } \\
\text { all }\end{array}$ & & $\begin{array}{c}\text { Very } \\
\text { Little }\end{array}$ & & Some & & Quite & & A Great \\
Degree & & A Bit & & Deal \\
N/A & 1 & 2 & 3 & 4 & 5 & 6 & 7 & 8 & 9 \\
\hline
\end{tabular}

30. How well can you explain new concepts using examples that are taken from your students' everyday lives in engineering design...

before this course:

\begin{tabular}{|c|c|c|c|c|c|c|c|c|c|}
\hline & $\begin{array}{c}\text { None at } \\
\text { all }\end{array}$ & & $\begin{array}{c}\text { Very } \\
\text { Little }\end{array}$ & & Some & & Quite & & A Great \\
Negree & & A Bit & & Deal \\
N/A & 1 & 2 & 3 & 4 & 5 & 6 & 7 & 8 & 9 \\
\hline
\end{tabular}

after this course:

\begin{tabular}{|c|c|c|c|c|c|c|c|c|c|}
\hline & $\begin{array}{c}\text { Not at } \\
\text { all }\end{array}$ & & $\begin{array}{c}\text { Very } \\
\text { Little }\end{array}$ & & Some & & Quite & & A Great \\
Degree & & A Bit & & Deal \\
N/A & 1 & 2 & 3 & 4 & 5 & 6 & 7 & 8 & 9 \\
\hline
\end{tabular}

31. To what extent can you use the interests of your students to make learning meaningful for them in engineering design...

before this course:

\begin{tabular}{|c|c|c|c|c|c|c|c|c|c|}
\hline & $\begin{array}{c}\text { None at } \\
\text { all }\end{array}$ & & $\begin{array}{c}\text { Very } \\
\text { Little }\end{array}$ & & Some & & Quite & & A Great \\
Deal & A Bit & & & \\
N/A & 1 & 2 & 3 & 4 & 5 & 6 & 7 & 8 & 9 \\
\hline
\end{tabular}

after this course:

\begin{tabular}{|c|c|c|c|c|c|c|c|c|c|}
\hline & $\begin{array}{c}\text { Not at } \\
\text { all }\end{array}$ & & $\begin{array}{c}\text { Very } \\
\text { Little }\end{array}$ & & Some & & Quite & & A Great \\
Degree & & A Bit & & Deal \\
N/A & 1 & 2 & 3 & 4 & 5 & 6 & 7 & 8 & 9 \\
\hline
\end{tabular}


32. To what extent can you identify how ways your students' communicate at home may differ from your classroom/school communication norms in engineering design... before this course:

\begin{tabular}{|c|c|c|c|c|c|c|c|c|c|}
\hline & $\begin{array}{c}\text { None at } \\
\text { all }\end{array}$ & & $\begin{array}{c}\text { Very } \\
\text { Little }\end{array}$ & & Some & & Quite & & A Great \\
Negree & & A Bit & & Deal \\
N/A & 1 & 2 & 3 & 4 & 5 & 6 & 7 & 8 & 9 \\
\hline
\end{tabular}

after this course:

\begin{tabular}{|c|c|c|c|c|c|c|c|c|c|}
\hline & Not at & & Very & & Some & & Quite & & A Great \\
all & & Little & & Degree & & A Bit & & Deal \\
N/A & 1 & 2 & 3 & 4 & 5 & 6 & 7 & 8 & 9 \\
\hline
\end{tabular}

33. How well can you implement strategies to minimize the effects of the mismatch between your students' home culture and your classroom/school culture in engineering design... before this course:

\begin{tabular}{|c|c|c|c|c|c|c|c|c|c|}
\hline & $\begin{array}{c}\text { None at } \\
\text { all }\end{array}$ & & $\begin{array}{c}\text { Very } \\
\text { Little }\end{array}$ & & Some & & Quite & & A Great \\
Negree & & A Bit & & Deal \\
N/A & 1 & 2 & 3 & 4 & 5 & 6 & 7 & 8 & 9 \\
\hline
\end{tabular}

after this course:

\begin{tabular}{|c|c|c|c|c|c|c|c|c|c|}
\hline & $\begin{array}{c}\text { Not at } \\
\text { all }\end{array}$ & & $\begin{array}{c}\text { Very } \\
\text { Little }\end{array}$ & & Some Skill & & $\begin{array}{c}\text { Quite } \\
\text { A Bit }\end{array}$ & & A Great \\
Deal \\
N/A & 1 & 2 & 3 & 4 & 5 & 6 & 7 & 8 & 9 \\
\hline
\end{tabular}




\section{Appendix G}

\section{Teacher Interview Questions}

1. Can you share with me your motivation to participate in the engineering course? What brought you here?

2. How would you describe your confidence to teach engineering before the engineering professional development course?

3. How did the engineering professional development course affect your confidence to teach engineering?

4. How did an actual engineering teaching experience affect your confidence to teach engineering?

5. Please review the outline of the engineering professional development course. Did anything specific within the course help make you more confident to teach engineering?

6. Did anything specific within the actual engineering teaching experience help make you more confident to teach engineering?

7. Describe any other factors that influenced your confidence to teach engineering.

8. Describe how your improved confidence to teach engineering has influenced or not influenced your teaching practices.

9. Describe how your improved confidence to teach engineering has influenced or not influenced your students.

10. Is there anything else you'd like to share with me that I need to know about your engineering professional development experience? 


\section{Appendix H}

Observational Notes

Date, Time, Location:

Part. \#

Happenings

What does it mean? 


\section{Appendix I}

\section{ED Course Post-post Survey}

In reflecting on your experiences today and in your classroom thus far this year, specifically regarding your teaching of engineering design:

1. By show of hands, how many of you have taught engineering lessons so far this year?

2. Can you share what you did? Can you share how your students responded to the engineering lesson and describe any interesting impacts (outcomes) for students?

3. Please describe any improvements you would recommend to the engineering design course to be taught this next summer? 


\section{Appendix J}

\section{ED Course Assessment Rubrics}

Question $1(\mathrm{CK})$ :

\begin{tabular}{|c|c|c|c|c|}
\hline $\begin{array}{l}\text { Rubric } \\
\text { Score }\end{array}$ & 1 & 2 & 3 & 4 \\
\hline $\begin{array}{l}\text { Charac- } \\
\text { teristics }\end{array}$ & $\begin{array}{c}3 \text { or less } \\
\text { Engineering } \\
\text { Design words } \\
\text { correct }\end{array}$ & $\begin{array}{c}4 \text { to } 6 \\
\text { Engineering } \\
\text { Design words } \\
\text { correct }\end{array}$ & $\begin{array}{c}7 \text { to } 9 \\
\text { Engineering } \\
\text { Design words } \\
\text { correct }\end{array}$ & $\begin{array}{c}10 \text { to } 12 \\
\text { Engineering } \\
\text { Design words } \\
\text { correct }\end{array}$ \\
\hline Example & $\begin{array}{l}\text { "Construct, } \\
\text { prototype, } \\
\text { solve" }\end{array}$ & $\begin{array}{l}\text { "Client, human } \\
\text { needs, } \\
\text { prototype, } \\
\text { optimize, } \\
\text { trade-offs" }\end{array}$ & $\begin{array}{l}\text { "Human needs, } \\
\text { refine, } \\
\text { construct, } \\
\text { create, } \\
\text { optimize, } \\
\text { criteria, design, } \\
\text { prototype" }\end{array}$ & $\begin{array}{l}\text { "Problem, } \\
\text { create, } \\
\text { construct, } \\
\text { trade-offs, } \\
\text { client, } \\
\text { prototype, } \\
\text { optimize, } \\
\text { human needs, } \\
\text { criteria, design" }\end{array}$ \\
\hline
\end{tabular}

Question 2 (CK):

\begin{tabular}{|c|c|c|c|c|}
\hline $\begin{array}{l}\text { Rubric } \\
\text { Score }\end{array}$ & 1 & 2 & $3 a$ & $3 b$ \\
\hline $\begin{array}{l}\text { Charac- } \\
\text { teristics }\end{array}$ & $\begin{array}{l}\text { Placed at least } \\
\text { one word in } \\
\text { correct } \\
\text { category } \\
\text { Gave no } \\
\text { explanation of } \\
\text { how sorted the } \\
\text { words or } \\
\text { explanation } \\
\text { was wrong }\end{array}$ & $\begin{array}{l}\text { Placed two } \\
\text { words in the } \\
\text { correct } \\
\text { category } \\
\text { Gave } \\
\text { explanation of } \\
\text { how sorted } \\
\text { words that was } \\
\text { incomplete or } \\
\text { wrong }\end{array}$ & $\begin{array}{l}\text { Placed two to } \\
\text { three words in } \\
\text { correct } \\
\text { category } \\
\text { Gave good } \\
\text { explanation of } \\
\text { how words } \\
\text { were sorted }\end{array}$ & $\begin{array}{c}\text { Placed all three } \\
\text { words in correct } \\
\text { category } \\
\text { Gave good and } \\
\text { detailed } \\
\text { explanation of } \\
\text { how words were } \\
\text { sorted }\end{array}$ \\
\hline
\end{tabular}




\begin{tabular}{|c|c|c|c|c|}
\hline Example & $\begin{array}{l}\text { "SI is used to } \\
\text { solve } \\
\text { engineering } \\
\text { problems. I } \\
\text { placed all of } \\
\text { the words in } \\
\text { common to } \\
\text { both" }\end{array}$ & $\begin{array}{c}\text { "Most of the } \\
\text { words seem to } \\
\text { apply to both. I } \\
\text { put } \\
\text { phenomena in } \\
\text { SI because it is } \\
\text { a word that is } \\
\text { used in } \\
\text { reference to a } \\
\text { natural } \\
\text { occurrence, not } \\
\text { a human } \\
\text { construction. I } \\
\text { put solve in } \\
\text { both because SI } \\
\text { and ED require } \\
\text { problem } \\
\text { solving. I put } \\
\text { prototype in ED } \\
\text { because I } \\
\text { believe that is } \\
\text { the label used } \\
\text { in engineering } \\
\text { that applies to } \\
\text { your first } \\
\text { attempt at } \\
\text { construction" }\end{array}$ & $\begin{array}{l}\text { "Investigation } \\
\text { under SI to } \\
\text { investigate a } \\
\text { question about } \\
\text { a natural } \\
\text { phenomena in } \\
\text { the world. } \\
\text { Solve under ED } \\
\text { is to identify } \\
\text { problems and } \\
\text { designing a } \\
\text { solution to } \\
\text { solve the } \\
\text { problem. Apply } \\
\text { under both } \\
\text { because both } \\
\text { processes } \\
\text { include } \\
\text { application of } \\
\text { basic science } \\
\text { concepts in } \\
\text { their process" }\end{array}$ & $\begin{array}{l}\text { "SI-hypothesize. I } \\
\text { chose this word } \\
\text { because an } \\
\text { inquiry needs to } \\
\text { start with a } \\
\text { testable } \\
\text { guess/prediction. } \\
\text { Both- } \\
\text { communicate. } \\
\text { Both SI and ED } \\
\text { require that } \\
\text { solutions or data } \\
\text { are clearly } \\
\text { communicated. } \\
\text { ED-prototype. I } \\
\text { chose this word } \\
\text { because } \\
\text { constructing a } \\
\text { prototype gives } \\
\text { the designer a } \\
\text { better idea of a } \\
\text { solutions } \\
\text { capability" }\end{array}$ \\
\hline
\end{tabular}


Question 3 (CK):

\begin{tabular}{|c|c|c|c|}
\hline $\begin{array}{l}\text { Rubric } \\
\text { Score }\end{array}$ & 1 & 2 & 3 \\
\hline $\begin{array}{l}\text { Charac- } \\
\text { teristics }\end{array}$ & Incorrect steps. & $\begin{array}{l}\text { Mentions one to } \\
\text { two steps: } \\
\text { Identify/ask } \\
\text { problem; } \\
\text { imagine/brainstorm } \\
\text { solutions; } \\
\text { plan/select } \\
\text { prototype; } \\
\text { build/create and } \\
\text { test; } \\
\text { improve/refine. }\end{array}$ & $\begin{array}{l}\text { Mentions three to } \\
\text { four steps. }\end{array}$ \\
\hline Example & $\begin{array}{l}\text { "Defined outcome } \\
\text { with defined } \\
\text { process = teacher } \\
\text { led. Defined } \\
\text { outcome with } \\
\text { undefined process } \\
=\text { student/teacher } \\
\text { interactions" }\end{array}$ & $\begin{array}{l}\text { "Question, } \\
\text { hypothesis, plan } \\
\text { (materials), test } \\
\text { (experiment), re- } \\
\text { test, summarize. In } \\
\text { 1st grade, the } \\
\text { children build and } \\
\text { question over and } \\
\text { over, build the } \\
\text { model, test the } \\
\text { model, question } \\
\text { what works and } \\
\text { what doesn't } \\
\text { according to } \\
\text { criteria" }\end{array}$ & $\begin{array}{l}\text { "You have a humar } \\
\text { need that needs to } \\
\text { be met, you } \\
\text { brainstorm ways } \\
\text { you can solve it, } \\
\text { you build a } \\
\text { prototype, you test } \\
\text { it, and then you } \\
\text { refine it to get } \\
\text { better results" }\end{array}$ \\
\hline
\end{tabular}




\begin{tabular}{|l|l|l|}
\hline $\begin{array}{l}\text { Rubric } \\
\text { Score }\end{array}$ & 4 & 5 \\
\hline $\begin{array}{l}\text { Charac- } \\
\text { teristics }\end{array}$ & $\begin{array}{l}\text { Mentions all five } \\
\text { steps. }\end{array}$ & $\begin{array}{l}\text { Mentions all five } \\
\text { steps with lots of } \\
\text { detail. }\end{array}$ \\
\hline Example & $\begin{array}{l}\text { "ID a problem } \\
\text { (criteria and } \\
\text { constraints), research } \\
\text { it (talk to experts, } \\
\text { examine other ideas), } \\
\text { brainstorm solutions, } \\
\text { choose one and } \\
\text { design it, build } \\
\text { model/prototype, } \\
\text { test, redo if necessary } \\
\text { until criteria is met" }\end{array}$ & $\begin{array}{l}\text { imagine a solution, } \\
\text { plan to build the } \\
\text { solution, create the } \\
\text { solution and improve } \\
\text { to better solve the } \\
\text { problem. In class we } \\
\text { built a car that could } \\
\text { travel down a ramp } \\
\text { (criteria), we } \\
\text { imagined a car that } \\
\text { could be built with } \\
\text { constraints offered, } \\
\text { we made a plan for } \\
\text { the car and created } \\
\text { it. Finally, we asked if } \\
\text { the data showed we } \\
\text { were answering the } \\
\text { problem and we } \\
\text { improved the design" }\end{array}$ \\
\hline & $\begin{array}{l}\text { "Ask the students to } \\
\text { solve problem, }\end{array}$ \\
\hline
\end{tabular}


Question 4a (CK):

\begin{tabular}{|l|c|c|c|c|}
\hline $\begin{array}{l}\text { Rubric } \\
\text { Score }\end{array}$ & 1 & 2 & 3a & 3b \\
\hline $\begin{array}{l}\text { Charac- } \\
\text { teristics }\end{array}$ & $\begin{array}{c}\text { Something that } \\
\text { makes things } \\
\text { easier. Tools. }\end{array}$ & $\begin{array}{c}\text { Tools. } \\
\text { Information } \\
\text { used to help } \\
\text { answer } \\
\text { questions. } \\
\text { Mentions one } \\
\text { or two of: } \\
\text { object, system, } \\
\text { or process. } \\
\text { Example }\end{array}$ & $\begin{array}{c}\text { Technology is } \\
\text { an object, } \\
\text { system, or } \\
\text { process. }\end{array}$ & $\begin{array}{c}\text { Technology is } \\
\text { anything } \\
\text { human-made } \\
\text { used to solve a } \\
\text { problem or } \\
\text { fulfill a desire. } \\
\text { Not only tools } \\
\text { such as } \\
\text { computers and } \\
\text { electronics. }\end{array}$ \\
\hline $\begin{array}{c}\text { "Anything you } \\
\text { use to improve } \\
\text { your life, make } \\
\text { work easier" }\end{array}$ & $\begin{array}{c}\text { "Tools to help } \\
\text { us in work and } \\
\text { school. These } \\
\text { tools help } \\
\text { make daily } \\
\text { tasks easier" }\end{array}$ & N/A & $\begin{array}{c}\text { "Anything } \\
\text { created that } \\
\text { meets a human } \\
\text { need or satifies } \\
\text { a desire" }\end{array}$ \\
\hline
\end{tabular}

Question 4bc (PCK):

\begin{tabular}{|l|c|c|c|}
\hline Rubric Score & 1 & 2 & 3 \\
\hline Characteristics & $\begin{array}{c}\text { Think of technology } \\
\text { as computers, } \\
\text { electronics, things } \\
\text { plugged in. } \\
\text { No misconception } \\
\text { or incorrect } \\
\text { misconception } \\
\text { mentioned. }\end{array}$ & $\begin{array}{c}\text { Name one different } \\
\text { view and one } \\
\text { misconception } \\
\text { about technology }\end{array}$ & $\begin{array}{c}\text { Name at least two } \\
\text { different views and } \\
\text { one misconception } \\
\text { of technology. }\end{array}$ \\
& & \\
\hline
\end{tabular}




\begin{tabular}{|c|c|c|c|}
\hline Example & $\begin{array}{c}\text { "It is electronic. See } \\
\text { above" }\end{array}$ & $\begin{array}{l}\text { "They think of it in } \\
\text { terms of computers } \\
\text { and electrical } \\
\text { equipment. That } \\
\text { only everyday } \\
\text { objects like their } \\
\text { toothbrush are } \\
\text { examples of } \\
\text { technology" }\end{array}$ & $\begin{array}{l}\text { "Technology refers } \\
\text { to cutting edge } \\
\text { digital tools. } \\
\text { Technology is hard } \\
\text { to understand. You } \\
\text { have to be really } \\
\text { smart to create } \\
\text { technology. } \\
\text { Technology is only } \\
\text { related to digital } \\
\text { things- computers, } \\
\text { cell phones, video } \\
\text { games" }\end{array}$ \\
\hline
\end{tabular}

Question 5 (CK):

\begin{tabular}{|l|c|c|c|c|}
\hline $\begin{array}{l}\text { Rubric } \\
\text { Score }\end{array}$ & 1 & 2 & 3 & 4 \\
\hline $\begin{array}{l}\text { Charac- } \\
\text { teristics }\end{array}$ & $\begin{array}{c}\text { Incorrect } \\
\text { answer }\end{array}$ & $\begin{array}{c}\text { Explained } \\
\text { connection } \\
\text { between 2 of } 3 \\
\text { concepts. } \\
\text { Vague } \\
\text { connection }\end{array}$ & $\begin{array}{c}\text { Explained how } \\
\text { all three } \\
\text { connected }\end{array}$ & $\begin{array}{c}\text { Defined each } \\
\text { and explained } \\
\text { how all three } \\
\text { connected. } \\
\text { Explained how } \\
\text { all three are } \\
\text { connected and } \\
\text { describes it as a } \\
\text { cycle. }\end{array}$ \\
\hline
\end{tabular}




\begin{tabular}{|c|c|c|c|c|}
\hline Example & $\begin{array}{l}\text { "They are all } \\
\text { connected } \\
\text { because they } \\
\text { all involve } \\
\text { observing } \\
\text { things, } \\
\text { understanding } \\
\text { how things } \\
\text { work, problem } \\
\text { solving, } \\
\text { analyzing, } \\
\text { testing, and } \\
\text { evaluating" }\end{array}$ & $\begin{array}{l}\text { "Science is the } \\
\text { overarching } \\
\text { topic including } \\
\text { life, physical, } \\
\text { earth, inquiry, } \\
\text { engineering, } \\
\text { etc. So, } \\
\text { engineering is a } \\
\text { type of science. } \\
\text { Technology is a } \\
\text { tool to be used } \\
\text { in all fields of } \\
\text { science to help } \\
\text { answer } \\
\text { questions and } \\
\text { solve } \\
\text { problems" }\end{array}$ & $\begin{array}{l}\text { "Technology is } \\
\text { used in the } \\
\text { science of } \\
\text { engineering to } \\
\text { solve problems. } \\
\text { Engineering } \\
\text { also leads to } \\
\text { advances in } \\
\text { technology that } \\
\text { helps us } \\
\text { answer larger } \\
\text { scientific } \\
\text { questions" }\end{array}$ & $\begin{array}{l}\text { "Science is } \\
\text { studying and } \\
\text { learning about } \\
\text { the world } \\
\text { around you and } \\
\text { engineering } \\
\text { uses that } \\
\text { knowledge to } \\
\text { construct } \\
\text { things to meet } \\
\text { human needs. } \\
\text { Those things } \\
\text { they construct } \\
\text { are examples } \\
\text { of technology } \\
\text { and some of } \\
\text { that technology } \\
\text { can be used to } \\
\text { inform and } \\
\text { study science" }\end{array}$ \\
\hline
\end{tabular}

Question 6 (PCK):

\begin{tabular}{|l|c|c|c|c|}
\hline $\begin{array}{l}\text { Rubric } \\
\text { Score }\end{array}$ & 1 & 2 & 3 & 4 \\
\hline $\begin{array}{l}\text { Charac- } \\
\text { teristics }\end{array}$ & $\begin{array}{c}\text { Describe } \\
\text { demographics. } \\
\text { Describes one } \\
\text { strategy, but } \\
\text { not culturally } \\
\text { responsive. } \\
\text { No strategy } \\
\text { stated. }\end{array}$ & $\begin{array}{c}\text { Describe } \\
\text { demographics. } \\
\text { Describes one } \\
\text { to two } \\
\text { strategies, one } \\
\text { being culturally } \\
\text { responsive. }\end{array}$ & $\begin{array}{c}\text { Describe } \\
\text { demographics. } \\
\text { Describes two } \\
\text { or more } \\
\text { strategies, two } \\
\text { being culturally } \\
\text { responsive. }\end{array}$ & $\begin{array}{c}\text { Describe } \\
\text { demographics. } \\
\text { Describes more than } \\
\text { two strategies; at } \\
\text { least two being } \\
\text { culturally } \\
\text { responsive. }\end{array}$ \\
\hline
\end{tabular}




\begin{tabular}{|c|c|c|c|c|}
\hline Example & $\begin{array}{l}\text { "Need help in } \\
\text { this area!" }\end{array}$ & $\begin{array}{l}\text { "Use texts to } \\
\text { introduce } \\
\text { problems that } \\
\text { are based in } \\
\text { other cultures" }\end{array}$ & $\begin{array}{l}\text { "More hands- } \\
\text { on, better and } \\
\text { more relevant } \\
\text { problems to } \\
\text { solve" }\end{array}$ & $\begin{array}{l}\text { "SIOP strategies to } \\
\text { help make } \\
\text { instruction } \\
\text { comprehensible. } \\
\text { Some of these } \\
\text { include: posting } \\
\text { objectives, } \\
\text { connecting with } \\
\text { prior } \\
\text { learning/background } \\
\text { knowledge, use of } \\
\text { visuals, multiple } \\
\text { opportunities to } \\
\text { talk, and hands-on } \\
\text { learning" }\end{array}$ \\
\hline
\end{tabular}

Question 7 (PCK):

\begin{tabular}{|l|c|c|c|c|}
\hline $\begin{array}{l}\text { Rubric } \\
\text { Score }\end{array}$ & 1 & 2 & 3 & 4 \\
\hline $\begin{array}{l}\text { Charac- } \\
\text { teristics }\end{array}$ & $\begin{array}{c}\text { Wrong answer } \\
\text { given (A, D, or } \\
\text { all of the } \\
\text { above) }\end{array}$ & $\begin{array}{c}\text { Answer C given } \\
\text { with } \\
\text { supporting } \\
\text { detail } \\
\text { Answer B given } \\
\text { with wrong } \\
\text { reason. }\end{array}$ & $\begin{array}{c}\text { Answer B given } \\
\text { and explained } \\
\text { what is wrong } \\
\text { with other } \\
\text { answers. }\end{array}$ & $\begin{array}{c}\text { Answer B given } \\
\text { and explains } \\
\text { that own } \\
\text { criteria (choice) } \\
\text { is better. }\end{array}$ \\
& & & & \\
\hline
\end{tabular}




\begin{tabular}{|l|c|c|c|c|}
\hline Example & "All; I believe & "C; I like that & "B; If you tell & "B: Students \\
& all teachers & the teacher & them what & come up with \\
& here present & gave specific & materials to & their own \\
& critical & criteria that & use and how to & criteria. \\
& elements to & he/she could & use them, the & Teacher \\
engineering & evaluate. This & teacher is & provides basic \\
& design" & also gives the & doing the & instruction and \\
& students an & engineering & materials" \\
& & objective to & design not the & \\
& aim for with & students. Not a & \\
& the freedom to & lot of critical & \\
& be creative & thinking or & \\
& with the use of & creativity going & \\
& & their materials" & on for the kids" & \\
& & &
\end{tabular}

Question 8 (PCK):

\begin{tabular}{|c|c|c|c|c|}
\hline $\begin{array}{l}\text { Rubric } \\
\text { Score }\end{array}$ & 1 & 2 & 3 & 4 \\
\hline $\begin{array}{l}\text { Charac- } \\
\text { teristics }\end{array}$ & $\begin{array}{l}\text { Wrong answer } \\
\text { given }(A, D \text {, or } \\
E)\end{array}$ & $\begin{array}{c}\text { Answer B given } \\
\text { and explained } \\
\text { with } \\
\text { supporting } \\
\text { detail. }\end{array}$ & $\begin{array}{l}\text { Answer B given, } \\
\text { but included } \\
\text { evaluating } \\
\text { criteria. } \\
\text { Answer C given, } \\
\text { but didn't give } \\
\text { correct } \\
\text { supporting } \\
\text { detail. }\end{array}$ & $\begin{array}{l}\text { Answer C given } \\
\text { and explains } \\
\text { that it's } \\
\text { important to } \\
\text { evaluate ideas } \\
\text { using criteria. }\end{array}$ \\
\hline
\end{tabular}




\begin{tabular}{|c|c|c|c|c|}
\hline Example & $\begin{array}{l}\text { "D: Teacher } \\
\text { gave } \\
\text { opportunity to } \\
\text { students to } \\
\text { explore their } \\
\text { ideas" }\end{array}$ & $\begin{array}{l}\text { "B: Trying to } \\
\text { solve things in } \\
\text { different ways } \\
\text { and seeing } \\
\text { different } \\
\text { perspectives is } \\
\text { key" }\end{array}$ & $\begin{array}{l}\text { "C: Teacher } \mathrm{C} \text { is } \\
\text { allowing for } \\
\text { creativity but } \\
\text { also paying } \\
\text { attention to the } \\
\text { goals of the } \\
\text { lesson. The } \\
\text { other teachers } \\
\text { are either } \\
\text { missing the } \\
\text { importance of } \\
\text { creativity (A) or } \\
\text { allowing for too } \\
\text { much } \\
\text { disorganization" }\end{array}$ & $\begin{array}{l}\text { "C: Solving a } \\
\text { particular } \\
\text { problem is the } \\
\text { skill. Building } \\
\text { boats wasn't so } \\
\text { keeping } \\
\text { students } \\
\text { focused on a } \\
\text { design that } \\
\text { meets the } \\
\text { criteria is } \\
\text { important" }\end{array}$ \\
\hline
\end{tabular}

